\title{
Religions, Fertility, and Growth in South-East Asia
}

\author{
David de la Croix ${ }^{1} \quad$ Clara Delavallade ${ }^{2}$
}

April 7, 2017

\begin{abstract}
We investigate the extent to which religions' pronatalism is detrimental to growth via the fertility/education channel. Using censuses from South-East Asia, we first estimate an empirical model of fertility and show that having a religious affiliation significantly raises fertility, especially for couples with intermediate to high education levels. We next use these estimates to identify the parameters of a structural model of fertility choice. On average, Catholicism is the most pro-child religion (increasing total spending on children), followed by Buddhism, while Islam has a strong pro-birth component (redirecting spending from quality to quantity). We show that pro-child religions depress growth in the early stages of growth by lowering savings, physical capital, and labor supply. These effects account for $10 \%$ to $30 \%$ of the actual growth gaps between countries over 1950-1980. At later stages of growth, pro-birth religions lower human capital accumulation, explaining between $10 \%$ to $20 \%$ of the growth gap between Muslim and Buddhist countries over 1980-2010.
\end{abstract}

Keywords: Quality-quantity tradeoff, Catholicism, Buddhism, Islam, Indirect Inference, Education

JEL Classification numbers: J13, Z13, O11

${ }^{1}$ IRES and CORE, UCLouvain. Email: david.delacroix@uclouvain.be.

${ }^{2}$ International Food Policy Research Institute (IFPRI). Email: clara.delavallade@ensae.org

Acknowledgements: David de la Croix acknowledges the financial support of the project ARC 15/19-063 of the Belgian French speaking Community. We thank Thomas Baudin, Sascha Becker, Bastien Chabé-Ferret, John Knowles, Paola Giuliano, Anastasia Litina and Ester Rizzi for useful discussions on the paper. The text also benefitted from comments at the OLG days in Paris \& Luxemburg, at the Barcelona GSE Summer Forum, at the SED 2016 conference, and at seminars in Bonn, Gröningen, IRES (Louvain), GREQAM (Marseille), and UCLA. 


\section{Introduction}

Many religions are theoretically pro-natalist, to varying degrees. The Catholic doctrine promotes fertility by discouraging sexual intercourse other than for reproductive purposes, therefore forbidding artificial birth control and abortion. Only natural family planning methods are allowed for. The reluctance towards contraception builds upon the idea that men "must also recognize that an act of mutual love which impairs the capacity to transmit life which God the Creator, through specific laws, has built into it, frustrates His design which constitutes the norm of marriage, and contradicts the will of the Author of life." (Encyclical Letter Humanae Vitae Section 13). ${ }^{1}$ In Islam, "procreation is a sign of God's will and a large family is perceived as a blessing" (Blyth and Landau 2009), although the Qur'an does not take a firm position on contraception, leaving room for interpretation by local religious leaders. Buddhism's sacred texts are more silent about family issues, but Buddhism also displays pro-family features: Guanyin, the Bodhisattva of compassion and mercy, is portrayed as a fertility goddess who has the power to grant children, especially sons, and to ensure safe childbirth (Lee et al. 2009).

What implications do these beliefs have for economic growth? We know from empirical studies using microdata that belonging to a religious denomination indeed increases fertility. In addition, from the family economics literature, we know that there is a trade-off between fertility and education, i.e. between the quantity of children and the quality of those children's education. $^{2}$ Finally, the growth literature suggests that increased fertility may slow down human capital accumulation through this trade-off, as well as physical capital accumulation, as in the standard Solow model. The objective of this paper is to link these three mechanisms and examine the extent to which religion may affect growth through these channels. We first estimate the impact of religion on fertility at the microeconomic level. We then map the identified effect into a macroeconomic model to infer consequences for economic growth. South-East Asia provides the ideal ground to study this question, as its countries host most of the major world religions in a small geographical area, allowing to separate out country fixed effects (related to colonial origin, legal system, etc.) from religion fixed effects.

In our model, religion is not a choice, it is inherited from the parents. Religious affiliations influence fertility behaviors by affecting households' incentives. We assume that incentives are affected by religion through preferences, ${ }^{3}$ either that those preferences result from ideology,

\footnotetext{
${ }^{1}$ Similarly, "Children are really the supreme gift of marriage and contribute in the highest degree to their parents' welfare." (Encyclical Letter Humanae Vitae Section 9). While they have no central authority to diffuse this message across the world, other Christian denominations are also pro-natalist religions, following the Bible's commandment to "be fruitful, and multiply" (Genesis 1:28).

${ }^{2}$ See Doepke (2015) for a survey on the emergence of this concept.

${ }^{3}$ Using the World Value Survey, Guiso, Sapienza, and Zingales (2003) show correlations between being raised religiously along different denominations and reported preferences and values about trust and gender equality.
} 
or that they were shaped by socialization (Mosher, Williams, and David 1992). ${ }^{4}$ Looking through the lenses of an optimal fertility model where parents choose the number and the quality (health and level of education) of their children, we assume that religious values can affect fertility behaviors through two different channels. A religion can be pro-child if it leads people to put more weight on the number and quality of children, as opposed to their own consumption and saving. It is pro-birth if it leads people to put more weight on the sole number of children with respect to the other components of utility. We will see that these two features of religions affect differently the relationship between parents' education and their fertility.

To identify these theoretical channels, we need a method able to estimate the structural parameters of a model which is non-linear and which implies cross-equations restrictions (some parameters are assumed equal for all religions). We use indirect inference, a simulation method that allows the estimation of structural parameters from a standard fertility regression without imposing a priori restrictions on the econometric model. Indirect inference follows a two step procedure. We first estimate an auxiliary model to capture aspects of the data - here the effect of parents' education and religion on fertility - upon which to base the subsequent estimation of the structural model. One advantage of this auxiliary model is that it is directly comparable to what one can find in the literature in demography and applied economics. Another advantage is to draw the moments used in the structural estimation from a single coherent sample, here the IPUMS international dataset. In a second step, we then choose the parameters of the structural economic model such that they minimize the distance between the estimations of the parameters of the auxiliary model obtained with the observed data and those obtained with artificial data simulated from the structural model (Gourieroux, Monfort, and Renault (1993), Smith (2008)). Once the parameters have been identified, we use the structural model to simulate the influence of religion on growth. We then run experiments to compute the impact of religion on the growth process of artificial countries populated by non religious, Catholic, Buddhist or Muslim inhabitants. We finally simulate the effect of religion on the growth path of actual countries taking their religious composition into account.

In the first step, we estimate the empirical relationship between parental background and fertility, including religion and education. Religion is modelled as affecting both the level of fertility and the marginal effect of parents' education on fertility. We use pooled census data from South-East Asian countries for which religious affiliation is available as an individual variable (Cambodia, Indonesia, Malaysia, Philippines, Thailand, and Vietnam). South-East Asia is a particularly rich region in terms of religious affiliations both within and across countries: Catholics are present in the Philippines, as well as in Indonesia and Vietnam.

\footnotetext{
${ }^{4} \mathrm{~A}$ third view, according to which religion affects behavior through the minority status hypothesis, is implemented in Section 5.2.
} 
Buddhist and Muslims are present in all the countries we study (except for Muslims in Vietnam). People with no religious affiliation are a majority in Vietnam and form small minorities everywhere else. As we want to study the interaction effects of couples' education and religion, pooling censuses allows us to have enough observations in each category (for example, couples with no religious affiliation in which one spouse has a university degree and the other one has no education).

Three main features emerge from the estimation of the empirical model. First, fertility decreases as both men and women become more educated. Second, belonging to any religious affiliation (except Hinduism) raises fertility. Third, the effect of religion on fertility varies with the couple's level of education. Catholicism has the strongest effect on fertility, but all predominant religions raise fertility, especially for couples with intermediate and high levels of education.

In the second step, we estimate the parameters of a structural model of optimal fertility, using the fertility-religion relationship estimated in the first step as the "auxiliary" model. Compared to calibration strategies which consist in exactly identifying the parameters from a set of moments selected from various sources (two recent examples of calibrated fertility models are Doepke, Hazan, and Maoz (2015) and Tamura, Curtis, and Murphy (2016)), our moments are generated from the estimation of the auxiliary regression on a coherent set of data. Another difference with the calibrated models is that our moments have standard errors, enabling us to compute the standard errors of the structural parameters, making possible to measure the uncertainty surrounding both our estimates and counterfactual simulations. We find that Catholicism clearly displays a pro-child effect. Moreover, the fertility pattern of religious women points to strong pro-birth effects, in particular for Muslim couples, and, to a lesser extent, for Buddhists and Catholics. This is true when one takes into account the interaction between religion and education in the auxiliary model: the highly educated couples with a religious denomination, and Muslims in particular, do not reduce their fertility as much as predicted by the behaviour of non-religious couples, as if the quantity-quality substitution mechanism were less at play for them.

The consequences for growth depend strongly on the size of the pro-birth effect. Indeed, if religion only increases the taste for children (pro-child), it leads to more spending on children and less saving. It depresses growth temporarily by lowering physical capital accumulation but not human capital accumulation. These temporary effects account for $10 \%$ to $50 \%$ of the actual growth gaps between countries over 1950-1980. On the contrary, if religion also decreases the relative weight of quality over quantity (pro-birth), it depresses growth permanently through human capital accumulation. We show that countries with a large population affiliated to pro-birth religions have a lower human capital accumulation. In particular, religious composition explains between $10 \%$ and $20 \%$ of the gap between Muslim 
and Buddhist countries over 1980-2010.

These results cannot be fully compared with the existing literature, as this paper is the first to take the full journey from microdata estimates to growth simulations. Qualitatively, our effects in the auxiliary model are in line with the vast empirical literature at the microeconomic level which shows that fertility choices can be heavily affected by the partners' religion and/or religiosity. For example, Sander (1992) shows that Catholic norms have a highly significant positive effect on fertility for respondents born before 1920 in the United Kingdom. Lin and Pantano (2015) show that mother's religion affects the likelihood to have unintended birth(s) in the US (using PSID data). Adsera (2006a, 2006b) shows that, in a secular society, religion predicts both a higher fertility norm and actual fertility. Baudin (2015) has similar findings on French data. Berman, Iannaccone, and Ragusa (2012) show that fertility across European countries is related to the population density of nuns, who are likely to provide services to families, alleviating child rearing costs.

As far as developing countries are concerned, Heaton (2011) studies the effect of religion on fertility in a set of 22 developing countries using survey data. He shows that the level of educational achievements matter for this relationship, stressing the importance of interaction effects, which is also a conclusion of our auxiliary model. Chabé-Ferret (2016) shows that religious affiliation is a substantial channel through which cultural norms affect fertility choices of second generation migrants in France. In particular, controlling for religion reduces the effect of fertility norms from the origin country. Finally, Skirbekk et al. (2015) study the effect of Buddhism in several Asian countries, and claim that it is the less pro-natalist religion. Although most of these studies control for the education level of the mother, few of them control for the education level of the father, and none of them allows, like we do, for an interaction between education and religion.

There is also an empirical literature at the macroeconomic level linking religion to education and growth. The debate goes back, at least, to Weber, who praised the virtues of Protestant ethics for economic growth. Along Weberian lines, Becker and Woessmann (2009) and Boppart et al. (2013) show that Protestantism led to better education than Catholicism in nineteenth-century Prussian counties and in Swiss districts. This difference between Catholics and Protestants is however not visible in our study. It should be noted, though, that Protestantism is far from being uniform. McCleary (2013) compares Protestant missionaries in Korea and Guatemala and shows that their approach to exporting Protestantism was different, with a focus on education in Korea from mainline denominations but little investment in human capital in Guatemala, from fundamentalist denominations. Finally, using contemporaneous data, Barro and McCleary (2003) attempt to isolate the direction of causation from religiosity to economic performance, and find a negative effect of religious practice on growth; however their results are shown not robust by Durlauf, Kourtellos, and Tan (2006). 
Several authors propose growth models embedding religious considerations. Some, like us, consider religion as exogenous. Cavalcanti, Parente, and Zhao (2007) explicitly model an afterlife period (heaven or hell) in an overlapping generation set-up, and show that beliefs about how to maximize one's chance to go to heaven affect capital accumulation. Strulik (2012) defends the view that religion may affect preferences, either for fertility or leisure (individuals with "religious" values attach a lower weight to consumption utility than individuals with "secular" values). Compared to our model in which religion is treated as an exogenous difference in the parameters, the interest of Strulik (2012) is to make religious affiliation endogenous. Endogenous religion is also modeled by Baudin (2010), who studies the joint dynamics of cultural values and fertility, and shows the conditions under which a demographic transition accompanied by a rise in "modern" (vs. "traditional") culture happens. Finally, Cervellati, Jansen, and Sunde (2014) model religion as an insurance against idiosyncratic shocks, and determine which system of religious norms is incentive compatible. They explicitly show that individual incentives are modified by religious norms, which is what we implicitly assume when we make preferences depend directly on religious affiliation. None of these theoretical models, however, provides a quantitative measure of their implications disciplined by microeconometric estimates.

The layout of the remainder of the article is as follows. Section 2 presents and estimates the auxiliary model of fertility. We develop the structural model in Section 3. Section 4 uses a growth model to infer dynamic and long-run implications of religion on fertility, education and growth. Section 6 concludes.

\section{The Auxiliary Model}

We specify an auxiliary model to estimate the marginal effects of education on fertility. This in turn will be used to estimate the parameters of the structural economic model such that the distance between these empirical marginal effects and those obtained from the structural model is minimal.

\subsection{Data and Empirical Strategy}

Our empirical analysis uses data from the Integrated Public Use Micro Series, International (IPUMS-I) (Minnesota Population Center 2013). The IPUMS-I census microdata are unique in providing internationally comparable, detailed information on demographics, religion and education. We restrict our analysis to South-East Asia because it covers a variety of religions 
while still having common historical, cultural, and geographical influences, ${ }^{5}$ thus reducing the noise inherent to a cross-country analysis. Harmonized data for South-East Asia come from 11 censuses collected by national statistical agencies in Cambodia, Indonesia, Malaysia, Philippines, Thailand and Vietnam between 1970 and 2008. All results presented here are weighted to adjust for different sampling probabilities across countries.

As our theory will be based on the model of a couple, and our identification requires to know the education level of the husband, we restrict the sample to married women, excluding divorced and widowed women. To focus the analysis on completed fertility, we restrict the sample to married women aged between 45 and 70 at the time of the census. For countries with several censuses, we further restrict the age span to avoid including the same cohort several times in the analysis. For instance, in Malaysia, the sample includes married women aged between 50 and 70 in the 1998 census (born between 1928 and 1948), and aged between 45 and 59 in the 2008 census (born between 1949 and 1963). For the cohort born between 1938 and 1948, we use data from the 1998 census (when they are aged between 50 and 60) rather than from the 2008 census (when they are aged between 60 and 70) to reduce the chances of sample loss due to mortality. Figure 1 shows the cohorts used in all 11 censuses.

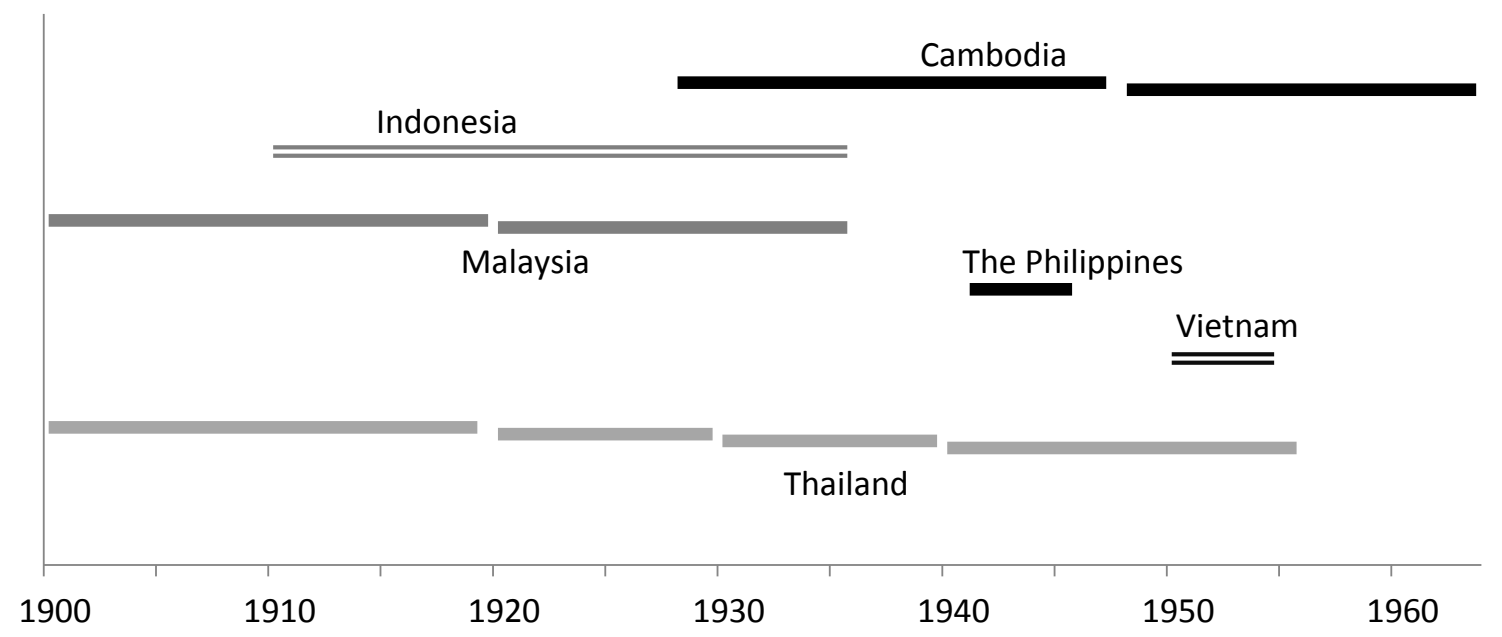

Note: Each bar represents one census and indicates the cohorts (by year of birth) retained in the sample

Figure 1: Cohorts in the sample, by country

Fertility is measured for each woman by the number of children ever born. In Vietnam and the Philippines, only women below 49 years old were asked about fertility. In these two countries,

\footnotetext{
${ }^{5}$ According to Putterman (2006), transition to agriculture took place from 6000 (Vietnam) before present to 4000 (Indonesia). Following Alesina, Giuliano, and Nunn (2013), the plough was used in pre-historical times in all six countries considered, which is important for shaping gender roles. A large part of the population lives close to the sea, and stilt houses are common all over South-East Asia. Climate is tropical everywhere but North Vietnam where it is temperate.
} 
our sample is thus restricted to married women aged between 45 and 49. To avoid outliers, we drop observations for which fertility is equal to or higher than 30 children $(\mathrm{N}=234)$.

We use detailed information about religion in the six countries to construct religious affiliation dummies for (1) Catholic; (2) Protestant and other Christian, including Baptist, Adventist, and Methodist; (3) Buddhist; (4) Hindu; (5) Muslim; (6) Other, including Confucianist and Taoist; and (7) No religion. The measure used in the analysis is that of the woman's religion, as 99 percent of the couples in our sample share the same religion. In census questionnaires, there is either a case "religion" to fill in next to age and gender (Cambodia, Indonesia) or the question asked is "what is your religion?" (Malaysia, Thailand, Vietnam) or "what is your religious affiliation?" (Philippines). Religious affiliation is exogenous to the individual. Being currently of a certain religion, say Catholic, is a good proxy for a Catholic upbringing, with 97 percent of women having the same religion as their mother in the subset of our sample for which we have information on the mother's religion $(\mathrm{N}=2020){ }^{6}$

Censuses in Cambodia, Malaysia and Thailand do not distinguish between Catholics, Protestants and other Christians. Although Protestantism is on the rise in these three countries, Catholics composed a vast majority of Christians in the period relevant to the birth cohorts of the individuals in our sample, born at the latest in 1963. We thus club Christians in Cambodia, Malaysia and Thailand with Catholics. All the results presented here are robust to clubbing Christians with Protestants and other Christians instead.

For each individual, we distinguish five levels of educational attainment: (1) no education (or pre-school); (2) some primary; (3) primary completed ; (4) secondary completed; (5) university completed. Education categories have been harmonized across countries. We construct the same five educational categories for the woman's husband. We next factor them, thus constructing 25 educational categories for the couple, as presented in Table 1.

Table 2 displays summary statistics for the main measures used in the analysis. Panel A shows fertility levels by country. Given that our sample is restricted to married women with completed fertility, fertility levels are relatively high in all countries, varying between 4.17 and 5.88, in Vietnam and Malaysia respectively. Panel B shows the distribution of religion by country. ${ }^{7}$ All countries except Malaysia have a predominant religion (or no religious affiliation for Vietnam), with other religions in minority. This could potentially bias our estimates of the effect of religion on fertility in the empirical analysis. We will discuss this

\footnotetext{
${ }^{6}$ This subsample in which the mother's religion is known is surprisingly quite representative of the whole sample. Its descriptive statistics are presented in Appendix C, to be compared wit the descriptive statistics of the whole sample in Table 2.

${ }^{7}$ The distribution of religious groups from census data seems to be somewhat different from Barro's religious adherence data: http://scholar.harvard.edu/files/barro/files/7_religion_adherence_data.xls. The discrepancy comes from the fact that we consider the population aged $40+$ only, and that in some special cases, there has been recent changes in religious affiliation (children from Catholic families becoming Protestants, children from atheist parents growing up in communist regimes declaring them as Buddhist in recent surveys.
} 


\section{Man Education}

\begin{tabular}{|c|c|c|c|c|c|c|}
\hline $\begin{array}{l}\text { Woman } \\
\text { Educ. }\end{array}$ & $\begin{array}{r}\text { No } \\
\text { schooling }\end{array}$ & $\begin{array}{r}\text { Some } \\
\text { primary }\end{array}$ & $\begin{array}{r}\text { Primary } \\
\text { completed }\end{array}$ & $\begin{array}{l}\text { Secondary } \\
\text { completed }\end{array}$ & $\begin{array}{l}\text { University } \\
\text { completed }\end{array}$ & Total \\
\hline $\mathrm{No}$ & 155,029 & 89,151 & 24,542 & 1,392 & 113 & 270,227 \\
\hline Some & 13,978 & 109,132 & 38,078 & 4,930 & 541 & 166,659 \\
\hline Primary & 2,235 & 16,874 & 55,567 & 14,065 & 2,097 & 90,838 \\
\hline Secondary & 100 & 1,058 & 5,234 & 12,779 & 3,834 & 23,005 \\
\hline University & 17 & 117 & 936 & 3,568 & 6,581 & 11,219 \\
\hline Total & 171,359 & 216,332 & 124,357 & 36,734 & 13,166 & 561,948 \\
\hline
\end{tabular}

Table 1: Sample size, by couple education

in Section D.2. Thailand and Cambodia are mainly Buddhist (97 percent and 95 percent respectively). While a majority of Indonesians are Muslim (87 percent), 83 percent of Filipinos are Catholic. Eighty-one percent of the population in Vietnam reports having no religious affiliation. However, this is likely to include individuals adhering to informal religious customs and practices, such as ancestor and local spirits worship. The religious spectrum in Malaysia is diverse, with 54 percent Muslim, 24 percent Buddhist, 11 percent other religions, mostly Confucianist and Taoist, and 7 percent Hindu.

We next report the distribution of educational levels for each country, for women (Panel C) and for their husbands (Panel D). Vietnam shows the highest levels of education with 10 percent of women completing university and 65 percent of women completing at least primary schooling. On the contrary, in Indonesia and Malaysia, most women did not receive any education (71 and 74 percent respectively). In all countries except Vietnam, educational levels are higher for men than for women. Finally, birth cohorts are shown in Panel E: individuals in our sample are born between 1900 and 1963.

Our final sample includes 561,948 women. This is a sufficient sample size for identifying the mean fertility of the 25 combined levels of education of a couple and estimating the marginal effect of religion on fertility for most of these 25 combined levels of education.

\subsubsection{Empirical Methods}

We estimate the parameters of two auxiliary models using an ordinary least squares (OLS) regression. Model $\mathbf{A}$ is a simple linear equation, while Model $\mathbf{B}$ includes interaction terms between education and religion. Model $\mathbf{A}$ is as follows:

$$
\mathcal{N}_{i}=\beta_{1}^{A} \mathcal{R}_{i}+\beta_{2}^{A} \mathcal{E}_{i}^{f} \times \mathcal{E}_{i}^{m}+\beta_{3}^{A} \mathcal{B}_{i}+\beta_{4}^{A} \mathcal{C}_{i}+\epsilon_{i}^{A}
$$




\begin{tabular}{|c|c|c|c|c|c|c|}
\hline & Cambodia & Indonesia & Malaysia & Philipp. & Vietnam & Thailand \\
\hline \multicolumn{7}{|c|}{ A: Number of children ever born } \\
\hline Mean & 5.49 & 5.75 & 5.88 & 5.24 & 4.17 & 4.22 \\
\hline $\mathrm{Sd}$ & 2.87 & 3.53 & 3.23 & 2.93 & 2.09 & 2.88 \\
\hline Min & 0 & 0 & 0 & 0 & 0 & 0 \\
\hline Max & 20 & 29 & 23 & 20 & 14 & 25 \\
\hline \multicolumn{7}{|l|}{ B: Religion (in \%) } \\
\hline No religious affil. & 0.00 & 0.00 & 0.72 & 0.33 & 80.69 & 0.04 \\
\hline Buddhist & 96.91 & 1.09 & 24.31 & 0.05 & 10.84 & 95.43 \\
\hline Hindu & 0.00 & 2.35 & 6.71 & 0.00 & 0.00 & 0.01 \\
\hline Muslim & 2.05 & 87.08 & 54.23 & 4.48 & 0.01 & 3.65 \\
\hline Catholic & 0.38 & 2.34 & 2.57 & 83.43 & 5.42 & 0.74 \\
\hline Protestant/Other Christ & 0.00 & 5.77 & 0.00 & 10.58 & 0.45 & 0.00 \\
\hline Other & 0.66 & 1.36 & 11.47 & 1.14 & 2.60 & 0.13 \\
\hline \multicolumn{7}{|c|}{ C: Women's Education (in \%) } \\
\hline No schooling & 47.0 & 70.6 & 74.4 & 6.9 & 7.8 & 27.8 \\
\hline Some primary & 34.9 & 20.8 & 16.7 & 28.3 & 34.1 & 62.8 \\
\hline Primary completed & 16.6 & 7.7 & 8.7 & 40.6 & 41.5 & 5.0 \\
\hline Secondary completed & 1.4 & 0.9 & 0.1 & 14.1 & 13.4 & 3.1 \\
\hline University completed & 0.2 & 0.0 & 0.1 & 10.2 & 3.2 & 1.3 \\
\hline \multicolumn{7}{|c|}{ D: Husband's Education (in \%) } \\
\hline No schooling & 23.2 & 46.3 & 40.3 & 6.4 & 3.9 & 18.4 \\
\hline Some primary & 39.7 & 37.1 & 35.3 & 29.4 & 25.5 & 63.9 \\
\hline Primary completed & 32.7 & 14.2 & 23.4 & 35.7 & 45.7 & 9.9 \\
\hline Secondary completed & 3.7 & 2.2 & 0.4 & 20.2 & 16.9 & 5.2 \\
\hline University completed & 0.7 & 0.2 & 0.6 & 8.3 & 7.9 & 2.6 \\
\hline \multicolumn{7}{|l|}{ E: Birth year } \\
\hline Mean & 1952 & 1928 & 1923 & 1943 & 1952 & 1936 \\
\hline Min & 1928 & 1910 & 1900 & 1941 & 1950 & 1900 \\
\hline Max & 1963 & 1935 & 1935 & 1945 & 1954 & 1955 \\
\hline
\end{tabular}

Table 2: Descriptive Statistics

where $\mathcal{N}_{i}$ is the number of children ever born for woman $i$, and $\mathcal{R}_{i}$ is a vector of religion dummies indicating woman $i$ 's religion. The level of education of the couple is indicated by $\mathcal{E}_{i}^{f} \times \mathcal{E}_{i}^{m}$, a vector of 25 categorical variables. $\mathcal{B}_{i}$ indicates the birth year of woman $i$ and $\mathcal{C}_{i}$ accounts for census (country and year) fixed effects. The $\beta$ 's are vectors of parameters. This specification allows us to isolate the effect of religion from country-specific effects. Countryyear fixed effects also account for variations in factors affecting the demographic transitions across countries, such as changes in child mortality and in family planning technology.

Model B allows for the effect of religion to vary by level of educational attainment:

$$
\mathcal{N}_{i}=\beta_{1}^{B} \mathcal{R}_{i} \times \mathcal{E}_{i}^{f} \times \mathcal{E}_{i}^{m}+\beta_{2}^{B} \mathcal{B}_{i}+\beta_{3}^{B} \mathcal{C}_{i}+\epsilon_{i}^{B}
$$


where $\mathcal{R}_{i} \times \mathcal{E}_{i}^{f} \times \mathcal{E}_{i}^{m}$ stands for the level of education of the couple interacted with the wife's religion. This term stands for a vector of $7 \times 25$ categorical variables.

\subsection{Estimation of the Parameters}

\subsubsection{Main Results}

The results of the OLS regression of Model A are presented partially in Tables 3 and 4 and in full in Table E in the Appendix. They are robust to restricting the sample to women with children. All religions, except for Hinduism, significantly increase the number of children ever born (Table 3). The effect of religion is about three times higher for Protestants and Catholics than for Buddhists, in line with Lehrer (2004). The coefficients for Catholicism and Protestantism echo the results of Zhang (2008) who shows, for the US, "no significant fertility differences between fundamentalist Protestants, other Protestants, and Catholics. Catholics only show a significantly higher level of fertility when compared to other nonChristian religious people." Our ranking of Islam vs Hinduism is consistent with the results in Munshi and Myaux (2006) that Hindus maintain higher levels of contraceptive prevalence compared to Muslims (in rural Bangladesh). Finally, compared to Skirbekk et al. (2015) who look at Asian countries, we also find that Buddhism is less pro-natalist than the Abrahamic religions, but, unlike their findings, the coefficient for Buddhism is significant.

For easier interpretation, the estimated fertility for all 25 combined levels of education of a couple, drawn from the OLS regression of Model A, are presented in Table 4. The reference category is a woman with no religious affiliation in the Philippines born in 1945 . The average number of children ever born for a non-educated couple with no religious affiliation is 4.25. Overall expected fertility declines with the couple's level of education. One interpretation is that the time spent on child care becomes more expensive when people are more productive. The higher value of time raises the cost of children and thereby reduces the demand for large families (Becker 1993). The average is 2.83 for a couple in which both spouses have a university degree. Interestingly though, among couples with low education, fertility is slightly higher for couples in which at least one of the spouses has received some primary education. This suggests that, for low levels of education, additional years of schooling translate into higher income, thus alleviating the cost of child-rearing and translating into higher fertility. For couples with an educational level higher than primary school, the opportunity cost of child-rearing compensates this effect however, causing fertility to decline with years of schooling.

We next turn to the OLS estimation of Model B in which we regress fertility on the 25 education couples, on education couples interacted with all religions, as well as on census and birth year dummies. The full results are presented in Table E in the Appendix and the 


\begin{tabular}{lcc}
\hline & $\widehat{\beta_{1}^{A}}$ & s.e. \\
\hline Buddhism & $0.331^{a}$ & $(0.0725)$ \\
Hinduism & 0.218 & $(0.1127)$ \\
Islam & $0.560^{a}$ & $(0.0907)$ \\
Catholicism & $0.914^{a}$ & $(0.0461)$ \\
Protestantism & $1.040^{a}$ & $(0.0803)$ \\
Other religion & $0.675^{a}$ & $(0.1113)$ \\
\hline
\end{tabular}

Notes: Sample includes 561,948 observations. Column 1 represents coefficients for religion estimated with an OLS regression of model A; standard errors clustered by country in parentheses in column 2 . All specifications also include dummy vectors for combined education levels of couples, birth years and censuses.

${ }^{a}$ Significantly different from zero at 99 percent confidence level.

${ }^{b}$ Significantly different from zero at 95 percent confidence level.

${ }^{c}$ Significantly different from zero at 90 percent confidence level.

Table 3: Model A - Effect of religion on fertility

\begin{tabular}{|c|c|c|c|c|c|}
\hline \multicolumn{6}{|c|}{ Man Education } \\
\hline Woman & No & Some & Primary & Secondary & University \\
\hline Educ. & schooling & primary & completed & completed & completed \\
\hline $\mathrm{No}$ & $4.25^{a}$ & $4.78^{a}$ & $4.66^{a}$ & $4.54^{a}$ & $4.16^{a}$ \\
\hline Some & $4.90^{a}$ & $4.82^{a}$ & $4.70^{a}$ & $4.33^{a}$ & $3.77^{a}$ \\
\hline Primary & $4.26^{a}$ & $4.65^{a}$ & $4.36^{a}$ & $4.09^{a}$ & $3.39^{a}$ \\
\hline Secondary & $4.23^{a}$ & $3.89^{a}$ & $3.52^{a}$ & $3.42^{a}$ & $3.12^{a}$ \\
\hline University & $4.32^{a}$ & $3.28^{a}$ & $2.99^{a}$ & $2.75^{a}$ & $2.83^{a}$ \\
\hline \multicolumn{6}{|c|}{$\begin{array}{l}\text { Notes: Sample includes } 561,948 \text { observations. Coefficients from OLS regression of fertility } \\
\text { model A; standard errors clustered by country. All specifications include dummy vectors } \\
\text { for religions, birth years and censuses. The reference category is a woman with no religious } \\
\text { affiliation in the Philippines born in } 1945 \text {. } \\
{ }^{a} \text { Significantly different from zero at } 99 \text { percent confidence level. } \\
{ }^{b} \text { Significantly different from zero at } 95 \text { percent confidence level. } \\
{ }^{c} \text { Significantly different from zero at } 90 \text { percent confidence level. }\end{array}$} \\
\hline
\end{tabular}

Table 4: Model A - Effect of couples' education on fertility 

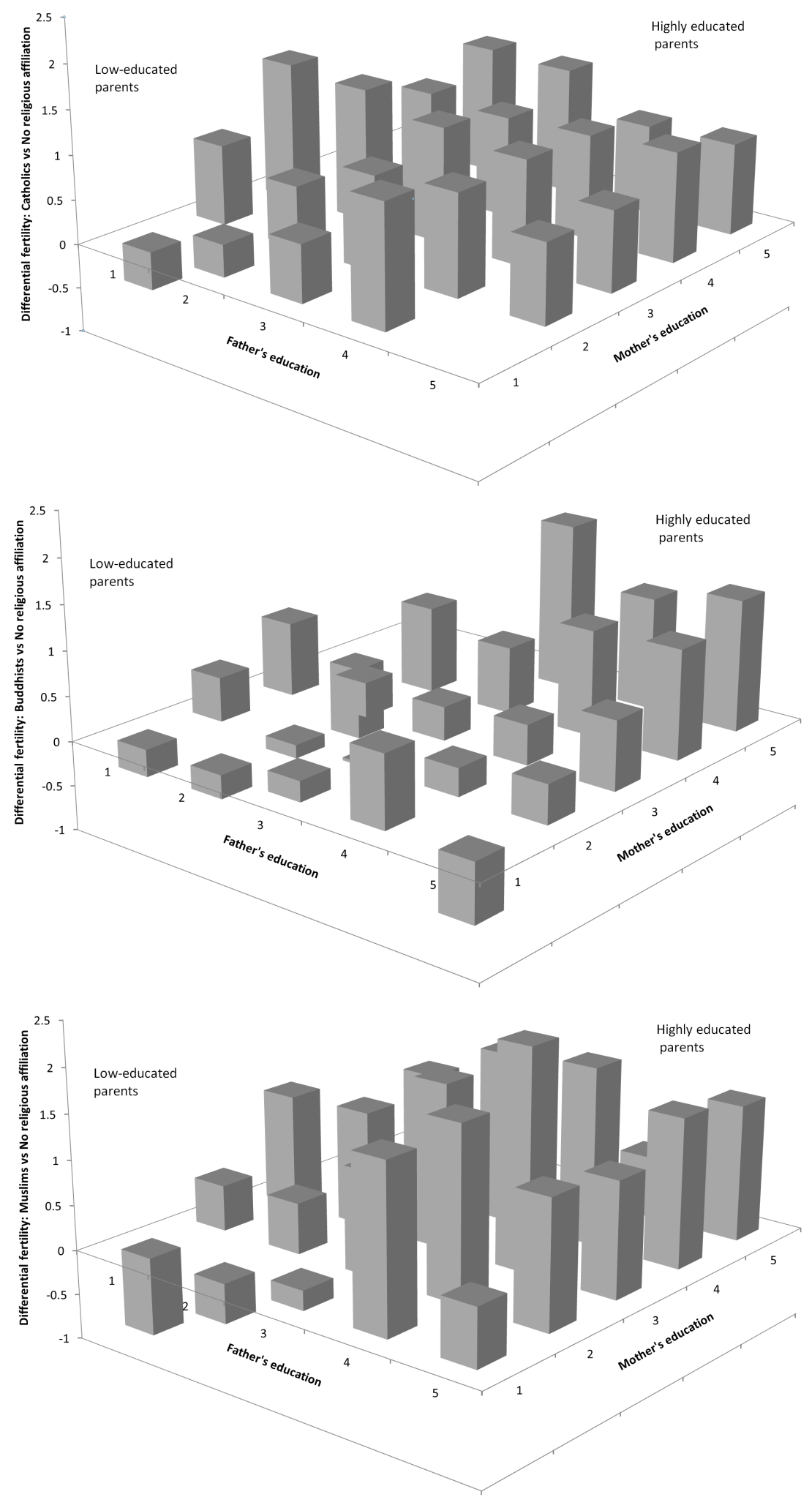

Figure 2: Model B - Effect of religious affiliation (Catholic, Buddhist, Muslim) on fertility by couple's education level 
resulting moments used for estimation are in Appendix G.1. In Figure 2, we only present estimates of the marginal effect of being Catholic (resp. Buddhist, or Muslim) rather than non-religious on fertility at each educational level. For each religion, the couples with low education are on the left, and those with high education on the right. Allowing the impact of religion to vary across educational levels shows a more complex picture than the one shown by model A, with three main features. First, the marginal effect of Catholicism on fertility (top panel) is stronger for couples with middle to high levels of education (completed primary or secondary). A Catholic couple who completed primary education has on average 1.29 more children than a couple without religious affiliation (a difference of 33 percent in the number of children), while for couples with no education, the effect is negligible (even negative). This implies that this religious affiliation tends to dampen the decline in fertility due to education. Second, the main feature highlighted for Catholicism is also true for Buddhism (middle panel). However, there are differences with the patterns highlighted for the marginal effect of Catholicism at varying education levels. The marginal effects of Buddhism on fertility are overall lower in magnitude than the effects of Catholicism, in line with estimates from Model A (Table 4). Buddhism has the strongest positive impact on the fertility of couples with the highest levels of education (secondary schooling and above). A Buddhist woman in a couple in which both spouses hold a university degree has 1.44 more children than one without religious affiliation (62 percent more), while there is no significant difference between a Buddhist and a woman without religious affiliation in non-educated couples (with 5.58 children on average). Third, looking at Islam (bottom panel), we also find that educated couples' fertility is more affected by being religious than that of less educated couples. The effect is particularly strong for fathers and mothers with secondary education and more, and is even stronger for Islam than for Catholicism.

Notice finally that, in Figure 2, some coefficients are based on a very small number of observations. ${ }^{8}$ When estimating the structural parameters of the model we will develop in the next section, we are going to discard estimates based on less than 30 observations. ${ }^{9}$

We compute an $F$-statistic to compare both models. The $F$-statistic is 2233 with a p-value of 0.00 , leading to a rejection of the null hypothesis that Model $\mathbf{B}$ does not provide a significantly better fit than Model A.

\footnotetext{
${ }^{8}$ Note that our sample only counts 17 couples in which the woman has a university degree while her husband has no education and 113 couples in which the woman has no education while her husband has a university degree.

${ }^{9}$ Cells $(\mathrm{i}) \times(\mathrm{iv}),(\mathrm{i}) \times(\mathrm{v}),(\mathrm{iv}) \times(\mathrm{i})$, and $(\mathrm{v}) \times(\mathrm{i})$ for persons without religious affiliation, $(\mathrm{i}) \times(\mathrm{v})$, (iv) $\times(\mathrm{i})$, and $(\mathrm{v}) \times(\mathrm{i})$ for Catholics, $(\mathrm{v}) \times(\mathrm{i})$, and $(\mathrm{v}) \times($ ii) for Buddhists, $(\mathrm{iv}) \times(\mathrm{i}),(\mathrm{v}) \times(\mathrm{ii})$, and $(\mathrm{v}) \times($ iii $)$ for Muslims.
} 


\subsubsection{Additional Tests}

In this subsection, we discuss and test the robustness of the estimation of the auxiliary model presented above.

Our dependent variable, fertility, is a count variable, taking values between 0 and 29. Because the distribution of residuals is not normal, applying a linear regression model might lead to inefficient and inconsistent estimates (Long and Freese 2006), but allows us to directly interpret the results in terms of number of children. To assess the robustness of our main estimations, we estimate Models $\mathbf{A}$ and $\mathbf{B}$ with a Poisson regression. Results are presented in Table E in Appendix (Col. 2 and 4). The significance of coefficients is not weakened by substituting Poisson to OLS estimations. Moreover, the size of the effects are very similar. For example, considering the coefficients presented in Table 3, the Poisson estimation leads to the following estimates of the marginal effect of each religion: $0.336,0.269,0.565,0.910$, $0.995,0.654$. The only difference is that the coefficient related to Hinduism is now significant.

An additional concern is that the impact of religion (and of religion interacted with education) may vary between countries. Our estimation provides in fact an estimation of the average effect of religions on fertility in South-East Asia. To account for country specific effects of religions, one option would be to incorporate dummy variables interacting country and religion (and country, religion and education) but this puts too many constraints on the model and prevents us from estimating coefficients' standard errors. To nevertheless evaluate whether the estimation results are driven by a particular country, we estimate Models $\mathbf{A}$ and B with restricted samples. Tables $\mathrm{F}$ presents the results from these regressions. For easier comparison, columns (1) and (2) report results from the main OLS regressions using the full sample presented earlier (in Table E). The sample excludes the Philippines, mostly Catholic, in columns (3) and (4), and Thailand, predominantly Buddhist, in columns (5) and (6). Although the specification is identical to that described above, we do not report estimates of the educational categories, census and birth year coefficients for better readability. The results using the three different samples are very similar. Being a Catholic, as opposed to not having a religious affiliation, brings an additional 0.88 child on average when the Philippines or Thailand are excluded from the sample, compared to an additional 0.91 child on average with the full sample. The positive impact of being Hindu is significant in the models estimated with the restricted samples. Finally, the estimates of the marginal effect of religion at different levels of couple's education are very similar across all three samples.

Another potential limitation is that education might be endogenous to fertility due to teenage pregnancies. Restricting our sample to women aged more than 20 at the time of their first child's birth, instrumenting for age at menarche (Ribar 1994) or for miscarriage (Hotz, McEl-

roy, and Sanders 2005) would allow us to rule out this argument, but these data are not available in the IPUMS data. 
Finally, the robustness of the results to the inclusion of variables reflecting the minority status hypothesis is analyzed in Section 5.2.

\section{The Structural Model}

We now estimate the structural parameters of an economic model with a quality-quantity tradeoff. We identify these parameters with an indirect inference method, using the fertility equation from Section 2 as the auxiliary model. The structural model we use is the one proposed by de la Croix and Doepke (2003), extended to allow for different sources of income and optimal degrees of involvement in child rearing from the father and the mother (inspired by Hazan, Leukhina, and Zoaby (2014)). It is a very parsimonious model which captures one key feature: the time cost of rearing children being higher for more educated parents, they prefer having fewer children but investing more in their quality. A critical assumption of this model is that the most important cost of having children is a time cost rather than a good cost (see the estimation of Córdoba and Ripoll (2016) for the US).

As stated in the introduction, we view religion as exogenous and affecting households' preferences, and thereby their incentives. We focus on four types of hypothetical households: Catholic, Buddhist, Muslim and without religious affiliation. These are the religions for which we have enough individuals in each educational cell to be confident in the estimation of Model $\mathbf{B}$ described above.

Notice that we could alternatively assume that religions modify the household technology for example by affecting the good cost needed to raise and/or to educate one child. In that case, preferences can be identical across all households, but technology differs by religion. For example, a feature of Catholicism is that churches are also involved in education. Private catholic schooling is common around the world and it is generally subsidized. One could then rationalize Catholicism as being pro-child because highly educated parents are able to spend more on both quantity and quality of children, since the church provides relatively cheap access to private schooling. From this perspective, it may not be that Catholic parents have a high weight on quality of children embedded in their preferences (high $\eta$ in the model), but that subsidized private schooling allows parents to educate more children. In fact, we cannot distinguish between household technology and preferences. Observationally, the two approaches are equivalent, but the interpretation in terms of preferences is in line with the literature on religion as a cultural trait (Bisin and Verdier 2010). Both interpretations imply that religions modify incentives, which is what we measure in the first order conditions of the household maximization problem, either through preferences parameters and shadow prices or through technology and actual costs. 


\subsection{Households' Problem}

Consider a hypothetical economy populated by overlapping generations of individuals with the same religion who live over three periods: childhood, adulthood, and old age. All decisions are made in the adult period of their life. Households care about adult consumption $c_{t}$, old-age consumption $d_{t+1}$, the number of their children $n_{t}$, and their quality (human capital) $h_{t+1}$. They have the same preferences and act cooperatively (unitary model of the household). Their utility function is given by:

$$
\ln \left(c_{t}\right)+\sigma \ln \left(d_{t+1}\right)+\gamma \ln \left(n_{t} h_{t+1}^{\eta}\right)
$$

The parameter $\sigma>0$ is the psychological discount factor and $\gamma>0$ is the weight of children in the utility function. Parameter $\eta \in(0,1)$ is the weight of quality versus quantity of children for the household. The budget constraint for a couple with human capital $\left(h_{t}^{f}, h_{t}^{m}\right)$ is:

$$
c_{t}+s_{t}+e_{t} n_{t} w_{t} h^{\mathrm{T}}=\omega w_{t} h_{t}^{f}\left(1-a_{t}^{f} n_{t}\right)+w_{t} h_{t}^{m}\left(1-a_{t}^{m} n_{t}\right)
$$

where $w_{t}$ is the wage per unit of human capital and $\omega$ is an exogenous gender wage gap (due for example to discrimination). $a_{t}^{f}$ and $a_{t}^{m}$ are the time parents spend on child rearing. The total educational cost per child is given by $e_{t} h^{\mathrm{T}}$, where $e_{t}$ is the number of hours of teaching bought from a teacher with human capital $h^{\mathrm{T}}$. The assumption that teachers are potentially different human capital than parents is similar to Tamura (2001). When coupled with the assumption that there is a minimum time cost required to bare children, it implies that highly educated parents will spend more on the quality of their children (de la Croix and Doepke (2003) and Moav (2005)).

The technology that allows to produce children is given by: ${ }^{10}$

$$
n_{t}=\frac{1}{\phi} \sqrt{a_{t}^{f} a_{t}^{m}} .
$$

It stresses that time is essential to produce children, and that mother's and father's time are substitutes. We do not introduce an a priori asymmetry between parents. Asymmetry will arise as an equilibrium phenomenon: with the gender wage gap $\omega<1$, it will be optimal to have the mother spending more time on child rearing. The parameter $\phi \in(0,1)$ gives an upper bound to the number of children. If both parents devote their entire time to produce children, they will get $1 / \phi$ of them. As it is clear from (3), we abstract from uncertainty on child production. The two main sources of uncertainty we abstract from are child mortality (how the different ways to introduce child mortality into similar models see Doepke (2005)),

\footnotetext{
${ }^{10}$ Adapted from Browning, Chiappori, and Weiss (2014) p.265, and Gobbi (2014) to the production of quantity instead of quality.
} 
young adult mortality (see Tamura (2006)), and family planning failures (see Bhattacharya and Chakraborty (2013) for modelling them).

The budget constraint for the old-age period is:

$$
d_{t+1}=R_{t+1} s_{t}
$$

$R_{t+1}$ is the interest factor. Children's human capital $h_{t+1}$ depends on their education $e_{t}$ :

$$
h_{t+1}=\mu_{t}\left(\theta+e_{t}\right)^{\xi}
$$

The presence of $\theta>0$ guarantees that parents have the option of not educating their children, because even with $e_{t}=0$ future human capital remains positive. It can be interpreted as the level of public education provided to parents for free. Parameter $\xi$ is the elasticity of human capital to education. It is to be understood as determining the rate of return of parental investment in education. Parents' influence on their children's human capital is limited to the effect through education spending. The specification of the efficiency parameter $\mu_{t}$ does not affect individual choices and is left to the next section.

The household's maximization problem is solved in Appendix A. For a household whose human capital is high enough to ensure that the opportunity cost of an additional child is high, such that

$$
\omega h_{t}^{f} h_{t}^{m}>\left(\frac{\theta h^{\mathrm{T}}}{2 \phi \eta \xi}\right)^{2},
$$

there is an interior solution with positive spending on education. For households with lower human capital, the optimal choice for education $e_{t}$ is zero. Education and fertility decisions can be summarized by:

$$
\begin{aligned}
& e_{t}=\max \left[0, \frac{2 \phi \eta \xi \sqrt{\omega h_{t}^{f} h_{t}^{m}}-\theta h^{\mathrm{T}}}{(1-\eta \xi) h^{\mathrm{T}}}\right], \\
& n_{t}=\max \left[\frac{\gamma\left(\omega h_{t}^{f}+h_{t}^{m}\right)}{2(1+\sigma+\gamma) \phi \sqrt{\omega h_{t}^{f} h_{t}^{m}}}, \frac{(1-\eta \xi) \gamma\left(\omega h_{t}^{f}+h_{t}^{m}\right)}{1+\sigma+\gamma} \frac{2 \phi \sqrt{\omega h_{t}^{f} h_{t}^{m}}+\theta h^{\mathrm{T}}}{4 \phi^{2} \omega h_{t}^{f} h_{t}^{m}-\theta^{2} h^{\mathrm{T}^{2}}}\right] .
\end{aligned}
$$

In the corner regime (first terms in the max), there is no tradeoff between quality and quantity of children. In the interior regime, the second terms inside the max reflect the quality-quantity tradeoff: when the opportunity cost of raising children $\phi \sqrt{\omega h_{t}^{f} h_{t}^{m}}$ increases, parents substitute education $e_{t}$ for quantity $n_{t}$. There is strong empirical evidence that this mechanism is at work in developing countries (see e.g. the study on Chinese twins by Li, Zhang, and Zhu (2008) and the one by Klemp and Weisdorf (2016) on pre-industrial England). This substitution only occurs in the interior regime. 
We now use these equations to interpret the effect of religion on individual choices. We consider here that religion is exogenous and implies different preference parameters across denominations and compared to non religious people. We assume that religion neither influences the time cost parameter $\phi$, the constant $\theta$, nor the rate of return of education $\xi$. $\phi$ flows from a technological constraint. $\theta$ represents the provision of education good (possibly public) imposed to the parents. $\xi$ depends on the labor market of each country. We focus on the two parameters which most likely depend on religious values.

If a religion increases the preference for children $\gamma$, it leads to more children, the same level of education per child, and less saving. This holds both in the interior regime and in the corner regime. It may thus depress growth through physical capital accumulation but not through human capital accumulation. We will call this religion pro-child as it promotes both quantity and quality.

If a religion decreases the relative weight of quality over quantity $\eta$, it has no effect in the corner regime. In the interior regime, it leads to more children, less education, and the same level of saving. It may therefore depress growth through human capital accumulation. Such a religion is said to be pro-birth.

The two notions we introduce, pro-child and pro-birth, describe how households that increase the share of children in total spending actually spend that income. Coming back to the budget constraint (17), the total spending on children can be decomposed into spending on quality and spending on quantity. Using the first order conditions in the interior regime, we can see how these two spending shares are directly expressed in terms of the parameters $\gamma$ and $\eta$ when $\theta$ is small:

$$
\begin{gathered}
\text { Spending on quality: } \frac{e_{t} n_{t} h^{\mathrm{T}}}{\omega h_{t}^{f}+h_{t}^{m}}=\frac{\gamma \eta \xi}{1+\gamma+\sigma} \text { for } \theta=0 \\
\text { (opportunity) Cost on quantity: } \frac{2 \phi \sqrt{\omega h_{t}^{f} h_{t}^{m}} n}{\omega h_{t}^{f}+h_{t}^{m}}=\frac{\gamma(1-\eta \xi)}{1+\gamma+\sigma} \text { for } \theta=0
\end{gathered}
$$

Hence a pro-child religion (high $\gamma$ ) leads to more spending of the two types, while a pro-birth religion (low $\eta$ ) redirects spending from quality towards quantity. ${ }^{11}$

\footnotetext{
${ }^{11}$ The logarithmic utility is essential is getting these simple expressions. Assuming a more general utility with an elasticity of substitution between goods different from unity would lead to more complicated expressions, with spending shares depending on the shadow prices of quantity and quality of children. Except for the Barro-Becker approach which develops a model of optimal fertility with rational altruism and infinite horizon, the rest of the literature assumes logarithmic utility, reflecting that there is little to gain in terms of insights by having more complicated functional forms.
} 


\subsection{Identification}

One period is assumed to be 30 years. Some parameters are set a priori, based on commonly accepted values, supposed common to all countries. The biological time cost of raising children per couple is $\phi=0.065$, implying a maximum number of children per couple of $\lfloor 1 / \phi\rfloor=15$. The discount factor $\sigma$ is set at $1 \%$ per quarter, i.e. $\sigma=0.99^{120}=0.3$. The rate of return on education spending $\xi$ is set to $1 / 3$. As we can see from the first order conditions, it cannot be identified separately from $\eta$, hence it can be seen as a scaling factor on $\eta$. Parameter $\xi$ is related to the Mincerian rate of return $\varrho$ (defined by $h_{t+1}=\exp (\varrho \times$ years of education $\left.)\right)$ through the following relation:

$$
\varrho=\frac{\mathrm{d} \ln h_{t+1}}{\mathrm{~d} e} \frac{\mathrm{d} e}{\mathrm{~d}(\text { years of education })}
$$

where $\mathrm{d} e / \mathrm{d}$ (years of education) represents the increase in educational spending needed to increase the number of years of education by one. Assuming as in de la Croix and Doepke (2003) that an additional year of schooling raises educational expenditure by 20 percent, and using the first order condition for $e$ in the interior regime, we get

$$
\varrho=\frac{\xi}{\theta+e} 0.2 e
$$

which leads to $\varrho=0.066$ for $\theta$ negligible. A Mincerian return of $6.6 \%$ seems a reasonably conservative estimate for emerging countries.

In order to compute the fertility of the 25 types of couples in Table 1, we need to map educational levels into earnings levels. We use the study of Luo and Terada (2009) who estimate the earnings of men and women of different educational categories in the Philippines. The advantage of this study is that the categories of education they use maps perfectly with those of IPUMS international. They find that the gender wage gap for low educational levels is $\omega=0.75$. Table 5 shows the human capital level for all educational categories. Women's income is given by $\omega h^{f}$.

\begin{tabular}{llllll}
\hline & $\begin{array}{l}\text { No } \\
\text { education }\end{array}$ & $\begin{array}{l}\text { Some } \\
\text { primary }\end{array}$ & $\begin{array}{l}\text { Primary } \\
\text { completed }\end{array}$ & $\begin{array}{l}\text { Secondary } \\
\text { completed }\end{array}$ & $\begin{array}{l}\text { University } \\
\text { completed }\end{array}$ \\
\hline$h^{f}$ & 1 & 1.035 & 1.07 & 1.46 & 2.14 \\
$h^{m}$ & 1 & 1.065 & 1.13 & 1.37 & 1.86 \\
\hline
\end{tabular}

Notes: Estimations from Luo and Terada (2009). Results normalized to 1 for category (i).

Table 5: Income by Education Categories in the Philippines

The Mincerian rate of return implicit in Table 5 depends on whether education includes years of primary education or not. Including years of primary education leads to low estimates of $\varrho$. 
For example, for women, ${ }^{12}$ assuming that one needs 16 years to complete university, we have $2.14=\exp (\varrho 16)$, leading to $\varrho=4.7 \%$. Computing the rate of return once primary education is completed leads to higher estimates: $2.14 / 1.07=\exp (\varrho(16-6))$, i.e. $\varrho=6.9 \%$.

An alternative way of measuring human capital is to use Mincerian rates of return surveyed by Montenegro and Patrinos (2014). They provide such rates for the three education levels, primary, secondary and tertiary, and for males and females. In appendix D.1 we use a crosscountry average of these returns, leading to substantially higher numbers than in the main text; the structural estimation shows, however, that the deep parameters adjust to these higher returns, leading in the end to similar results than in the benchmark.

Finally, we set the teacher's human capital $h^{\mathrm{T}}$ equal to the human capital of a woman with secondary education (without gender gap in the education sector). This implies that education is relatively costly for someone with a low educational level, but cheap for someone with a university degree.

There remains three parameters to identify: $\theta, \gamma$, and $\eta$. We assume that $\theta$ is common to all religions. To verify that these parameters can be identified through the fertility pattern described in Equation (8), we draw the shift in the fertility function implied by a change in each of the parameters. Figure 3 reports the results, with, in the left column, fertility as a function of the human capital of a mother married to a man with no education, and, in the right column, fertility as a function of the human capital of a father married to a woman with no education. The left panel of each figure depicts the corner regime with no education. Entering the interior regime, fertility drops as the quality - quantity tradeoff kicks in. As parents' education increases, spending on quality (education) substitutes to spending on quantity.

The preference for children $\gamma$ acts as a shift on the whole pattern, affecting fertility in the same way in both the corner regime and the interior regime. The parameter $\eta$ acts on the point where the regime shifts. It also affects the speed at which fertility declines as the parents' education rises. The existence of the corner regime is critical for identification. In the absence of such a regime, fertility would be monotonically decreasing in education, and both $\eta$ and $\gamma$ would shift the whole pattern in the same way. The existence of different regimes of fertility is strongly confirmed by the literature on fertility differentials in developing countries. (Jejeebhoy 1995) finds a positive or no relationship for 7 countries, a negative relationship for 26 countries, and an inverse U-shaped relationship for 26 other countries. More recently, (Vogl 2016) finds evidence of a relationship ranging over time from positive to negative.

\footnotetext{
${ }^{12}$ Notice that, in the theory, we have abstracted from different rates of return for boys and girls. If $\xi$ was different across genders, it would be optimal to differentiate the education of boys and girls, investing more in the human capital with the highest return. One would then need to consider fertility as a sequential choice, where the total number of children would depend on whether parents had boys or girls in the first place. See Hazan and Zoabi (2015).
} 

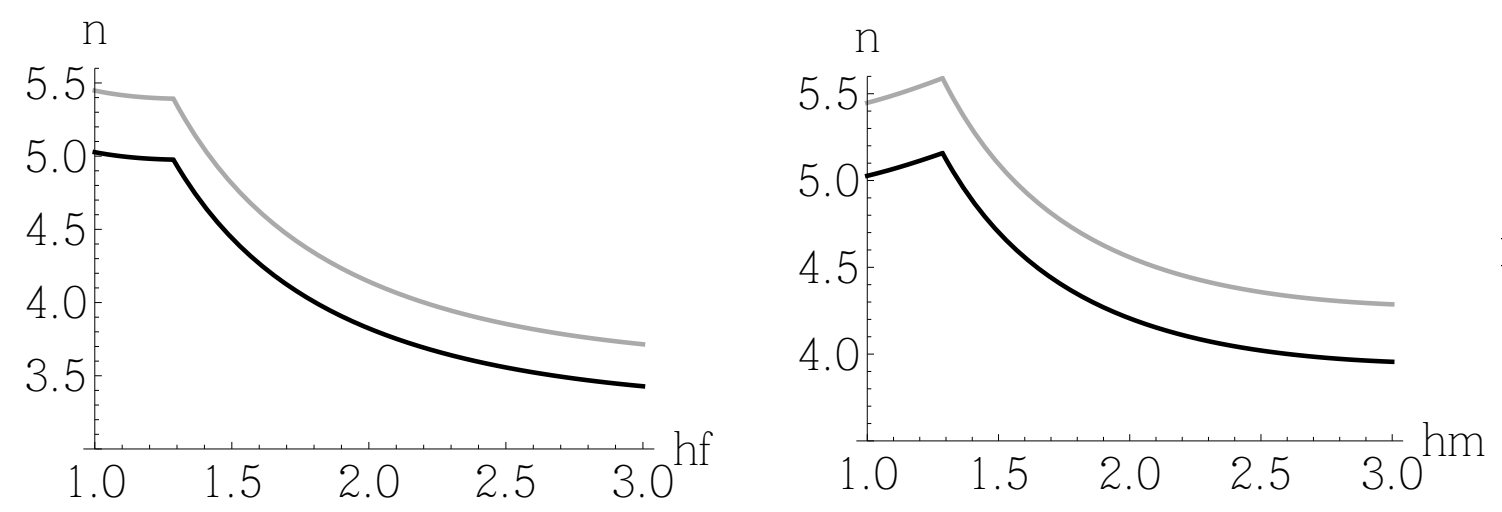

Rise in $\gamma$
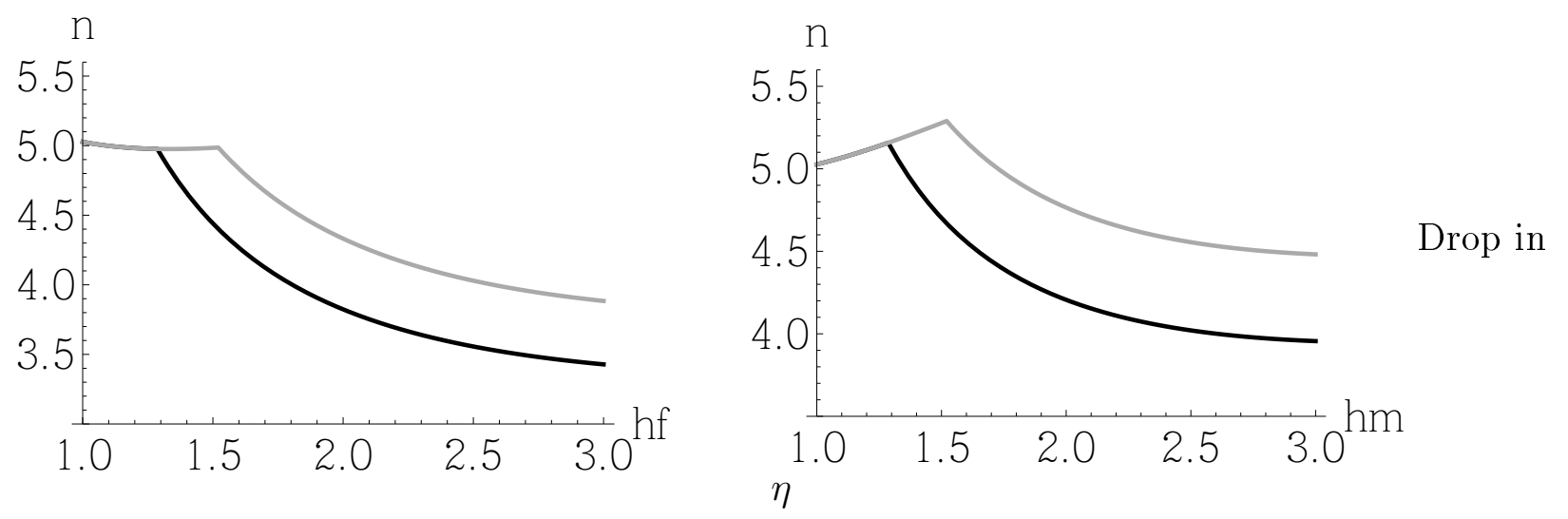

Note: The first line shows the effect on fertility of a rise in $\gamma$. On the left, fertility is shown as a function of the human capital of the mother. On the right, as a function of the human capital of the father. The second line shows the effect of a drop in $\eta$.

Figure 3: Comparative Statics of the Fertility Pattern

We conclude that each parameter has a unique role in determining how fertility varies across household types. We can now identify these parameters to reproduce the characteristics of the auxiliary models $\mathbf{A}$ and $\mathbf{B}$. Although Model $\mathbf{A}$ is inferior in terms of fit, we investigate whether relying on Model $\mathbf{B}$ instead of $\mathbf{A}$ matters for the structural analysis. Introducing the index $z$ for religion, we focus on households with $z \in\{$ no religious affil., Catholic, Buddhist, Muslim\}, i.e. having preferences described by $\eta_{z}$ and $\gamma_{z}$.

To identify the 9 deep parameters, we use a minimum distance estimation procedure that matches, for each religion, the $5 \times 5$ matrix of the empirical moments from the data with the matrix of moments implied by the model for a given choice of parameters. Formally, given some weights $p_{i, j, z}$, the minimum distance estimator is obtained from

$$
\min _{\theta, \gamma_{z}, \eta_{z}} \sum_{z} \sum_{i, j} p_{i, j, z}\left(\hat{\mathcal{N}}_{i, j, z}-n^{\star}\left[\theta, \gamma_{z}, \eta_{z}, h^{f}(i), h^{m}(j)\right]\right)^{2} .
$$

The empirical moments $\hat{\mathcal{N}}_{i, j, z}$ are drawn from the distribution of the coefficients of the education dummies in Table 4 for Model A and in Table 2 for Model B. $n^{\star}\left[\theta, \gamma_{z}, \eta_{z}, h^{f}(i), h^{m}(j)\right]$ 
denotes the theoretical fertility of a couple with human capital $h^{f}(i), h^{m}(j)$, where $i$ and $j$ are the education categories, and $z$ its religious affiliation.

The weights $p_{i, j, z}$ are equal to one when there is at least 30 observations from which the moment $\hat{\mathcal{N}}_{i, j, z}$ is computed, and zero otherwise. ${ }^{13}$ Results are shown in Table 6 . Parameters mean and standard deviation are computed by drawing 200 matrices $\hat{\mathcal{N}}_{i, j}$ from the distribution of the parameters of the auxiliary model, which provide 200 estimations of the deep parameters.

Using Model A, differences in $\eta_{z}$ across religions are small, while the ranking of the $\gamma_{z}$ reproduces the ranking in the religion fixed effect (Table 3). Using the auxiliary model $\mathbf{B}$, all religions are in fact biased against the quality of children (lower $\eta$ ), but less so for Catholicism and Buddhism compared to Islam. This estimation shows how crucial it is to account for interaction effects between religion and education in the auxiliary model. For example, if these effects are neglected, the pro-child effect of Catholicism (rise in $\gamma$ ) is overestimated and its pro-birth effect (drop in $\eta$ ) underestimated. We also miss the strong effect on $\eta$ of Buddhism and Islam.

Figure 4 summarizes the results obtained with Model B by showing the allocation of spending on children by religious denominations. Remember that $\gamma \eta \xi /(1+\sigma+\gamma)$ is closely tight to the share of income spent on quality, while $\gamma(1-\eta \xi) /(1+\sigma+\gamma)$ is related to the spending on quantity. Those are the two dimensions plotted on the graph. The line with a negative slope is an iso- $\gamma$ line. Moving to the North-East means that $\gamma$ increases, as well as total spending on children and the pro-child dimension of the considered religion. Moving to the North-West means that $\eta$ decreases for a given $\gamma$ and the considered religion is more pro-birth, directing spending towards quantity.

For each religion, we plot the estimated deep parameters for 200 draws of the parameters of the auxiliary model. This gives a sense of the uncertainty surrounding the estimates. We also plot the mean estimation as a circle.

Let us finally comment on the value of $\theta$. Importantly, parameter $\theta$ determines the threshold at which parents shift from no spending in quality of children, to facing a trade-off between quantity and quality if children (Equation 6). To understand the implications of a $\theta$ estimated around 0.05 , let us consider a couple where husband and wife have the same human capital $h_{t}$. Equation 6 can be rewritten as (for a couple with no religion):

$$
h>\frac{\theta}{2 \sqrt{\omega} \phi \eta \xi} h^{\mathrm{T}}=\frac{0.055}{2 \sqrt{0.75} 0.065 \times 2.136 \times 0.333} h^{\mathrm{T}}=0.69 h^{\mathrm{T}} .
$$

\footnotetext{
${ }^{13} \mathrm{An}$ alternative would be to use the inverse of the variance of the estimated coefficients, which puts less weight on the coefficients that are less precisely estimated. This optimal weighting matrix is however very rarely used in practice, given the heavy computational burden it imposes. An alternative often found in the literature is to use $p_{i, j, z}=\hat{\mathcal{N}}_{i, j, z}^{2}$, which minimizes the deviations in percentage terms. Using these weights does not change our results, as our moments have all the same order of magnitude.
} 


\begin{tabular}{|c|c|c|c|c|c|c|c|c|}
\hline & \multicolumn{4}{|c|}{ Model A } & \multicolumn{4}{|c|}{ Model B } \\
\hline & No relig. & Catholic & Buddhist & Muslim & No relig. & Catholic & Buddhist & Muslim \\
\hline$\theta$ & \multicolumn{4}{|c|}{$\begin{array}{c}0.050 \\
(0.0035)\end{array}$} & \multicolumn{4}{|c|}{$\begin{array}{c}0.055 \\
(0.0012)\end{array}$} \\
\hline$\gamma_{z}$ & $\begin{array}{c}0.553 \\
(0.0227)\end{array}$ & $\begin{array}{c}0.717 \\
(0.0225)\end{array}$ & $\begin{array}{c}0.607 \\
(0.0215)\end{array}$ & $\begin{array}{c}0.649 \\
(0.0224)\end{array}$ & $\begin{array}{c}0.672 \\
(0.0360)\end{array}$ & $\begin{array}{c}0.746 \\
(0.0114)\end{array}$ & $\begin{array}{c}0.612 \\
(0.0156)\end{array}$ & $\begin{array}{c}0.703 \\
(0.0088)\end{array}$ \\
\hline$\eta_{z}$ & $\begin{array}{c}1.802 \\
(0.0877)\end{array}$ & $\begin{array}{c}1.737 \\
(0.0853)\end{array}$ & $\begin{array}{c}1.759 \\
(0.0900)\end{array}$ & $\begin{array}{c}1.748 \\
(0.0898)\end{array}$ & $\begin{array}{c}2.136 \\
(0.0535)\end{array}$ & $\begin{array}{c}1.943 \\
(0.0325)\end{array}$ & $\begin{array}{c}1.862 \\
(0.0350)\end{array}$ & $\begin{array}{c}1.746 \\
(0.0541)\end{array}$ \\
\hline
\end{tabular}

Notes: mean (st. dev.) of structural parameters minimizing Function (9), for 200 draws of the fertility matrices $\hat{\mathcal{N}}_{i, j, z}$.

Table 6: Estimation of the Deep Parameters with (9)

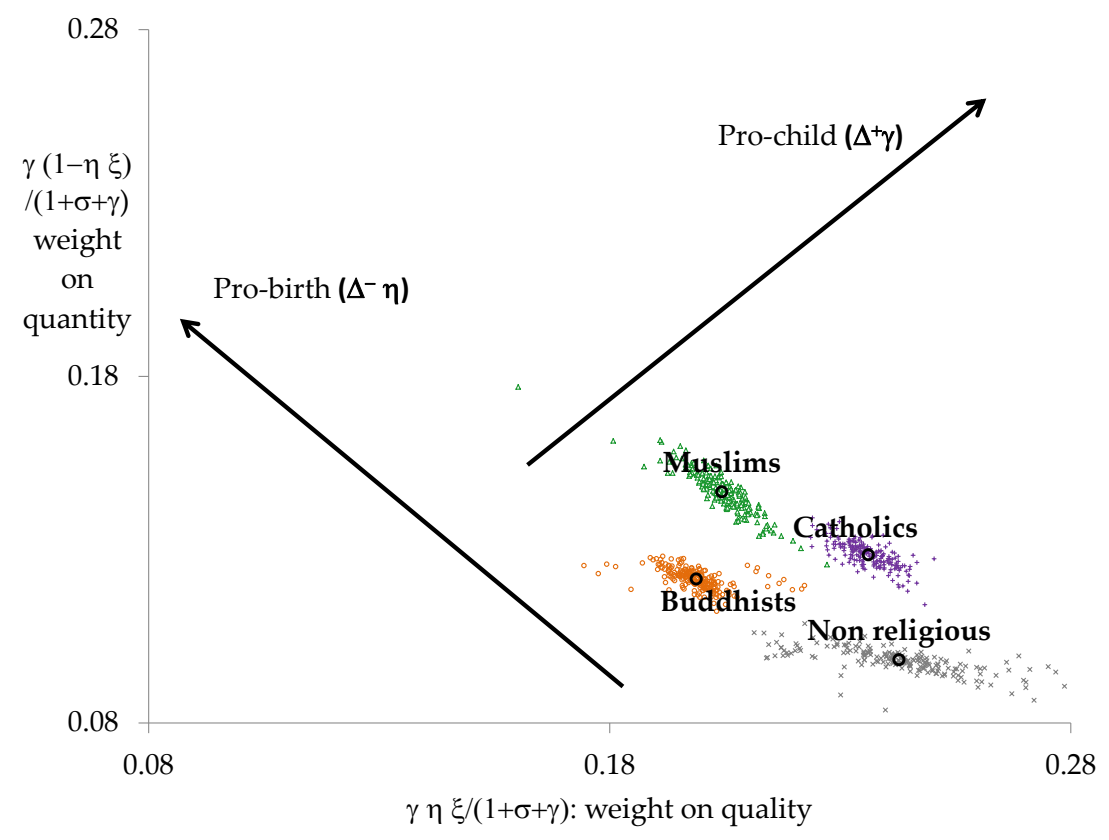

Figure 4: Pro-birth and Pro-child Religions 
Hence, only couples with human capital at least equal to $69 \%$ of the human capital of the teacher (which we assumed to be at the secondary school level) will invest in education, and lower their fertility. If $\theta$ was zero, all couples would invest in education.

\section{Religions and Growth}

We now embed the household model described above in a simple growth model. The objective is to infer some dynamic and long-run implications for growth, fertility and education. We however refrain from any statement on welfare effects, as it would involve comparing individuals with different preferences (induced by religion). We first develop the model, then simulate the path of hypothetical countries populated by homogeneous religious groups to understand the specificities of each of them, and finally simulate growth rates of real countries with the religious composition observed in the data.

\subsection{Theory}

To simplify, and to abstract from any role played by inequality, we consider the case of an economy composed of individuals with the same human capital $h_{t}=h_{t}^{m}=h_{t}^{f}$ and of teachers with human capital $h^{\mathrm{T}}$, whose demographic weight in the population is negligible. ${ }^{14}$ The efficiency parameter $\mu_{t}$ in the human capital accumulation equation (5) is assumed to follow

$$
\mu_{t}=\mu \hat{h}_{t}^{\kappa}(1+\rho)^{(1-\kappa) t}
$$

where human capital $\hat{h}_{t}$ is a geometric average of the parents' and the teacher's human capital:

$$
\hat{h}_{t}=h_{t}^{\tau} h^{\mathrm{T}^{1-\tau}} .
$$

The parameter $\tau$ captures the intergenerational transmission of ability and human capital formation within the family that do not go through formal schooling. Empirical studies detect such effects, but they are relatively small.

As in Rangazas (2000), Equation (10) is compatible with endogenous growth for $\kappa=1$, and with exogenous growth otherwise.

- When $\kappa=1, \mu_{t}$ depends linearly on aggregate human capital. This is the simplest way of modelling a human capital externality driving the growth process. The empirical evidence supporting that education is one of the key determinants of growth is strong,

\footnotetext{
${ }^{14}$ When there are no idiosynchratic ability shocks, the model of de la Croix and Doepke (2003) converges to a situation where inequality vanishes asymptotically.
} 
both in terms of quantity of education (Cohen and Soto 2007) and quality of education (Hanushek and Woessmann 2012). This is a case in which a change in parameters driving human capital accumulation will have the strongest effect on income per person, as the growth rate itself will be modified. Thus, it gives an upper bound on the pro-child effect on growth.

- On the contrary, when $\kappa<1$, growth is exogenous, and changes in parameters will only lead to differences in the levels of income per person. Parameter $\kappa$ could be interpreted as a measure of human capital externalities. Existing evidence (see Acemoglu and Angrist (2001) and Krueger and Lindahl (2001)) suggests that these externalities are small, i.e., the social return on human capital accumulation is only slightly larger than the private return. The standard model of exogenous growth is obtained when $\kappa=0$.

Production of the final good is carried out by a single representative firm which operates the technology:

$$
Y_{t}=A K_{t}^{\varepsilon} L_{t}^{1-\varepsilon}
$$

where $K_{t}$ is aggregate capital, $L_{t}$ is aggregate labor input in efficiency units, $A>0$ and $\varepsilon \in(0,1)$. Physical capital completely depreciates in one period. The firm chooses inputs by maximizing profits $Y_{t}-w_{t} L_{t}-R_{t} K_{t}$. As a consequence, factor prices are

$$
w_{t}=(1-\varepsilon) A K_{t}^{\varepsilon} L_{t}^{-\varepsilon}, \quad \text { and } \quad R_{t}=\varepsilon A K_{t}^{\varepsilon-1} L_{t}^{1-\varepsilon}
$$

Adult population, measured by the number of couple $P_{t+1}$, is given by:

$$
P_{t+1}=P_{t}\left(n_{t} / 2\right)
$$

The market-clearing conditions for capital is:

$$
K_{t+1}=P_{t} s_{t}
$$

Time spent at rearing children follows:

$$
a_{t}^{f}=\phi n / \sqrt{\omega}, \quad a_{t}^{m}=\phi n \sqrt{\omega},
$$

The market-clearing conditions for labor are:

$$
L_{t}=\left[\omega h_{t}(1-\phi n / \sqrt{\omega})+h_{t}(1-\phi n \sqrt{\omega})-e_{t} n_{t} h^{\mathrm{T}}\right] P_{t}
$$

This last condition reflects the fact that the time devoted to teaching is not available for goods production. 
When human capital of the population $h_{t}$ is small compared to the one of the teachers $h^{\mathrm{T}}$ (from Equation (6)), the economy is in a corner regime.

Proposition 1 (Corner Regime) In the corner regime, a pro-child religion $\left(\Delta^{+} \gamma\right)$ has a negative effect on income per capita. A pro-birth religion $\left(\Delta^{-} \eta\right)$ has no effect beyond making the corner regime more likely.

Proof: see Appendix B.

Many authors see the development process as initially driven by physical capital accumulation. Later on, "the process of industrialization was characterized by a gradual increase in the relative importance of human capital for the production process." (see Galor and Moav (2006)). In our simple set-up, this corresponds to crossing the threshold $x_{t}>\frac{\theta h^{\mathrm{T}}}{\phi \eta \xi}$. In the interior regime, human capital is endogenous as $e_{t}>0$. The economy converges ${ }^{15}$ toward a balanced growth path which is characterized by the following proposition:

\section{Proposition 2 (Growth along the Balanced Growth Path)} If

$$
2 \eta \phi \xi \sqrt{\omega}>\theta
$$

the long-run growth factor of gdp per capita is:

$$
g=\mu\left(\theta+\frac{2 \eta \phi \xi \sqrt{\omega}-\theta}{1-\eta \xi}\right)
$$

if $\kappa=1$, and $g=1+\rho$ otherwise.

A pro-child religion $\left(\Delta^{+} \gamma\right)$ has no effect on long-run growth. A pro-birth religion $\left(\Delta^{-} \eta\right)$ permanently affects the long-run growth rate in the endogenous growth case $(\kappa=1)$.

Proof: see Appendix B.

\section{Proposition 3 (Income per person along the BGP)}

When growth is exogenous $(\kappa<1)$ :

A pro-child religion $\left(\Delta^{+} \gamma\right)$ lowers the long run income per person $\hat{y}$ through physical capital accumulation $\hat{k}$. A pro-birth religion $\left(\Delta^{-} \eta\right)$ lowers the long run income per person $\hat{y}$ through human capital accumulation $\hat{h}$.

Proof: see Appendix B.

\footnotetext{
${ }^{15}$ Provided that some stability condition is met. $\xi \eta+\tau<1$ suffices. See de la Croix and Doepke (2003).
} 


\subsection{Calibration and simulation of religion specific effects}

In order to simulate the effect of religious composition on growth, we retain the individualspecific parameters identified in the previous section from Model B. In addition, we need to calibrate the macroeconomic parameters $\tau, \kappa, \rho, \varepsilon, \mu$, and $A$. $\tau$ is set to 0.1 , in line with the evidence in Leibowitz (1974) who finds that even after controlling for parents' schooling and education, a 10-percent increase in parental income increases a child's future earnings by up to 0.85 percent. $\kappa$ will be either 0 or 1 , depending on the assumed model (exogenous or endogenous growth respectively). The remaining parameters are chosen so as to match a hypothetical balanced growth path similar to the one achieved by developed countries in the post-war period (see e.g. Lagerlöf (2006)). $\rho$ is set so as to have a growth rate of income per capita of 2 percent per year in the exogenous growth model. The share of capital in added value is set to its usual value $\varepsilon=1 / 3$. We calibrate the constant $\mu$ so as to reproduce a long-run growth rate $g$ of 2 percent per year in a country whose entire population is without religious affiliation. Using the value of the growth rate along the BGP leads to $\mu=3.46$ with $\kappa=1$ and $\mu=1.91$ with $\kappa=0$. As a normalization we set the value of the scale parameter $A$ in the production function to obtain a wage equal to 1 in the long-run. It yields $A=3.4$.

We first consider the exogenous growth version of the model. We accordingly set $\kappa=0$ and simulate a dynamic path for a hypothetical economy composed of individuals with no religious affiliation. Initial conditions are such that $h^{\mathrm{T}}=1, h_{t}=0.3$, and capital is such that the capital labor ratio takes its steady state value. Starting from the same initial conditions, we do the same for a hypothetical economy composed of Catholics, Buddhists, and Muslims. Key macroeconomic variables after one period $(t=1)$ and six periods $(t=6)$ are presented in Table 7.

In period 1, fertility is high everywhere, but more so in the Catholic and Muslim artificial economies. Economies are not far from the corner regime, and households' educational spending $e_{t}$ are small. Considering $\theta$ as exogenous (possibly public) educational spending, the share of these spending in GDP is between 8 and 10 percent. Saving over maximum income is around 15 percent. The lowest saving rate is seen in the Catholic country, as it is the most pro-child religion (high $\gamma$ ). Labor supply is also lower in this economy, as having children takes time. The level of income per person, $y_{t}$, is smaller in the Catholic country for these two reasons. The simulation shows that the effect is however relatively small quantitatively.

In period 6, all economies are now well into the interior regime. Fertility fell compared to period 1, and is now clearly higher in the Muslim country. This arises because the pro-birth dimension of religions now matters in the interior regime, and Islam is estimated to be the most pro-birth one (lower $\eta$ ). The ranking of parameter $\eta$ is reflected in the share of education spending in GDP, which ranges from 14.01 percent in the country with no religious affiliation to 6.67 percent in the Muslim country. Saving rate is the same as in period 1 (this is a 


\begin{tabular}{|c|c|c|c|c|c|}
\hline \multirow[t]{2}{*}{ Period } & \multirow[t]{2}{*}{ Variable } & \multicolumn{4}{|c|}{ Value in each of the four hypothetical economy } \\
\hline & & No religious affil. & Catholics & Buddhists & Muslims \\
\hline \multirow{6}{*}{$t=1$} & $n_{t}$ & 4.62 & 5.07 & 4.56 & 5.10 \\
\hline & $\theta+e_{t}(\% \operatorname{gdp})$ & $10.19 \%$ & $10.10 \%$ & $8.48 \%$ & $8.37 \%$ \\
\hline & $s_{t} /\left((1+\omega) h_{t} w_{t}\right)$ & $15.17 \%$ & $14.64 \%$ & $15.59 \%$ & $14.94 \%$ \\
\hline & $L_{t} /\left(P_{t} h_{t}\right)$ & 1.17 & 1.13 & 1.19 & 1.14 \\
\hline & $y_{t}$ & 0.95 & 0.89 & 0.98 & 0.92 \\
\hline & annual growth & $2.03 \%$ & $1.91 \%$ & $2.09 \%$ & $1.95 \%$ \\
\hline \multirow[t]{6}{*}{$t=6$} & $n_{t}$ & 3.16 & 4.01 & 3.77 & 4.49 \\
\hline & $\theta+e_{t}(\% \operatorname{gdp})$ & $14.01 \%$ & $11.34 \%$ & $8.15 \%$ & $6.67 \%$ \\
\hline & $s_{t} /\left((1+\omega) h_{t} w_{t}\right)$ & $15.17 \%$ & $14.64 \%$ & $15.59 \%$ & $14.94 \%$ \\
\hline & $L_{t} /\left(P_{t} h_{t}\right)$ & 1.17 & 1.12 & 1.19 & 1.14 \\
\hline & $y_{t}$ & 29.21 & 23.74 & 25.52 & 21.56 \\
\hline & annual growth & $2.22 \%$ & $2.13 \%$ & $2.11 \%$ & $2.07 \%$ \\
\hline
\end{tabular}

Table 7: Macroeconomic variables after 1 and 6 periods $-\kappa=0$

consequence of the logarithmic utility function), while labor supply does not change much. The gap in GDP is now wider, as it results from accumulated discrepancies. In terms of growth rate, the pro-birth dimension of the different religions leads them to lose from 0.09 to 0.15 percentage points of growth per year.

We next consider the endogenous growth version of the model, that will give us an upper bound on the long-run effect of religions on growth and income levels. We accordingly set $\kappa=1$. Key macroeconomic variables after one period $(t=1)$ and six periods $(t=6)$ are presented in Table 8. We do not report savings rate and labor supply, as they are virtually identical as those in Table 7 . In period 1, households are in the corner regime and their educational spending $e_{t}$ are null. Considering again $\theta$ as exogenous (possibly public) educational spending, the share of these spending in GDP is around 4 percent. On the contrary, in period 6, all economies are in the interior regime, and endogenous human capital drives growth. As in the exogenous growth case, there is a reversal in the ranking of fertility because the pro-birth dimension of religion matters in the interior regime.

The major difference from the exogenous growth case is the magnitude of the income gaps after 6 periods. The growth "penalty" of religion is increased to a maximum of 0.8 percentage point of annual growth, and the differences in the level of income increased to around 62 percent. The Catholic and Buddhist countries now have an income equal to slightly more than one half of that of the country without religious affiliation. Income in the Muslim country is one third of the country without religion. 


\begin{tabular}{llrrrr}
\hline \multirow{2}{*}{ Period } & Variable & \multicolumn{3}{c}{ Value in each of the four hypothetical economy } \\
& & No religious affil. & Catholics & Buddhists & Muslims \\
\hline$t=1$ & $n_{t}$ & 5.31 & 5.67 & 5.03 & 5.46 \\
& $\theta+e_{t}(\%$ gdp $)$ & $4.26 \%$ & $4.49 \%$ & $4.08 \%$ & $4.35 \%$ \\
& $y_{t}$ & 1.28 & 1.22 & 1.34 & 1.25 \\
& annual growth & $3.06 \%$ & $2.97 \%$ & $3.15 \%$ & $3.02 \%$ \\
\multirow{2}{*}{$t=6$} & $n_{t}$ & 3.93 & 4.40 & 4.04 & 4.69 \\
& $\theta+e_{t}(\%$ gdp $)$ & $8.91 \%$ & $8.68 \%$ & $6.42 \%$ & $5.44 \%$ \\
& $y_{t}$ & 39.87 & 23.77 & 22.54 & 15.38 \\
& annual growth & $2.24 \%$ & $1.85 \%$ & $1.71 \%$ & $1.48 \%$ \\
\hline
\end{tabular}

Table 8: Macroeconomic variables after 1 and 6 periods $-\kappa=1$

\subsection{Uncertainty Surrounding the Effect of Religion on GDP}

The results of the previous subsection are computed using the estimated values of the structural parameters. Since those parameters are uncertain, we show here how this uncertainty translates into uncertainty surrounding the effect of religious affiliation on the GDP per capita of hypothetical economies populated by inhabitants with the same religion. Practically, we draw 200 fertility matrices $\hat{\mathcal{N}}_{i, j, z}$ from their empirical distribution. For each draw, we estimate the structural parameters $\theta, \eta_{z}$, and $\gamma_{z}$. We then calibrate the parameters $\mu$ and $A$ as explained above, and run a dynamic simulation. The procedure gives us 200 tables like Table 8. Let us concentrate on the GDP per capita after 6 periods $(t=6)$. Figure 5 shows the $95 \%$ confidence interval for the four religious denominations and the two growth models. Uncertainty is larger in the endogenous growth version, as the deep parameters determine the growth rate of income, and the uncertainty affecting them cumulates over time.

The result according to which income is larger in the country without religious affiliation than income in the Catholic country, which is itself larger than income in the Muslim country, appears as significant in both growth models. Concerning the Buddhist country, the uncertainty is large. Nothing significant can be concluded in the endogenous growth model, but the Buddhist country dominates the Muslim country significantly in the exogenous growth model.

\subsection{Implications for Countries' Growth}

Let us now draw some implications from these results for actual countries. Table 9 shows the actual growth rates of income per capita for the six South-East Asian countries, and for the two models considered. Assuming for simplicity that markets within each country are segmented by religion, the countries' economies are weighted averages of artificial economies 


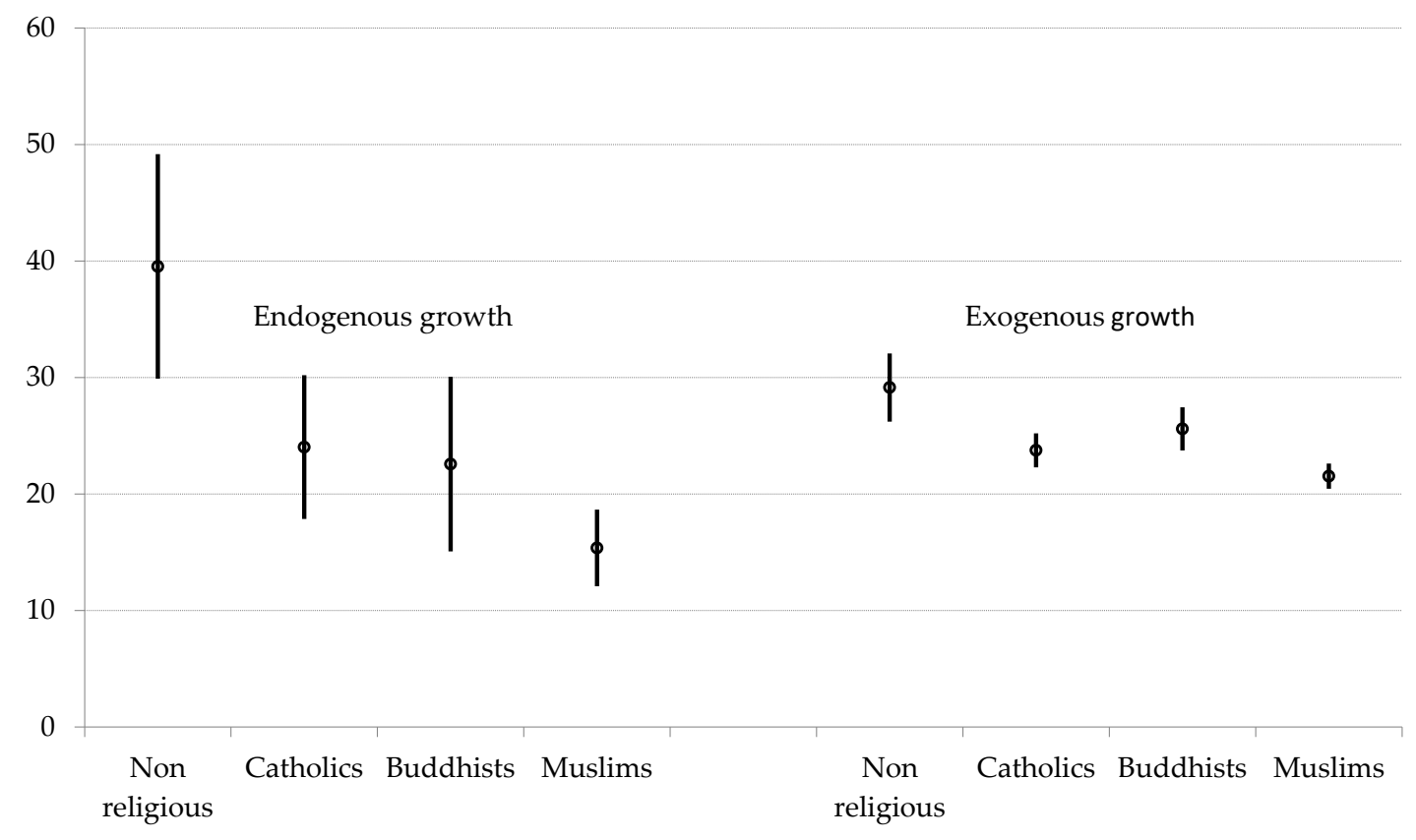

Figure 5: GDP per cap. in the Hypothetical Economies after 6 Periods: Confidence Intervals

with religion specific effects. ${ }^{16}$ For example, the Philippines are approximated by a composite country made of 88 percent of Catholics, 11 percent of Buddhists and 1 percent of people without religious affiliation. Thailand is 95 percent Buddhist, 4 percent Muslim, and 1 percent Catholic. Muslims countries are Indonesia (87 percent Muslim) and Malaysia (54 percent Muslim).

In the model economies, everything other than religious composition is the same across them: inequality, initial conditions, etc. The country fixed effect on fertility is also set at that of the Philippines. The gap between the two growth rates of any two pair of model countries measures the pure effect of religious composition.

Let us first consider the period 1950-1980, which we make correspond to period 1 in the model, a period where education was low and growth driven by physical capital accumulation. Abstracting from Cambodia and Vietnam which were devastated by war over that period, the model gets the ranking right for the period 1950-1980: the fastest growing country was Thailand, followed by Malaysia and Indonesia, then by the Philippines. The gap between Thailand and the Philippines is of 1.18 percent per year, while it is equal to 0.17 percent in the endogenous growth model ( 0.16 percent in the exogenous growth model). Hence, religion alone explains a little more than 10 percent of this gap. The gap between Indonesia and the

\footnotetext{
${ }^{16}$ Building a model economy with heterogeneous households of different religions would require to take a stand on which markets are segmented and which ones are not. Even if marriage markets are segmented, labor, capital, and school markets might not be. Allowing for interactions through wages and interest rates would however deliver very similar results because of constant returns to scale and homothetic preferences.
} 


\begin{tabular}{|c|c|c|c|c|c|c|c|c|c|c|}
\hline & \multicolumn{6}{|c|}{ countries' growth rates } & \multicolumn{4}{|c|}{ growth gaps } \\
\hline & Cam & Ind & Mal & Phi & Vie & Tha & Vie-Ind & Tha-Phi & Ind-Phi & Tha-Ind \\
\hline \multicolumn{11}{|l|}{ data } \\
\hline $1950-80$ & 1.82 & 2.85 & 2.88 & 2.69 & 0.47 & 3.87 & -2.38 & 1.18 & 0.15 & 1.02 \\
\hline $1980-2010$ & 3.68 & 3.09 & 3.44 & 0.81 & 4.94 & 4.43 & 1.85 & 3.62 & 2.28 & 1.34 \\
\hline \multicolumn{11}{|c|}{ endogenous growth } \\
\hline $\mathrm{t}=1$ & 3.15 & 3.02 & 3.06 & 2.97 & 3.07 & 3.14 & 0.04 & 0.17 & 0.05 & 0.12 \\
\hline $\mathrm{t}=2$ & 2.29 & 2.16 & 2.19 & 2.29 & 2.51 & 2.29 & 0.34 & 0.00 & -0.12 & 0.12 \\
\hline $\mathrm{t}=3$ & 1.93 & 1.78 & 1.81 & 2.00 & 2.25 & 1.93 & 0.47 & -0.07 & -0.22 & 0.15 \\
\hline $\mathrm{t}=6$ & 1.71 & 1.58 & 1.60 & 1.83 & 2.19 & 1.71 & 0.61 & -0.12 & -0.25 & 0.12 \\
\hline \multicolumn{11}{|c|}{ exogenous growth } \\
\hline $\mathrm{t}=1$ & 2.09 & 1.96 & 1.99 & 1.92 & 2.03 & 2.08 & 0.08 & 0.16 & 0.04 & 0.13 \\
\hline $\mathrm{t}=2$ & 2.25 & 2.17 & 2.19 & 2.22 & 2.31 & 2.25 & 0.14 & 0.03 & -0.05 & 0.09 \\
\hline $\mathrm{t}=3$ & 2.25 & 2.19 & 2.20 & 2.26 & 2.36 & 2.25 & 0.17 & -0.01 & -0.08 & 0.06 \\
\hline $\mathrm{t}=6$ & 2.11 & 2.08 & 2.09 & 2.13 & 2.20 & 2.11 & 0.12 & -0.02 & -0.04 & 0.02 \\
\hline
\end{tabular}

Notes: Cam: Cambodia, Ind: Indonesia, Mal: Malaysia, Phi: Philippines, Vie:Vietnam, Thai: Thailand. Data are Maddison (2010)'s data, updated by Bolt and van Zanden (2013).

Table 9: Growth rates in the data and in the models

Philippines was 0.15 percent per year. Differences in religion explain one third of this gap with the endogenous growth model, and a little less with the exogenous growth model. In sum, religion depresses growth in early stages by lowering saving, physical capital, and labor supply. These effects account for 10 percent to 30 percent of the actual growth gaps between countries over the period 1950-1980.

Looking at the more recent period, 1980-2010, both models explain well the predominance of non religious Vietnam over its neighbors. Religion alone explains one fifth of the gap between Vietnam and Indonesia (comparing 1980-2010 with $\mathrm{t}=2$ in the endogenous growth model). It also explains that Buddhist countries, Cambodia and Thailand, do better than Muslim countries. Religion explains 13 percent of the gap between Thailand and Indonesia, for example. There is however one feature of the data that we cannot explain by religion. In the endogenous growth model, the Philippines should do well because Catholics are relatively pro-child, and education is not neglected. This is obviously not the case in the data. ${ }^{17}$

In sum, at later stages of growth, pro-birth religions lower the growth and human capital accumulation, explaining between 10 percent and 20 percent of the gap between Muslim and Buddhist countries of South-East Asia over the period 1980-2010. The low performance of the Philippines remains however unexplained.

An interesting implication we can draw for actual countries is inferred from the artificial

\footnotetext{
${ }^{17}$ In his famous article, Lucas (1993) already stressed that the Philippines and South Korea started from similar initial conditions in 1950, but ended up growing at very different rates.
} 
period 6 . Here the two countries with a large Muslim population, Indonesia and Malaysia, are expected to suffer from a lack of investment in human capital. According to the endogenous human capital model, Indonesia (87 percent Muslim) and Malaysia (54 percent Muslim) would grow at 1.58 percent and 1.60 percent respectively, while the Philippines and Thailand would grow at 1.83 percent and 1.71 percent respectively.

Two remarks are in order before we turn to the robustness analysis. First, the use of an endogenous growth model where human capital is the engine of growth is in accordance with the recent empirical literature on education and growth but obviously gives a central role to the quality-quantity tradeoff. If endogenous growth were driven by physical capital accumulation instead, such as in the AK model, the religion that discourages saving the most would have had the most dramatic effects on growth. Second, our estimated effects rely upon the fertility behavior of women in South-Asia born between 1900 and 1963. During that time, one might think that there was a strong link between religious precepts and behavior. Using those results to forecast future trends would be far-fetched, as this link may get looser with the rise of secularization.

\section{$5 \quad$ Robustness Analysis}

In this section we analyze the robustness of the results to various assumptions we made along the way of the identification process. For each analysis, we reproduce Figures 4 and 5 with the new estimates; this allows to assess whether the characterization of religions in the pro-child/pro-birth dimension is amended, and whether the consequences for growth are altered.

\subsection{Higher Returns to Schooling}

First, instead of estimating in Table 5 the human capital by education levels from a single study on the Philippines (which fitted our needs well, as it used the same education categories as in IPUMS), we average over South-East Asian countries the recent estimates of Mincer regression coefficients provided in Montenegro and Patrinos (2014) (presented in Appendix D.1). Taking these returns makes a big difference. The income gap between lowly and highly educated persons is now much larger.

The structural parameters are estimated with these new levels of human capital, keeping all other assumptions unchanged. From Appendix D.1 we see that parameter $\theta$, which is 

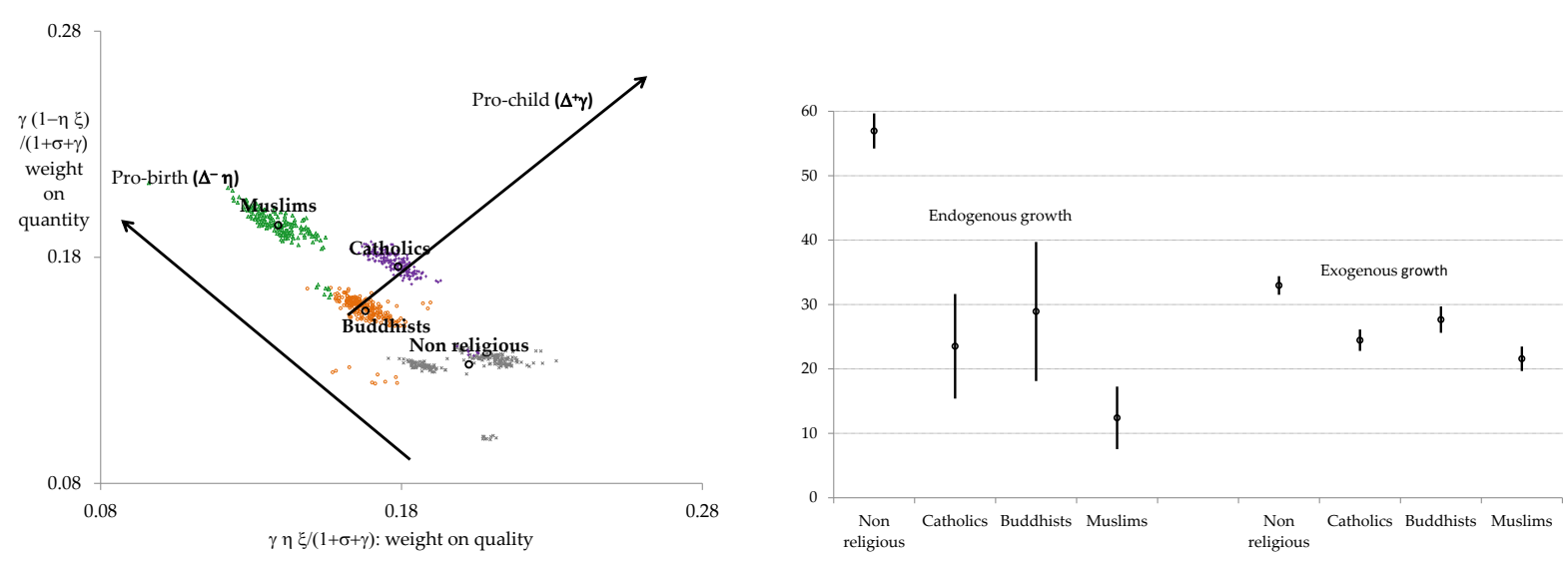

Figure 6: High Returns to Schooling: Pro-birth and Pro-child Religions (left), GDP per cap. after 6 Periods \& Conf. Intervals (right)

key in determining the human capital threshold below which households do not invest in education (Equation (6)), is halved compared to the benchmark estimation; this adjustment of $\theta$ ensures that households with primary education, which are now much poorer relatively because of the higher returns to schooling, are kept in the interior regime. Parameters $\eta_{z}$ are also revised downwards. The left panel of Figure 6, to be compared to Figure 4, shows that the relative characteristics of each religion are not altered by the higher returns to schooling. Islam remains the most pro-birth religion, and Catholicism the most pro-child. The results in terms of macroeconomic outcomes are presented in the right panel of Figure 6, to be compared with Figure 5 of the benchmark. The ranking in terms of growth of the various hypothetical countries is preserved, but the confidence intervals are narrower with the new estimation. In particular, the Muslim country's growth rate is now significantly lower than that of the other countries in the endogenous growth case.

\subsection{The Minority Status Hypothesis}

In the benchmark analysis, we view religion as ideology affecting preferences. An alternative view is the one of the minority status hypothesis. According to this view, belonging to a cultural or religious minority has an effect on groups' fertility (see Chabé-Ferret and Melindi Ghidi (2013) for a recent approach to this old idea). To analyze whether our estimates and simulations are biased by the exclusion of this possible mechanism, we estimate the following augmented auxiliary Model D: ${ }^{18}$

$$
\mathcal{N}_{i}=\beta_{1}^{D} \mathcal{R}_{i} \times \mathcal{E}_{i}^{f} \times \mathcal{E}_{i}^{m}+\beta_{2}^{D} \mathcal{B}_{i}+\beta_{3}^{D} \mathcal{C}_{i}+\beta_{4}^{D} \mathcal{L}_{i}+\beta_{5}^{D} \mathcal{U}_{i}+\beta_{6}^{D} \mathcal{M}_{i}+\epsilon_{i}^{D}
$$

\footnotetext{
${ }^{18}$ Model D extends Model B of Section 2, while in Appendix D.2 we also estimate a Model $\mathbf{C}$ which extends Model A of Section 2.
} 
where $\mathcal{L}_{i}$ stands for the administrative region where woman $i$ lives, $\mathcal{U}_{i}$ is a dummy equal to 1 if the woman lives in a rural area and $\mathcal{M}_{i}$ is a dummy for minority religions, which we define as religions with an incidence rate lower than $20 \%$ in woman's $i$ country. Estimating this equation leads to a new set of moments - shown in Appendix G.2 - to be used in the structural estimation. The structural parameters are estimated with these new estimations of the auxiliary model, keeping all the other assumptions unchanged. Detailed results are presented in Appendix D.2. The main difference is in the parameters $\gamma$, which reflect a general shift in the fertility rate, related to the inclusion of regional fixed factors in the auxiliary regression.
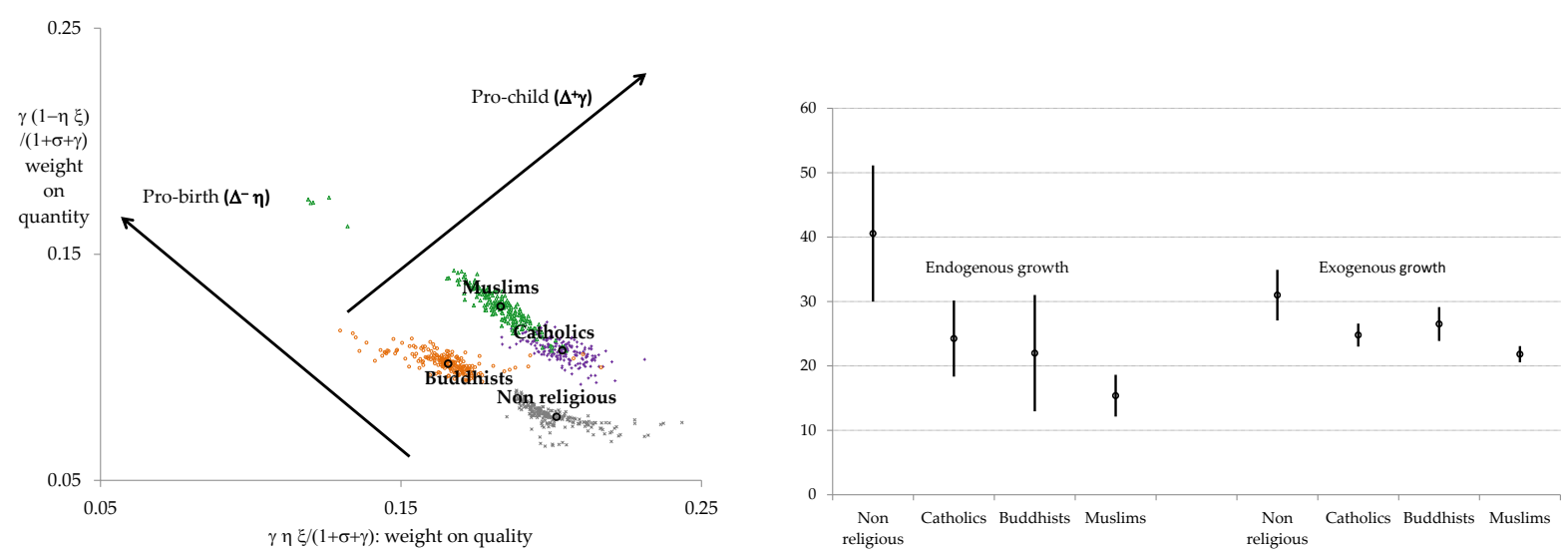

Figure 7: Controlling for Minorities: Pro-birth and Pro-child Religions (left panel), GDP per cap. after 6 Periods \& Conf. Intervals (right panel)

The left panel of Figure 7, to be compared to Figure 4, shows that the relative characteristics of each religion are not altered in the new estimation. Islam remains the most pro-birth religion, but its distance with Catholicism is reduced. It becomes slightly more pro child than before. The non-religious affiliation becomes on the contrary less pro-child. The results in terms of macroeconomic outcomes are presented in the right panel Figure 7, to be compared with Figure 5 of the benchmark. Results are very similar, despite the differences seen in the left panel, but confidence intervals are wider with the new estimation.

\subsection{Thrift $\sigma$ depending on Religious Affiliation}

Our model assumes that $\sigma$ (the psychological discount factor, which governs the willingness to save and invest) is independent from religious affiliation. However, one may argue that many religions promote a sense of selflessness and thrift as much as they promote fertility, which would translate in our model into $\sigma$ depending on religious affiliation. The absence of data on savings makes it difficult to test this alternative hypothesis. The only variable from the census which may be indicative concerns whether the respondent or her husband owns 
their house. Using house ownership as a proxy for savings, we can estimate religion-specific $\sigma$ using additional moment restrictions and analyze implications for our model and predictions.

We first estimate a new auxiliary regression in which house ownership is regressed on the same variables as fertility (education level of husband and wife, religious affiliation, interaction terms, census and birth fixed effects). This linear probability model allows to construct the $\hat{m}_{i, j, z}$, where $i$ and $j$ are education categories for wives and husbands, and $z$ is their religious affiliation. The values are reported in Appendix G.3.

For the structural model, we relate average house ownership $m_{i, j, z} \in[0,1]$ in each group $\{i, j, z\}$ to savings through a logistic function with parameters $\delta_{0}$ and $\delta_{1}$ :

$$
m_{i, j, z}=\frac{1}{1+\exp \left\{\delta_{1}\left(s_{i, j, z}-\delta_{0}\right)\right\}},
$$

while savings are given by Equation (18) from Appendix A:

$$
s_{t}=\frac{\sigma_{z}}{1+\sigma_{z}+\gamma_{z}}\left(\omega h_{i}^{f}+h_{j}^{m}\right)
$$

These two equations give a theoretical house ownership rate $m^{\star}\left[\theta, \gamma_{z}, \eta_{z}, \sigma_{z}, h^{f}(i), h^{m}(j)\right]$ which depends on religion-specific thrift $\sigma_{z}$. The minimization problem of the structural estimation can be written as:

$$
\begin{aligned}
\min _{\theta, \gamma_{z}, \eta_{z}, \sigma_{z}, \delta_{0}, \delta_{1}} \sum_{z} \sum_{i, j}\left[p_{i, j, z}\left(\hat{\mathcal{N}}_{i, j, z}-n^{\star}\left[\theta, \gamma_{z}, \eta_{z}, \sigma_{z}, h^{f}(i), h^{m}(j)\right]\right)^{2}\right. & \\
& \left.+p_{i, j, z}\left(\hat{m}_{i, j, z}-m^{\star}\left[\theta, \gamma_{z}, \eta_{z}, \sigma_{z}, h^{f}(i), h^{m}(j)\right]\right)^{2}\right]
\end{aligned}
$$

Compared to Equation (9), we have additional parameters to estimate, $\delta_{0}, \delta_{1}$ and the $\sigma_{z}{ }^{\text {'s, }}$, and additional moments to match, based on house ownership $\hat{m}_{i, j, z}$.

In the new estimation, presented in detail in Appendix D.3, the $\sigma_{z}$ 's are not significantly different from the value we had imposed a priori (0.3). They are estimated at: 0.411 (nonreligious), 0.251 (Catholics), 0.274 (Buddhists), 0.176 (Muslims), with admittedly limited precision (due to large standard errors).

The left panel of Figure 8, to be compared to Figure 4, shows that the relative characteristics $\gamma_{z}$ and $\eta_{z}$ of each religion are very similar to those in the benchmark. The fact that thrift is now different across affiliations has no repercussions on the estimated pro-birth or pro-child character of each religion. The results in terms of macroeconomic outcomes are presented in the right panel of Figure 8, to be compared with Figure 5 of the benchmark. Two differences are noteworthy. First, Muslim countries are penalized further not only because of their probirth character, but also because of their lower propensity to save. Second, the estimations of GDP per capita in the exogenous growth case are now subject to much wider confidence 

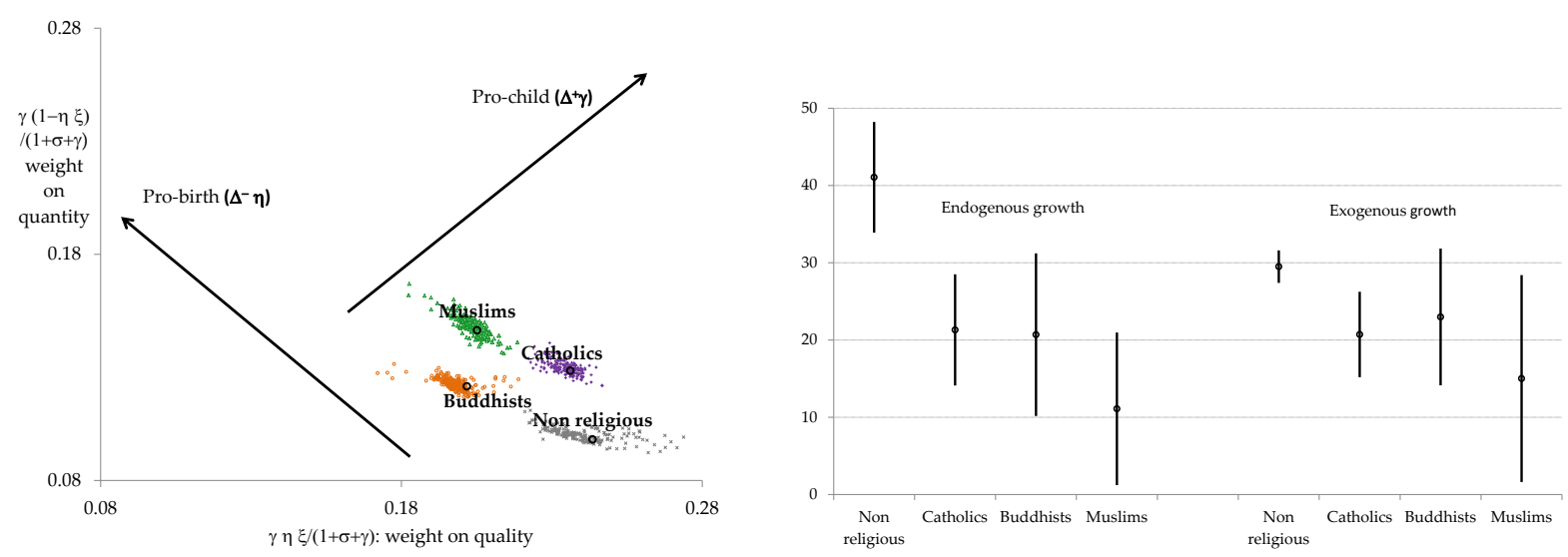

Figure 8: Religion-specific thrift $(\sigma)$ : Pro-Birth and Pro-Child Religions (left panel), GDP per cap. after 6 Periods \& Conf. Intervals (right panel)

intervals because of the additional noise surrounding $\sigma$.

Overall, the channel relating religions to growth through fertility is not affected by relaxing the assumption that thrift is independent from religion. A further investigation of the channel going through savings, however, would require additional data to reduce the confidence intervals around the estimates.

\section{Conclusion}

Most religions tend to increase the share of income that their members spend on their children. We argue in this paper that the way they do so has an impact on countries' growth process. In particular, the extent to which religions hamper long-run growth depends on whether they only encourage members to have more children (pro-birth religion) or they encourage members both to have more children and to educate them better (pro-child religion).

Viewing South-East Asia as a microcosm gathering most of the world religions, we first pool the censuses of countries for which information on religious affiliation is available, along with data on completed fertility and education. We show that, among all religions present in South-East Asia, Catholicism is the most pro-natalist on average $(+0.91$ child, controlling for parents' education). Protestants' fertility does not seem to differ much from Catholics'. Buddhists and Muslims also have a higher fertility compared to people with no religious denomination $(+0.33$ and +0.56 child respectively).

Second, taking advantage of the large number of observations for each religion, we show that the effect of religion on fertility is not uniformly distributed across education categories. Whether or not they have a religious denomination does not matter as much for less educated couples, who display high fertility rates anyway. For middle and highly educated couples, 
however, religions have a significant positive effect on couples' fertility. This effect holds for Catholics, Protestants and Buddhists, and is particularly strong for Muslims.

Third, we measure parents' preferences through indirect inference by estimating the empirical relationship between education and fertility, we show that Catholicism, Islam and Buddhism are both pro-birth (emphasizing quantity over quality) and pro-child (increasing spending on children). Catholicism and Buddhism are surprisingly similar in the bias they generate, with Catholicism being more pro-child. Islam appears more pro-birth than the other two.

Fourth, by mapping the microeconometric estimates into an endogenous growth model, we highlight that these characteristics have consequences for growth, which depend on the stage of the growth process. At the early stages of growth, the main driver of growth is physical capital accumulation. In that context, the bias against the quality of children does not matter; all that matters is the amount of resources devoted to saving and accumulation. Having many children diverts resources from growth. Our model predicts that Catholic countries should grow at a slower pace than other countries, as the pro-child bias is the strongest in Catholic households. At later stages of growth, human capital accumulation becomes key, and the pro-birth bias of religion becomes detrimental to the growth process. Muslim countries are expected to be the most affected, while predominantly atheist countries are expected to grow faster. The size of this effect is not small, with a penalty of 0.6 percentage points for Muslim countries and 0.4 for Catholic and Buddhist countries per year being an upper bound.

These results are derived from the behavior of married women born between 1900 and 1963 . With the general decline of attitudes toward religion and the rise of secularization, it is likely that the gap identified in this paper may shrink in the future.

\section{References}

Acemoglu, Daron, and Joshua Angrist. 2001. "How Large Are Human Capital Externalities? Evidence from Compulsory Schooling Laws." In NBER macroeconomics annual 2000, edited by Ben Bernanke and Kenneth Rogoff, 9-59. Cambridge, MA: MIT Press.

Adsera, Alicia. 2006a. "Marital fertility and religion in Spain, 1985 and 1999." Population Studies 60 (2): 205-221.

—. 2006b. "Religion and changes in family-size norms in developed countries." Review of Religious Research 47 (3): 271-286.

Alesina, Alberto, Paola Giuliano, and Nathan Nunn. 2013. "On the Origins of Gender Roles: Women and the Plough." The Quarterly Journal of Economics 128:469-530.

Barro, Robert J., and Rachel McCleary. 2003, May. "Religion and Economic Growth." Technical Report 9682, National Bureau of Economic Research, Inc. 
Baudin, Thomas. 2010. "A Role For Cultural Transmission In Fertility Transitions." Macroeconomic Dynamics 14 (04): 454-481 (September).

- 2015. "Religion and Fertility: The French Connection." Demographic Research 32:397-420.

Becker, Gary. 1993. "Nobel Lecture: The Economic Way of Looking at Behavior." Journal of Political Economy 101 (3): 385-409 (June).

Becker, Sascha O., and Ludger Woessmann. 2009. "Was Weber Wrong? A Human Capital Theory of Protestant Economic History." The Quarterly Journal of Economics 124 (2): 531-596 (May).

Berman, Eli, Laurence R. Iannaccone, and Giuseppe Ragusa. 2012, August. "From Empty Pews to Empty Cradles: Fertility Decline Among European Catholics." Technical Report 18350, National Bureau of Economic Research, Inc.

Bhattacharya, Joydeep, and Shankha Chakraborty. 2013. "Contraception and the Fertility Transition." Iowa State University.

Bisin, Alberto, and Thierry Verdier. 2010. "The economics of cultural transmission and socialization." Technical Report, National Bureau of Economic Research.

Blyth, Eric, and Ruth Landau, eds. 2009. Faith and Fertility: Attitudes Towards Reproductive Practices in Different Religions from Ancient to Modern Times. London: Jessica Kingsley Publishers.

Bolt, J., and J. L. van Zanden. 2013. "The First Update of the Maddison Project; ReEstimating Growth Before 1820." Maddison Project Working Paper 4.

Boppart, Timo, Josef Falkinger, Volker Grossmann, Ulrich Woitek, and Gabriela Wüthrich. 2013. "Under which conditions does religion affect educational outcomes?" Explorations in Economic History 50 (2): 242-266.

Browning, Martin, Pierre-André Chiappori, and Yoram Weiss. 2014. Economics of the Family. Cambridge MA: Cambridge University Press.

Cavalcanti, Tiago, Stephen Parente, and Rui Zhao. 2007. "Religion in macroeconomics: a quantitative analysis of Weber's thesis." Economic Theory 32 (1): 105-123 (July).

Cervellati, Matteo, Marcel Jansen, and Uwe Sunde. 2014. "Religious Norms and Long Term Development: Insurance, Human Capital and Technological Change." Paper presented at Barcelona GSE Summer Forum.

Chabé-Ferret, Bastien. 2016. "Adherence to Cultural Norms and Economic Incentives: Evidence from Fertility Timing Decisions." Technical Report 2016-23, Université catholique de Louvain, Institut de Recherches Economiques et Sociales (IRES). 
Chabé-Ferret, Bastien, and Paolo Melindi Ghidi. 2013. "Differences in fertility behavior and uncertainty: an economic theory of the minority status hypothesis." Journal of Population Economics 26 (3): 887-905 (July).

Cohen, Daniel, and Marcelo Soto. 2007. "Growth and human capital: good data, good results." Journal of Economic Growth 12 (1): 51-76 (March).

Córdoba, Juan, and Marla Ripoll. 2016. "Intergenerational Transfers and the FertilityIncome Relationship." Economic Journal 126:949-977.

de la Croix, David, and Matthias Doepke. 2003. "Inequality and Growth: Why Differential Fertility Matters." American Economic Review 93 (4): 1091-113.

Doepke, Matthias. 2005. "Child mortality and fertility decline: Does the Barro-Becker model fit the facts?" Journal of Population Economics 18 (2): 337-366.

- 2015. "Gary Becker on the Quantity and Quality of Children." Journal of Demographic Economics 81:59-66.

Doepke, Matthias, Moshe Hazan, and Yishay Maoz. 2015. "The Baby Boom and World War II: A Macroeconomic Analysis." Review of Economic Studies 82:1031-1073.

Durlauf, Steven N., Andros Kourtellos, and Chih Ming Tan. 2006. "Is God in the Details? A Reexamination of the Role of Religion in Economic Growth." Technical Report 0613, Department of Economics, Tufts University.

Galor, Oded, and Omer Moav. 2006. "Das Human-Kapital: A Theory of the Demise of the Class Structure." Review of Economic Studies 73 (1): 85-117.

Gobbi, Paula. 2014. "Childcare and Commitment within Households." Université catholique de Louvain, unpublished.

Gourieroux, C, A Monfort, and E Renault. 1993. "Indirect Inference." Journal of Applied Econometrics 8 (S): S85-118 (Suppl. Dec.).

Guiso, Luigi, Paola Sapienza, and Luigi Zingales. 2003. "People's opium? Religion and economic attitudes." Journal of Monetary Economics 50 (1): 225-282 (January).

Hanushek, Eric A, and Ludger Woessmann. 2012. "Do better schools lead to more growth? Cognitive skills, economic outcomes, and causation." Journal of Economic Growth 17 (4): $267-321$.

Hazan, Moshe, Oksana Leukhina, and Hosny Zoaby. 2014. "Does Inequality Benefit Growth." Washington University.

Hazan, Moshe, and Hosny Zoabi. 2015. "Sons or Daughters? Sex Preferences and the Reversal of the Gender Educational Gap." Journal of Demographic Economics, vol. 81. Heaton, Tim B. 2011. "Does Religion Influence Fertility in Developing Countries." Population Research and Policy Review 30 (3): 449-465. 
Hotz, V. Joseph, Susan Williams McElroy, and Seth G. Sanders. 2005. "Teenage Childbearing and Its Life Cycle Consequences: Exploiting a Natural Experiment." Journal of Human Resources 40 (3): 683-715.

Jejeebhoy, Shireen J. 1995. Women's education, autonomy, and reproductive behaviour: Experience from developing countries. New York: Oxford University Press.

Klemp, Marc, and Jacob Weisdorf. 2016. "Fecundity, Fertility, and the Formation of Human Capital." CAGE Working Paper No 296.

Krueger, Alan, and Mikael Lindahl. 2001. "Education and Growth: Why and for Whom?" Journal of Economic Literature 39 (4): 1101-1136.

Lagerlöf, Nils-Petter. 2006. "The Galor-Weil Model Revisited: A Quantitative Exercise." Review of Economic Dynamics 9 (1): 116-142 (January).

Lee, Geok Ling, Celia Hoi Yan Chan, Elizabeth Wai-Hing Choi Hui, and Cecilia Lai Wan Chan. 2009. "Chinese traditional belief systems, livelihood and fertility." Chapter 5 of Faith and Fertility: Attitudes Towards Reproductive Practices in Different Religions from Ancient to Modern Times, edited by Eric Blyth and Ruth Landau, 137-157. London: Jessica Kingsley Publishers.

Lehrer, Evelyn L. 2004. "Religion as a Determinant of Economic and Demographic Behavior in the United States." Population and Development Review 30 (4): 707-726.

Leibowitz, Arleen. 1974. "Home Investments in Children." Journal of Political Economy 82 (2): S111-31.

Li, Hongbin, Junsen Zhang, and Yi Zhu. 2008. "The quantity-Quality trade-Off of children In a developing country: Identification using chinese twins." Demography 45 (1): 223-243 (February).

Lin, Wanchuan, and Juan Pantano. 2015. "The unintended: negative outcomes over the life cycle." Journal of Population Economics 28 (2): 479-508.

Long, J.S., and J. Freese. 2006. Regression Models for Categorical Dependent Variables Using Stata. Edited by 2nd Edition. Stata Press.

Lucas, Robert. 1993. "Making a miracle." Econometrica 61 (2): 251-272.

Luo, Xubei, and Takanobu Terada. 2009, November. "Education and wage differentials in the Philippines." Technical Report 5120, The World Bank.

Maddison, Angus. 2010, March. "Historical Statistics." Groningen Growth and Development Center.

McCleary, Rachel M. 2013, January. "Protestantism and Human Capital in Guatemala and the Republic of Korea." Adb economics working paper series 332, Asian Development Bank. 
Minnesota Population Center. 2013. "Integrated Public Use Microdata Series, International: Version 6.2 [Machine-readable database]." Minneapolis: University of Minnesota.

Moav, Omer. 2005. "Cheap Children and the Persistence of Poverty." Economic Journal 115 (500): 88-110 (January).

Montenegro, Claudio E., and Harry Anthony Patrinos. 2014, September. "Comparable estimates of returns to schooling around the world." Policy research working paper series 7020, The World Bank.

Mosher, William D., Linda B. Williams, and David P. Johnson David. 1992. "Religion and fertility in the United States: New patterns." Demography 29 (2): 199-214.

Munshi, Kaivan, and Jacques Myaux. 2006. "Social norms and the fertility transition." Journal of Development Economics 80 (1): 1-38.

OECD. 2010. "The High Cost of Low Educational Performance." Paris.

Putterman, Louis. 2006. "Agricultural Transition Year Country Data Set." Brown University.

Rangazas, Peter. 2000. "Schooling and Economic Growth: A King-Rebelo Experiment with Human Capital." Journal of Monetary Economics 46 (2): 397-416.

Ribar, David C. 1994. "Teenage Fertility and High School Completion." The Review of Economics and Statistics 76 (3): 413-424 (August).

Sander, William. 1992. "Catholicism and the Economics of Fertility." Population Studies: A Journal of Demography 46:477-489.

Skirbekk, Vegard, Marcin Stonawski, Setsuya Fukuda, Thomas Spoorenberg, Conrad Hackett, and Raya Muttarak. 2015. "Is Buddhism the low fertility religion of Asia?" Demographic Research 32:1-28.

Smith, Anthony A., Jr. 2008. "Indirect Inference." In The New Palgrave Dictionary of Economics, edited by Steven N. Durlauf and Lawrence E. Blume. London: Palgrave Macmillan.

Strulik, Holger. 2012, June. "From Worship to Worldly Pleasures: Secularization and LongRun Economic Growth." Technical Report 116, Courant Research Centre PEG.

Tamura, Robert. 2001. "Teachers, growth and convergence." Journal of Political Economy 109 (5): 1021-1059.

- 2006. "Human capital and economic development." Journal of Development Economics 79:26-72.

Tamura, Robert, Simon Curtis, and Kevin M Murphy. 2016. "Black and White Fertility, Differential Baby Booms: The Value of Equal Education Opportunity." Journal of Demographic Economics 82 (1): 27-109. 
Vogl, Tom. 2016. "Differential Fertility, Human Capital, and Development." Review of Economic Studies 83:365-401.

Zhang, Li. 2008. "Religious affiliation, religiosity, and male and female fertility." Demographic Research 18:233-262. 


\section{APPENDICES (NOT FOR PUBLICATION)}

\section{A Solution to the Household Maximization Problem}

The maximization problem can be decomposed into two steps. First, for some given number of children, parents allocate their time efficiently, i.e. they minimize the cost of child rearing:

$$
\min _{\substack{f \\ a_{t}^{f}, a_{t}^{m}}} w_{t}\left(\omega h_{t}^{f} a_{t}^{f}+h_{t}^{m} a_{t}^{m}\right) n_{t} \quad \text { subject to }(3)
$$

This cost minimization problem leads to the following optimal rules (for $n<1 / \phi$ ):

$$
\begin{array}{lll}
\text { if } \frac{1}{\phi^{2} n_{t}^{2}}>\frac{h_{t}^{m}}{\omega h_{t}^{f}}>\phi^{2} n_{t}^{2}, & a_{t}^{f}=\sqrt{\frac{h_{t}^{m}}{\omega h_{t}^{f}}} \phi n_{t}, & a_{t}^{m}=\sqrt{\frac{\omega h_{t}^{f}}{h_{t}^{m}}} \phi n_{t}, \\
\text { if } \frac{h_{t}^{m}}{\omega h_{t}^{f}}>\frac{1}{\phi^{2} n_{t}^{2}}, & a_{t}^{f}=1, & a_{t}^{m}=\phi^{2} n_{t}^{2}, \\
\text { if } \phi^{2} n_{t}^{2}>\frac{h_{t}^{m}}{\omega h_{t}^{f}}, & a_{t}^{f}=\phi^{2} n_{t}^{2}, & a_{t}^{m}=1 .
\end{array}
$$

Focusing from now on on the interior solution where both $a_{t}^{f}$ and $a_{t}^{m}$ are lower than one, we see that the share of child-rearing supported by the mother is inversely related to her human capital, weighted by the gender wage gap:

$$
\frac{a_{t}^{f}}{a_{t}^{f}+a_{t}^{m}}=\frac{h_{t}^{m}}{h_{t}^{m}+\omega h_{t}^{f}}
$$

Given the optimal $a_{t}^{f}$ and $a_{t}^{m}$ from (16), we can rewrite the household income as:

$$
\omega w_{t} h_{t}^{f}\left(1-a_{t}^{f} n_{t}\right)+w_{t} h_{t}^{m}\left(1-a_{t}^{m} n_{t}\right)=w_{t} h_{t}^{m}+\omega w_{t} h_{t}^{f}-2 \phi w_{t} \sqrt{\omega h_{t}^{f} h_{t}^{m}} n
$$

The second step of the maximization problem allows us to characterize the quality-quantity tradeoff faced by individuals. A household has to choose a consumption profile $c_{t}$ and $d_{t+1}$, saving for old age $s_{t}$, number of children $n_{t}$, and schooling time per child $e_{t}$. Equation (2) can be rewritten as

$$
c_{t}+\frac{d_{t+1}}{R_{t+1}}+e_{t} w_{t} n_{t} h^{\mathrm{T}}+2 \phi w_{t} \sqrt{\omega h_{t}^{f} h_{t}^{m}} n=\omega w_{t} h_{t}^{f}+w_{t} h_{t}^{m} .
$$


where the left hand side represents the sum of consumption spending, education spending, and child rearing opportunity cost. The household problem is

$$
\max _{c_{t}, d_{t+1}, n_{t}, e_{t}}(1) \text { s.t. (5), (17) and } e_{t} \geq 0
$$

For a household with a sufficiently high human capital for the opportunity cost of an additional child to be large enough, i.e.

$$
\omega h_{t}^{f} h_{t}^{m}>\left(\frac{\theta h^{\mathrm{T}}}{2 \phi \eta \xi}\right)^{2}
$$

there is an interior solution for the optimal education level. The first-order conditions imply:

$$
\begin{aligned}
s_{t} & =\frac{\sigma}{1+\sigma+\gamma}\left(\omega h_{t}^{f}+h_{t}^{m}\right), \\
e_{t} & =\frac{2 \phi \eta \xi \sqrt{\omega h_{t}^{f} h_{t}^{m}}-\theta h^{\mathrm{T}}}{(1-\eta \xi) h^{\mathrm{T}}}, \\
n_{t} & =\frac{(1-\eta \xi) \gamma\left(\omega h_{t}^{f}+h_{t}^{m}\right)}{1+\sigma+\gamma} \frac{2 \phi \sqrt{\omega h_{t}^{f} h_{t}^{m}}+\theta h^{\mathrm{T}}}{4 \phi^{2} \omega h_{t}^{f} h_{t}^{m}-\theta^{2} h^{\mathrm{T}^{2}}} .
\end{aligned}
$$

For poorer households endowed with sufficiently little human capital, the optimal choice for education $e_{t}$ is zero. The first-order conditions imply equation (18) and:

$$
\begin{aligned}
e_{t} & =0, \\
n_{t} & =\frac{\gamma\left(\omega h_{t}^{f}+h_{t}^{m}\right)}{2(1+\sigma+\gamma) \phi \sqrt{\omega h_{t}^{f} h_{t}^{m}}} .
\end{aligned}
$$

\section{B Proofs of Propositions}

\section{Proof of Proposition 1.}

In the corner regime, $e_{t}=0$ and $n_{t}$ given by Equation (22). In that case, the parameter $\eta$ plays no role (except is the condition which should be satisfied for this corner case to hold). The economy is then like a Solow model, where there is exogenous technical progress (or exogenous human capital accumulation with $\kappa=1$ ) driving growth, and where physical capital accumulation is the key driver of dynamics.

The negative effect of increased $\gamma$ on income goes through increased fertility by Equation (22), lower labor supply $L_{t}$ by Equation (13), lower savings by Equation (18), and lower capital per person by Equation (12). 


\section{Proof of Proposition 2.}

Condition (14) ensures that the interior regime prevails in the long-run. Then, Equations (5), (19), and (10) imply the value of $g$ in the proposition.

Comparative statics are then straightforward.

\section{Proof of Proposition 3.}

Long-run variables in levels can be defined as:

$$
\begin{aligned}
\hat{e} & =e_{t}=\frac{2 \eta \phi \xi \sqrt{\omega}-\theta}{1-\eta \xi} \\
\hat{n} & =n_{t}=\frac{(1-\eta \xi) \gamma(1+\omega)}{1+\sigma+\gamma} \frac{2 \phi \sqrt{\omega}+\theta}{4 \phi^{2} \omega-\theta^{2}} \\
\hat{h} & =\frac{h_{t}}{g^{t}}=(\mu(\theta+\hat{e}) / g)^{\frac{1}{1-\kappa}} \\
\hat{s} & =\frac{s_{t}}{g^{t}}=\frac{\sigma}{1+\sigma+\gamma}(\omega+1) \hat{h} \\
\hat{\ell} & =\frac{L_{t}}{P_{t} g^{t}}=[\omega(1-\phi \hat{n} / \sqrt{\omega})+(1-\phi \hat{n} \sqrt{\omega})-\hat{e} \hat{n}] \hat{h} \\
\hat{k} & =\frac{K_{t}}{P_{t}(g)^{t}}=\frac{2 \hat{s}}{g \hat{n}} \\
\hat{y} & =\frac{Y_{t}}{P_{t}(g)^{t}}=A \hat{k}^{\varepsilon} \hat{\ell}^{1-\varepsilon}
\end{aligned}
$$

Computing how $\gamma$ and $\eta$ affect the above system, we infer the results in the proposition. 


\section{Descriptive Statistics}

\section{Subsample with Known Mother's Religion}

\begin{tabular}{|c|c|c|c|c|c|c|}
\hline & Cambodia & Indonesia & Malaysia & Philipp. & Vietnam & Thailand \\
\hline \multicolumn{7}{|c|}{ A: Number of children ever born } \\
\hline Mean & 3.65 & 3.79 & 5.00 & 2.88 & 3.23 & 2.55 \\
\hline $\mathrm{Sd}$ & 2.47 & 3.09 & 2.82 & 2.40 & 1.58 & 1.98 \\
\hline Min & 0 & 0 & 0 & 0 & 0 & 0 \\
\hline Max & 13 & 14 & 9 & 11 & 12 & 12 \\
\hline \multicolumn{7}{|l|}{ B: Religion (in \%) } \\
\hline No religious affil. & 0 & 0 & 0 & 0 & 78.7 & 0 \\
\hline Buddhist & 99.1 & 1.4 & 33.3 & 0 & 15 & 98.3 \\
\hline Hindu & 0 & 0.9 & 5.6 & 0 & 0 & 0 \\
\hline Muslim & 0.6 & 89.4 & 33.3 & 0.9 & 0 & 1.7 \\
\hline Catholic & 0 & 2.3 & 5.6 & 90.7 & 3.9 & 0 \\
\hline Protestant/Other Christ. & 0 & 3.2 & 0 & 8.4 & 0.6 & 0 \\
\hline Other & 0.3 & 2.8 & 22.2 & 0 & 1.8 & 0 \\
\hline \multicolumn{7}{|c|}{ C: Women's Education (in \%) } \\
\hline No schooling & 31.8 & 55.5 & 55.6 & 1.5 & 0.3 & 9.1 \\
\hline Some primary & 37.4 & 25 & 22.2 & 12.5 & 19.9 & 67.7 \\
\hline Primary completed & 26.6 & 17.6 & 22.2 & 31.4 & 45.9 & 9.4 \\
\hline Secondary completed & 3.9 & 1.9 & 0 & 21.8 & 21.7 & 8.6 \\
\hline University completed & 0.3 & 0 & 0 & 32.8 & 9.6 & 5.2 \\
\hline \multicolumn{7}{|c|}{ D: Husband's Education (in \%) } \\
\hline No schooling & 21.1 & 34.7 & 27.7 & 2.3 & 4.1 & 4.7 \\
\hline Some primary & 34.8 & 36.1 & 16.7 & 15.7 & 12.6 & 63.4 \\
\hline Primary completed & 37.7 & 25 & 55.6 & 28.2 & 37.4 & 13.6 \\
\hline Secondary completed & 5 & 4.2 & 0 & 34.6 & 26.8 & 12.7 \\
\hline University completed & 1.4 & 0 & 0 & 19.2 & 19.1 & 5.6 \\
\hline \multicolumn{7}{|l|}{ E: Birth year } \\
\hline Mean & 1957 & 1932 & 1931 & 1943 & 1952 & 1946 \\
\hline Min & 1929 & 1915 & 1925 & 1941 & 1950 & 1910 \\
\hline Max & 1963 & 1935 & 1935 & 1945 & 1954 & 1955 \\
\hline$N$ & 361 & 216 & 18 & 344 & 508 & 573 \\
\hline
\end{tabular}




\section{Robustness Analysis}

In this section we present a more detailed account of the results shown in the main text (Section 5).

\section{D.1 Higher Returns to Schooling}

First, instead of estimating the human capital by education levels from a single study on the Philippines (which fitted our needs well, as it used the same education categories as in IPUMS), we average over South-East Asian countries the recent estimates of Mincer regression coefficients provided in Montenegro and Patrinos (2014). The coefficients taken from Montenegro and Patrinos (2014) are presented in Table A.1. For each country, we use these rate of returns to compute human capital levels. We next average human capital across countries, and replace Table 5 with Table A.2. We observe that taking the returns from Montenegro and Patrinos (2014) makes a big difference. The income gap between lowly and highly educated persons is now much larger.

The structural parameters are estimated with these new levels of human capital, keeping all other assumptions unchanged. Results are presented in Table A.3, which is to be compared with Table 6. Parameter $\theta$, which is key in determining the human capital threshold below which households do not invest in education (Equation (6)), is now lower; this prevents households with primary education, which are now much poorer relatively because of the higher returns to schooling, to be in the corner regime with no education and high fertility. Parameters $\eta_{z}$ are also revised downwards.

\begin{tabular}{|c|c|c|c|c|c|c|c|}
\hline \multirow[t]{2}{*}{ Country } & \multirow[t]{2}{*}{ year } & \multicolumn{3}{|c|}{ male } & \multicolumn{3}{|c|}{ female } \\
\hline & & primary & secondary & tertiary & primary & secondary & tertiary \\
\hline Cambodia & 2004 & 5 & 3.1 & 14 & 11.8 & 4 & 16.6 \\
\hline Indonesia & 2010 & 9.6 & 8.7 & 12.6 & 12.7 & 12 & 12.9 \\
\hline Malaysia & 2010 & 7.6 & 9.3 & 21.8 & 6.8 & 12.3 & 23.1 \\
\hline Philippines & 2011 & 7 & 6.4 & 20.1 & 3.7 & 6.1 & 29.4 \\
\hline Thailand & 2011 & 2.7 & 4.6 & 16.6 & 1.4 & 5.9 & 19.2 \\
\hline Vietnam & $\mathrm{NA}$ & & & & & & \\
\hline
\end{tabular}

Table A.1: Returns to Schooling in South-East Asia 


\begin{tabular}{llllll}
\hline & (i) & (ii) & (iii) & (iv) & (v) \\
\hline$h^{f}$ & 1 & 1.21 & 1.48 & 2.23 & 3.76 \\
$h^{m}$ & 1 & 1.26 & 1.60 & 2.70 & 4.82 \\
\hline
\end{tabular}

Table A.2: Income by Education Categories with High Returns to Schooling

\begin{tabular}{ccccccccc}
\hline & \multicolumn{4}{c}{ Model A } & \multicolumn{5}{c}{ Model B } \\
& No relig. & Catholic & Buddhist & Muslim & No relig. & Catholic & Buddhist & Muslim \\
\hline$\theta$ & \multicolumn{4}{c}{0.025} & \multicolumn{5}{c}{0.027} \\
& \multicolumn{4}{c}{$(0.0022)$} & & & $(0.0030)$ & \\
$\gamma_{z}$ & 0.538 & 0.700 & 0.592 & 0.632 & 0.655 & 0.714 & 0.624 & 0.649 \\
& $(0.0235)$ & $(0.0256)$ & $(0.0272)$ & $(0.0278)$ & $(0.0438)$ & $(0.0134)$ & $(0.0214)$ & $(0.0150)$ \\
$\eta_{z}$ & 1.436 & 1.340 & 1.455 & 1.442 & 1.813 & 1.513 & 1.555 & 1.252 \\
& $(0.0626)$ & $(0.0681)$ & $(0.0668)$ & $(0.0664)$ & $(0.0629)$ & $(0.0701)$ & $(0.0535)$ & $(0.0689)$ \\
\hline
\end{tabular}

Table A.3: Deep Parameters with High Returns to Schooling

The left panel of Figure 6, to be compared to Figure 4, shows the relative characteristics of each religion. The results in terms of macroeconomic outcomes are presented in the right panel of Figure 6, to be compared with Figure 5 of the benchmark.

\section{D.2 The Minority Status Hypothesis}

To account for fertility effects imputable to living in a specific geographic area or to belonging to a minority, we estimate the following augmented Models $\mathbf{C}$ and $\mathbf{D}$ :

$$
\begin{gathered}
\mathcal{N}_{i}=\beta_{1}^{C} \mathcal{R}_{i}+\beta_{2}^{C} \mathcal{E}_{i}^{f} \times \mathcal{E}_{i}^{m}+\beta_{3}^{C} \mathcal{B}_{i}+\beta_{4}^{C} \mathcal{C}_{i}+\beta_{5}^{C} \mathcal{L}_{i}+\beta_{6}^{C} \mathcal{U}_{i}+\beta_{7}^{C} \mathcal{M}_{i}+\epsilon_{i}^{C} \\
\mathcal{N}_{i}=\beta_{1}^{D} \mathcal{R}_{i} \times \mathcal{E}_{i}^{f} \times \mathcal{E}_{i}^{m}+\beta_{2}^{D} \mathcal{B}_{i}+\beta_{3}^{D} \mathcal{C}_{i}+\beta_{4}^{D} \mathcal{L}_{i}+\beta_{5}^{D} \mathcal{U}_{i}+\beta_{6}^{D} \mathcal{M}_{i}+\epsilon_{i}^{D}
\end{gathered}
$$

where $\mathcal{L}_{i}$ stands for the administrative region where woman $i$ lives, $\mathcal{U}_{i}$ is a dummy equal to 1 if the woman lives in a rural area and $\mathcal{M}_{i}$ is a dummy for minority religions, which we define as religions with an incidence rate lower than $20 \%$ in woman's $i$ country. Partial results from the estimation of Model $\mathbf{C}$ are presented in Table A.4 and A.5. Being affiliated with a minority religion does not significantly affect a woman's fertility. However, as expected, living in a rural area has a positive and significant impact on the number of children born. ${ }^{19}$ By comparing Table 3 and A.4, we note that controlling for minority, region and urbanism induces minor changes. It slightly lowers the effect of Buddhism, Catholicism and Protestantism on fertility

\footnotetext{
${ }^{19}$ All estimates from the full regression available on request.
} 
while it slightly increases the impact of Islam on fertility. More importantly, Hindu women have now significantly higher fertility levels than women with no religious affiliation. Overall, the impact of one religion on fertility relative to the others is robust to this new specification. Compared to those in Table 4, average fertility levels reported in Table A.5 tend to be slightly more homogenous across couples' education levels. However, more educated couples still have lower expected fertility levels and the other patterns discussed in Section 2 hold.

Similarly, controlling for minority, region and urbanism in Model D tends to smooth the impact of couples' education on fertility across education levels. The moments corresponding to the estimation of model $\mathbf{D}$ are presented in Appendix G.2. More importantly, our main results hold in that the positive impact of religion on fertility increases with couples' education levels.

The structural parameters are estimated with these new estimations of the auxiliary model, keeping all the other assumptions unchanged. Results are presented in Table A.6, which is to be compared with Table 6 . The main difference is in the parameters $\gamma$, which reflect a general shift in the fertility rate, related to the inclusion of regional fixed factors in the auxiliary regression.

The left panel of Figure 7, to be compared to Figure 4, shows the relative characteristics of each religion. The non-religious affiliation becomes on the contrary less pro-child. The results in terms of macroeconomic outcomes are presented in the right panel of Figure 7, to be compared with Figure 5 of the benchmark.

\section{D.3 Thrift $\sigma$ Depending on Religious Affiliation}

Taking house ownership as a proxy for savings, we can estimate religion-specific $\sigma$ using additional moments restrictions.

We first estimate a new auxiliary regression where house ownership is regressed on the same variables as fertility (education level of husband and wife, religious affiliation, interaction terms, census and birth fixed effects. This linear probability model allows to construct the $\hat{m}_{i, j, z}$, where $i$ and $j$ are education categories for wives and husbands, and $z$ is religious affiliation. The values are reported in Appendix G.3.

For the structural model, we relate average house ownership $m_{i, j, z} \in[0,1]$ in each group $\{i, j, z\}$, to savings through a logistic function with parameters $\delta_{0}$ and $\delta_{1}$ :

$$
m_{i, j, z}=\frac{1}{1+\exp \left\{\delta_{1}\left(s_{i, j, z}-\delta_{0}\right)\right\}}
$$




\begin{tabular}{lcc}
\hline & $\widehat{\beta_{1}^{A A}}$ & S.e. \\
\hline Buddhism & $0.207^{a}$ & $(0.0422)$ \\
Hinduism & $0.374^{b}$ & $(0.1412)$ \\
Islam & $0.670^{a}$ & $(0.0217)$ \\
Catholicism & $0.796^{a}$ & $(0.1166)$ \\
Protestantism & $0.752^{a}$ & $(0.1383)$ \\
Other religion & $0.508^{a}$ & $(0.1031)$ \\
\hline Notes: Sample includes 561,948 observations. Column 1 represents \\
coefficients for religion estimated with an OLS regression of model \\
C; standard errors clustered by country in parentheses in column 2. \\
All specifications also include dummy vectors for combined education \\
levels of couples, birth years, censuses, rural, region and minority. \\
${ }^{a}$ Significantly different from zero at 99 percent confidence level. \\
${ }^{b}$ Significantly different from zero at 95 percent confidence level. \\
${ }^{c}$ Significantly different from zero at 90 percent confidence level. \\
\hline
\end{tabular}

Table A.4: Model C - Effect of religion on fertility

\begin{tabular}{llllll}
\hline \multicolumn{5}{c}{ Man Education } \\
Woman & No & Some & Primary & Secondary & University \\
Educ. & schooling & primary & completed & completed & completed \\
\hline No & $4.19^{a}$ & $4.63^{a}$ & $4.59^{a}$ & $4.45^{a}$ & $4.21^{a}$ \\
Some & $4.72^{a}$ & $4.57^{a}$ & $4.56^{a}$ & $4.25^{a}$ & $3.77^{a}$ \\
Primary & $4.17^{a}$ & $4.52^{a}$ & $4.35^{a}$ & $4.16^{a}$ & $3.55^{a}$ \\
Secondary & $4.02^{a}$ & $3.89^{a}$ & $3.61^{a}$ & $3.56^{a}$ & $3.33^{a}$ \\
University & $4.32^{a}$ & $3.35^{a}$ & $3.03^{a}$ & $2.88^{a}$ & $3.06^{a}$ \\
\hline
\end{tabular}

Notes: Sample includes 561,948 observations. Coefficients from OLS regression of fertility model A; standard errors clustered by country. All specifications include dummy vectors for religions, birth years and censuses. The reference category is a woman with no religious affiliation in the Philippines born in 1945 .

${ }^{a}$ Significantly different from zero at 99 percent confidence level.

${ }^{b}$ Significantly different from zero at 95 percent confidence level.

${ }^{c}$ Significantly different from zero at 90 percent confidence level.

Table A.5: Model C - Effect of couples' education on fertility

\begin{tabular}{ccccccccc}
\hline \multicolumn{9}{c}{ Model A } \\
& No relig. & Catholic & Buddhist & Muslim & No relig. & Catholic & Buddhist & Muslim \\
\hline$\theta$ & \multicolumn{4}{c}{0.045} & \multicolumn{5}{c}{0.055} \\
& \multicolumn{4}{c}{$(0.0045)$} & & \multicolumn{4}{c}{$(0.0017)$} \\
$\gamma_{z}$ & 0.541 & 0.668 & 0.560 & 0.642 & 0.505 & 0.587 & 0.474 & 0.584 \\
& $(0.0308)$ & $(0.0191)$ & $(0.0114)$ & $(0.0114)$ & $(0.0203)$ & $(0.0094)$ & $(0.0181)$ & $(0.0088)$ \\
$\eta_{z}$ & 1.662 & 1.590 & 1.608 & 1.582 & 2.163 & 1.964 & 1.860 & 1.772 \\
& $(0.1310)$ & $(0.1184)$ & $(0.1217)$ & $(0.1207)$ & $(0.0546)$ & $(0.0393)$ & $(0.0535)$ & $(0.0905)$ \\
\hline
\end{tabular}

Table A.6: Deep Parameters with Accounting for Minority Status 
while savings are given by Equation 18 from Appendix A:

$$
s_{t}=\frac{\sigma_{z}}{1+\sigma_{z}+\gamma_{z}}\left(\omega h_{i}^{f}+h_{j}^{m}\right) \text {. }
$$

Those two equations give a theoretical house ownership rate $m^{\star}\left[\theta, \gamma_{z}, \eta_{z}, \sigma_{z}, h^{f}(i), h^{m}(j)\right]$ which depends on religion specific thrift $\sigma_{z}$. The minimization problem of the structural estimation can be written as:

$$
\begin{aligned}
\min _{\theta, \gamma_{z}, \eta_{z}, \sigma_{z}, \delta_{0}, \delta_{1}} \sum_{z} \sum_{i, j}\left[p _ { i , j , z } \left(\hat{\mathcal{N}}_{i, j, z}-n^{\star}\left[\theta, \gamma_{z},\right.\right.\right. & \left.\left.\eta_{z}, \sigma_{z}, h^{f}(i), h^{m}(j)\right]\right)^{2} \\
& \left.+p_{i, j, z}\left(\hat{m}_{i, j, z}-m^{\star}\left[\theta, \gamma_{z}, \eta_{z}, \sigma_{z}, h^{f}(i), h^{m}(j)\right]\right)^{2}\right] .
\end{aligned}
$$

Compared to Equation (9), we have additional parameters to estimate, the $\sigma_{z}$ 's, and additional moments to match, based on house ownership $\hat{m}_{i, j, z}$. Results are presented in Table A.7.

\begin{tabular}{ccccc}
\hline & No relig. & Catholic & Buddhist & Muslim \\
\hline$\theta$ & \multicolumn{4}{c}{0.054} \\
& \multicolumn{4}{c}{$0.0010)$} \\
$\delta_{0}$ & \multicolumn{4}{c}{1.184} \\
\multicolumn{4}{c}{$0.1326)$} \\
$\delta_{1}$ & \multicolumn{4}{c}{0.628} \\
& \multicolumn{4}{c}{$0.1708)$} \\
$\gamma_{z}$ & 0.732 & 0.717 & 0.601 & 0.638 \\
& $(0.1136)$ & $(0.0330)$ & $(0.0437)$ & $(0.0558)$ \\
$\eta_{z}$ & 2.119 & 1.930 & 1.851 & 1.737 \\
& $(0.0418)$ & $(0.0262)$ & $(0.0316)$ & $(0.0397)$ \\
$\sigma_{z}$ & 0.411 & 0.251 & 0.274 & 0.176 \\
& $(0.2001)$ & $(0.0556)$ & $(0.0847)$ & $(0.01035)$
\end{tabular}

Notes: mean (st. dev.) of structural parameters minimizing Function (9), for 200 draws of the fertility matrices $\hat{\mathcal{N}}_{i, j, z}$.

Table A.7: Estimation of the Deep Parameters with (15)

The left panel of Figure 8, to be compared to Figure 4, shows the relative characteristics $\gamma_{z}$ and $\eta_{z}$ of each religion. The results in terms of macroeconomic outcomes are presented in the right panel Figure 8, to be compared with Figure 5 of the benchmark. 


\section{D.4 Additional Implications}

In this section we test whether assumptions and predictions of the structural model are in line with other available data. The effect of religious affiliation on the structural parameters we have identified has consequences not only for fertility, but also for savings and education. Education of the children is unfortunately unobserved. For savings, the only variable from the Census which can be indicative is whether the respondant or her husband own their house. This is only one component of savings, but it allows to check at the individual level the prediction of the model according to which savings

$$
s_{t}=\frac{\sigma}{1+\sigma+\gamma}\left(\omega h_{t}^{f}+h_{t}^{m}\right)
$$

(from Equation (18) in Appendix A) are decreasing in $\gamma$. We thus investigate whether the differences in $\gamma$ as identified from the fertility behavior influence the savings behavior, as they should. We accordingly run a linear probability model on a subsample including the affiliates to the four main religions for which we have estimated $\gamma(N=510,994)$. We regress home ownership on $s_{t}$, and census - year of birth fixed effects. The potential lifecycle income $\omega h_{t}^{f}+h_{t}^{m}$ is computed for each couple according to the values described in Section 3.2. Table A.8 shows the result. Theoretical savings $s_{t}$ are highly significant in explaining house ownership.

\begin{tabular}{|c|c|c|c|c|}
\hline \multicolumn{5}{|c|}{ Linear probability model } \\
\hline & \multicolumn{4}{|c|}{ dependent variable: house ownership } \\
\hline & Coef. & Std. Err. & $t$ & $P>|t|$ \\
\hline$s_{t}$ & .6526 & .1765 & 3.70 & 0.014 \\
\hline
\end{tabular}

Table A.8: House ownership as a Function of Theoretical Savings $s_{t}$

One can finally compare the macroeconomic predictions of the model in terms of human capital with the available information in the data. The recent literature emphasizes that quality of human capital is key for growth (OECD 2010). Table A.9 tentatively compares PISA test scores in mathematics and sciences (which are supposed to better reflect the cognitive abilities of the students) with education spending per child in the model. Four countries from our sample participated in the 2012 PISA wave. Their ranking is perfectly matched by our simulation results. Hence we have a rank correlation of one between the simulation and the data, although this comparison may be pushing the model's performance more than one can do. ${ }^{20}$

\footnotetext{
${ }^{20}$ We are moreover well served by the fact that the Philippines did not participate to PISA. In theory, the Philippines are supposed to do very well in terms of education quality, but their actual achievement is likely to
} 


\begin{tabular}{lccc}
\hline Country & Math. PISA 2012 & Science PISA 2012 & $e_{t}$ at $t=4$ \\
Vietnam & 511 & 528 & 5.8 \\
Thailand & 427 & 444 & 5.1 \\
Malaysia & 421 & 420 & 4.8 \\
Indonesia & 375 & 382 & 4.8 \\
Cambodia & NA & NA & 5.1 \\
Philippines & NA & NA & 6.4 \\
\hline
\end{tabular}

Table A.9: Quality of Education

be poor. They indeed participated to the TIMSS tests in 1999 and 2003, and, despite a strong improvement between these two waves, they are very low in the international ranking (for math scores, eight grade). 


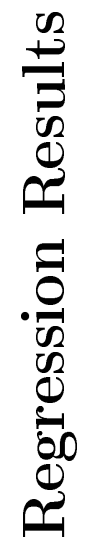

[I] 


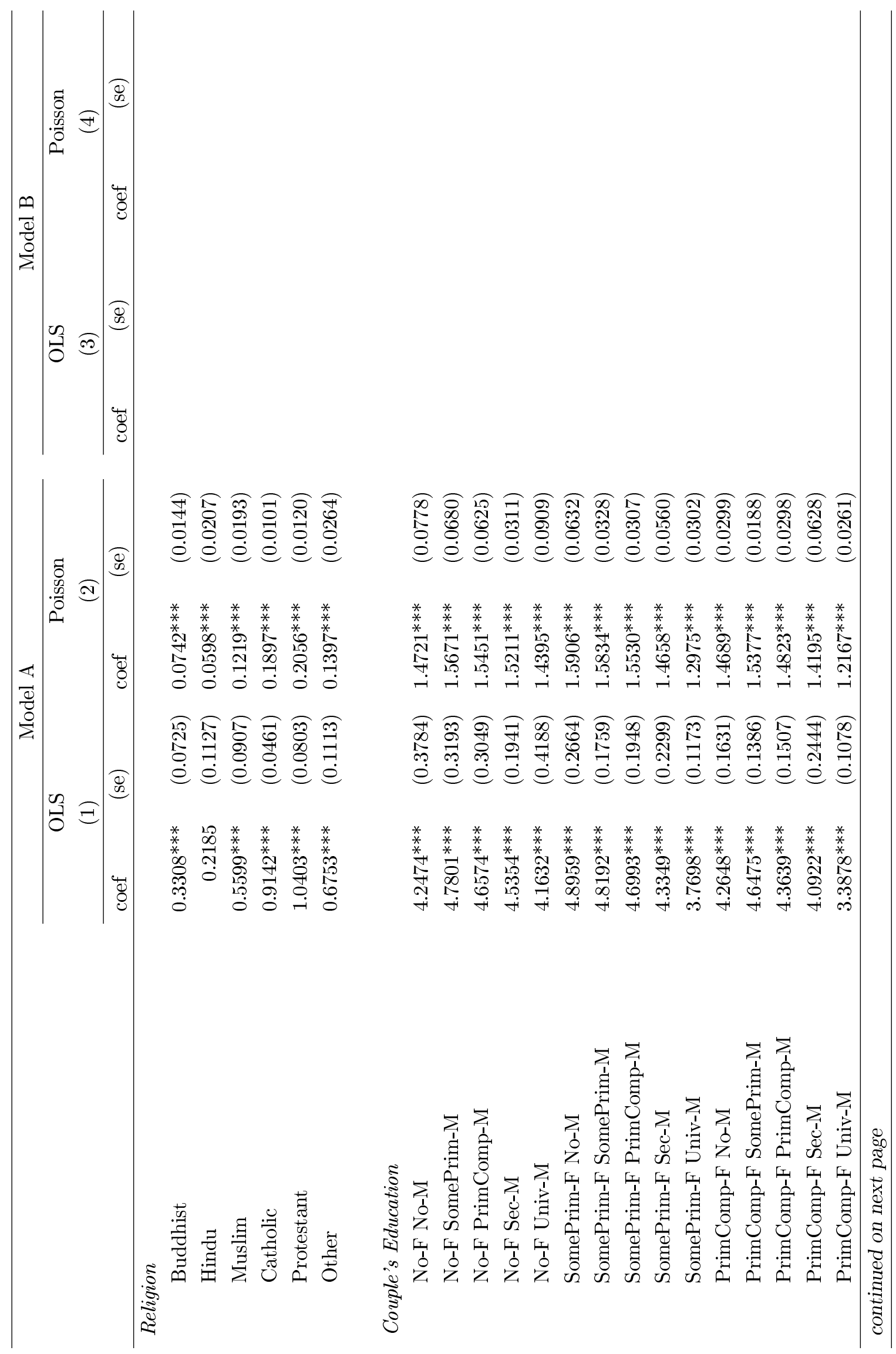




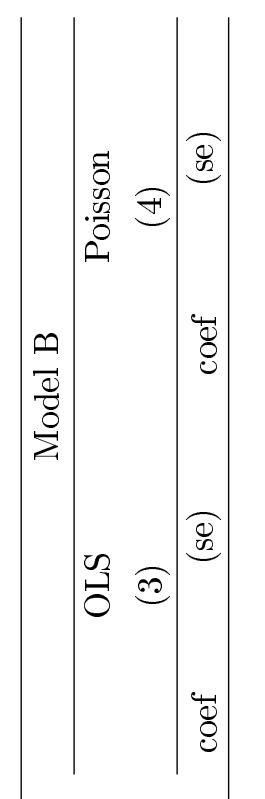

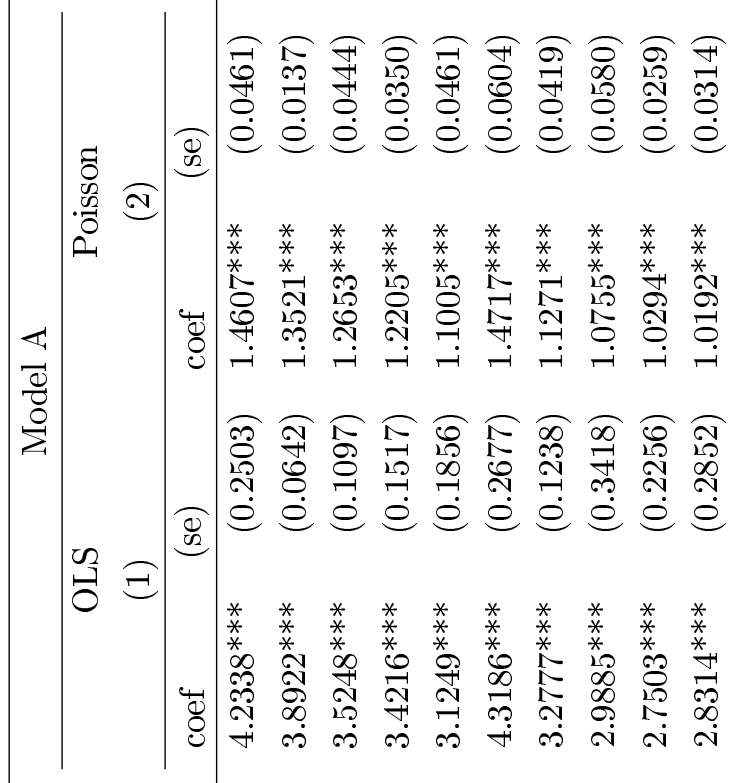

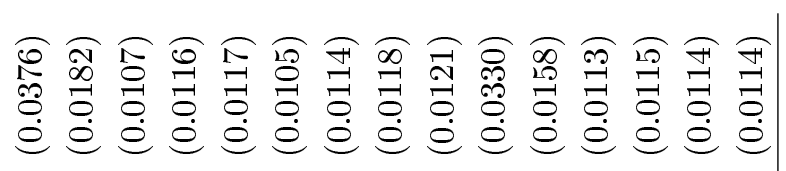

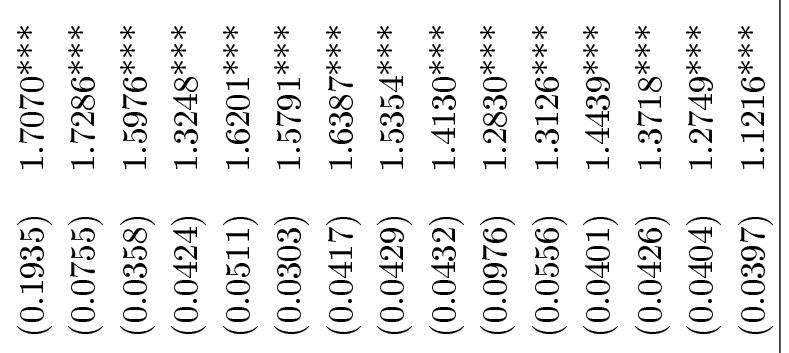

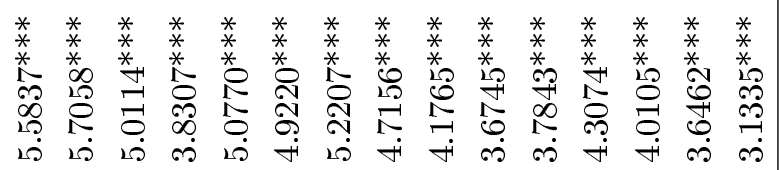




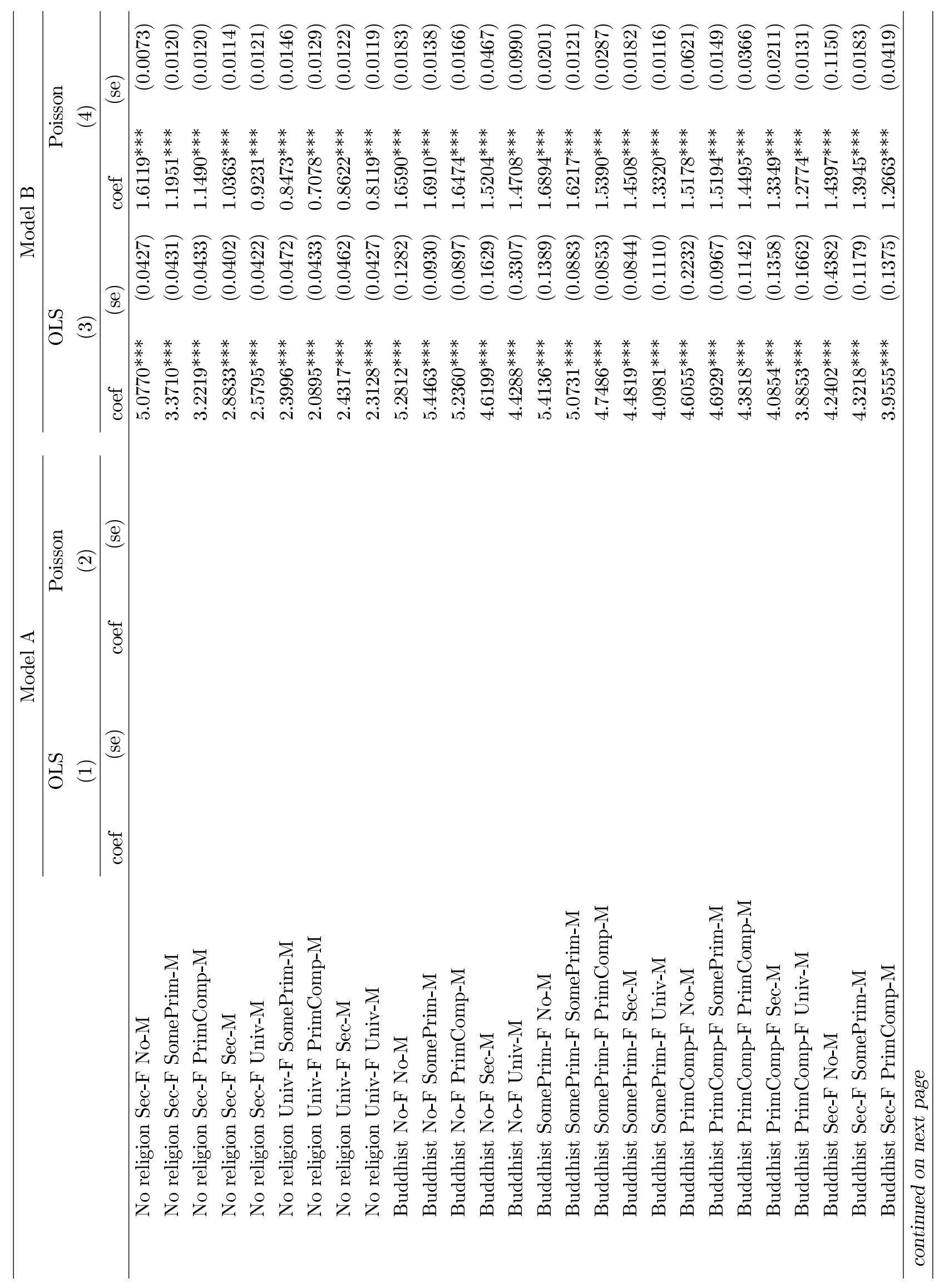




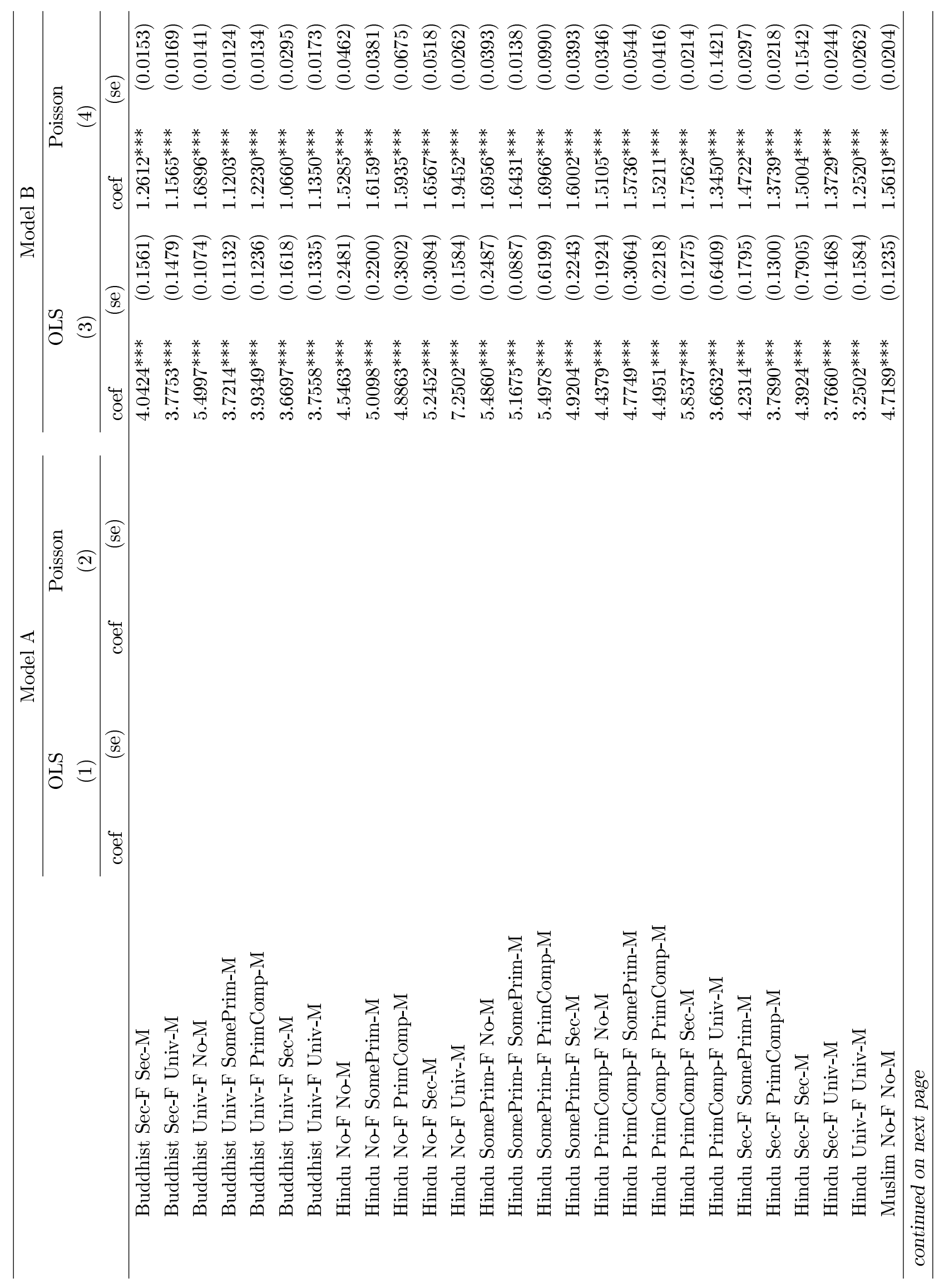




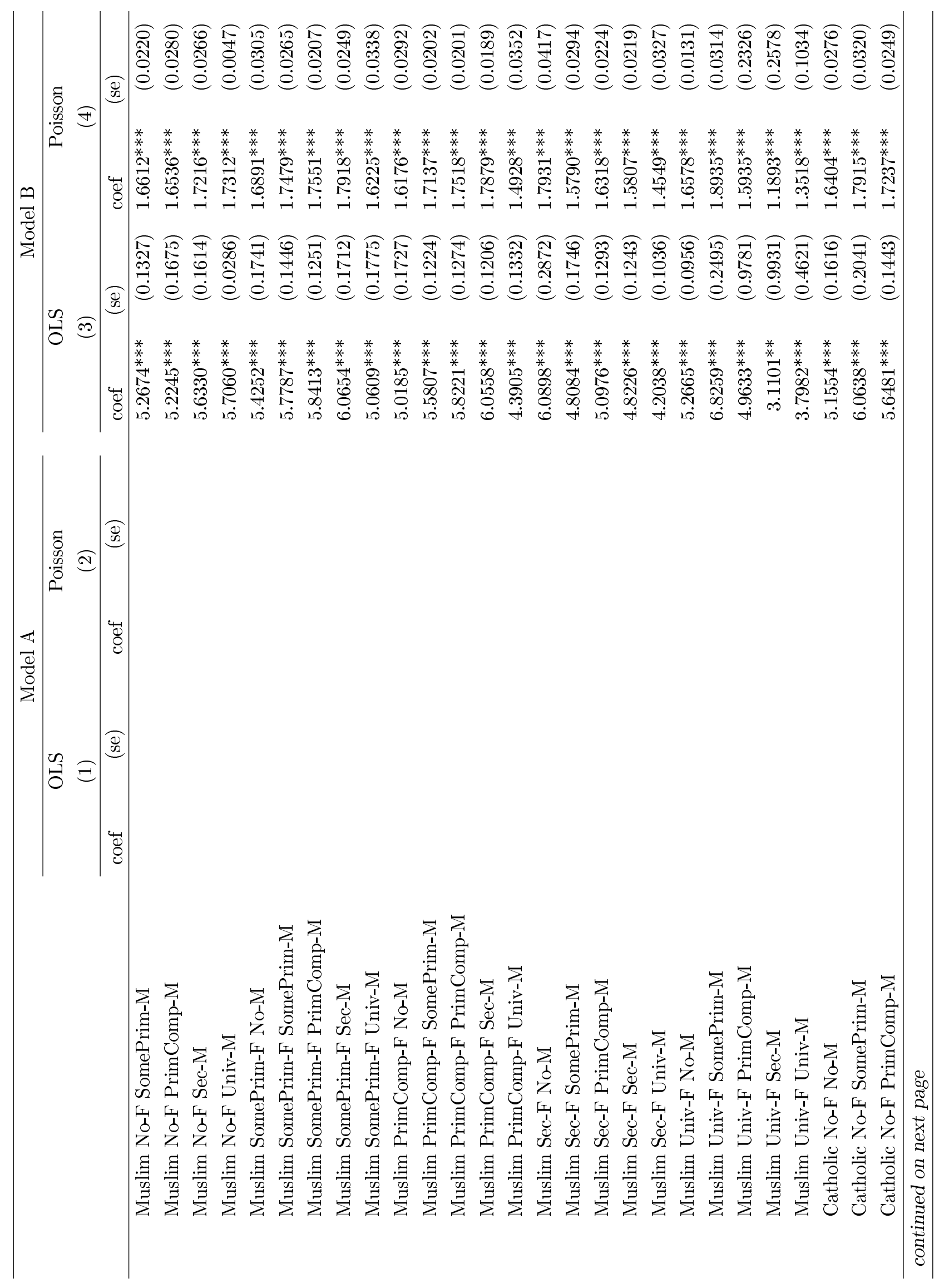




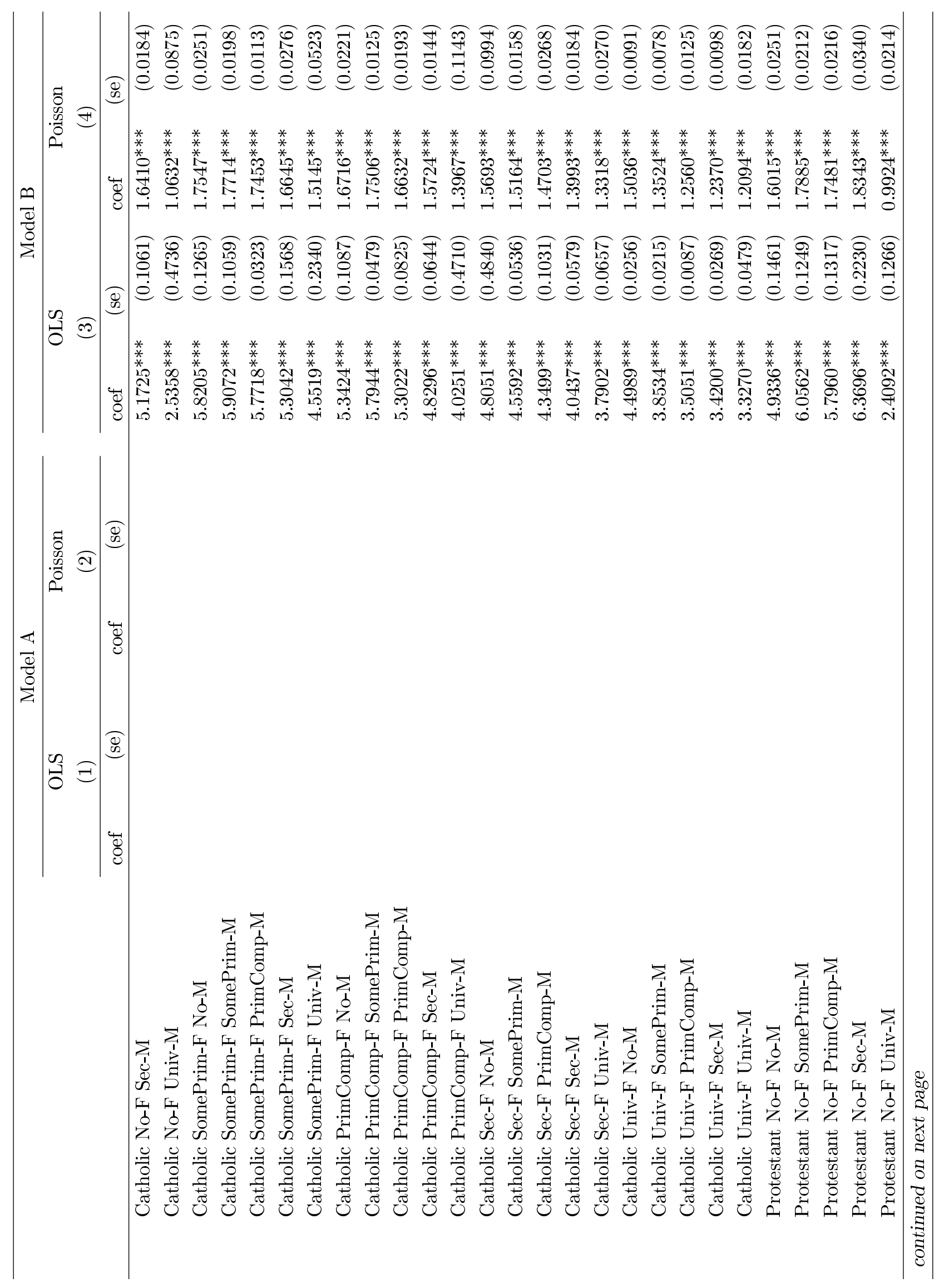




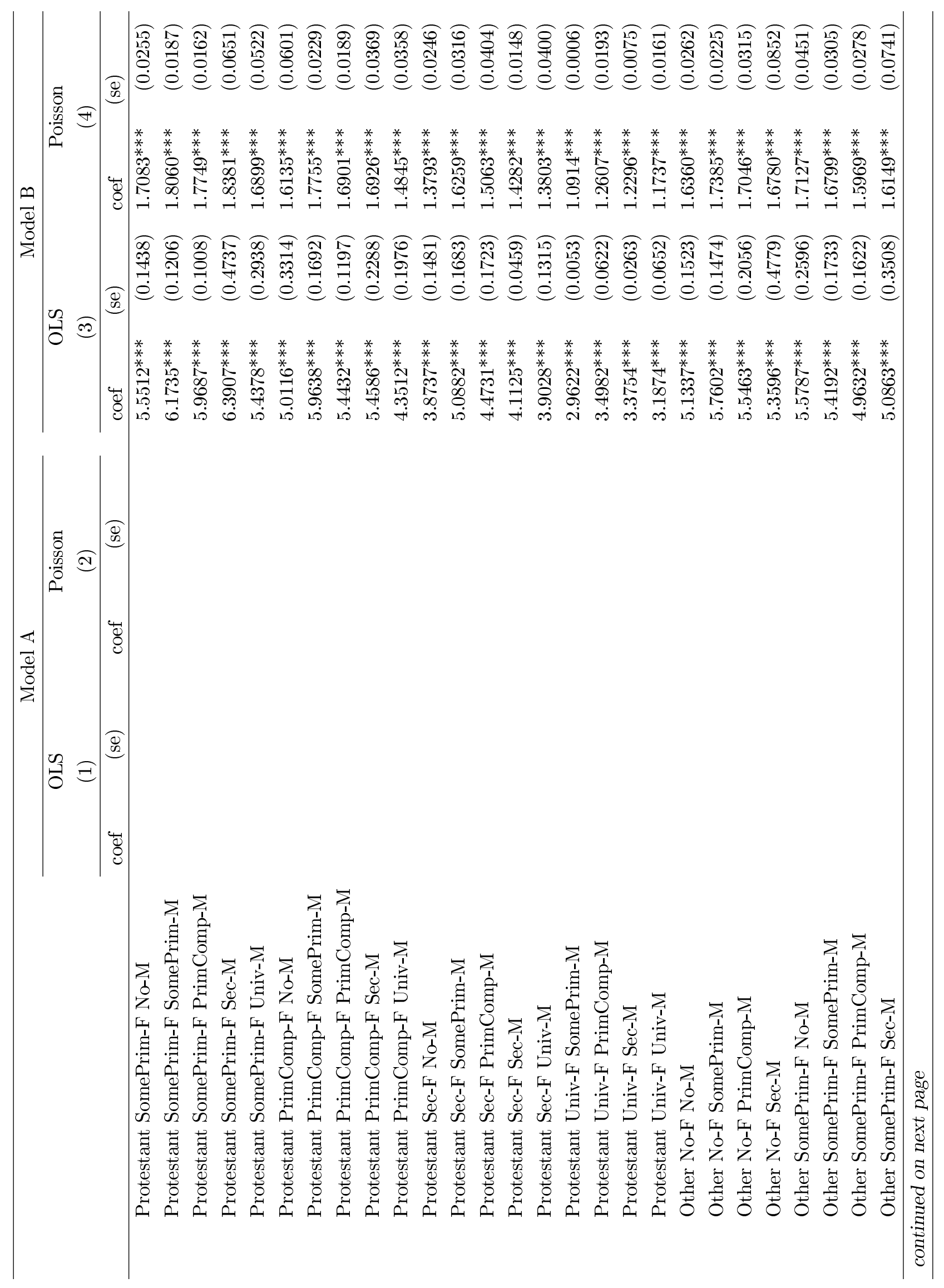




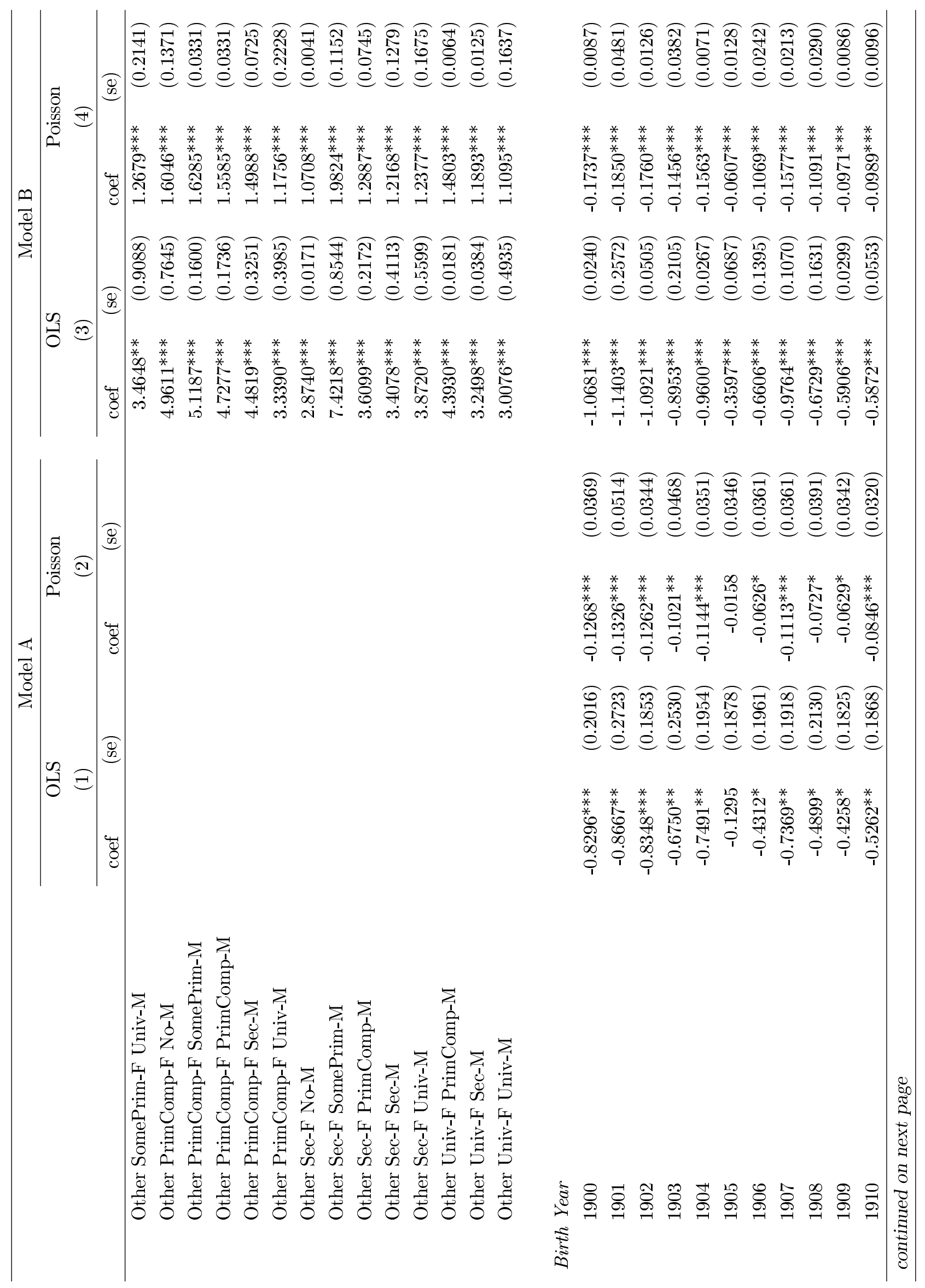




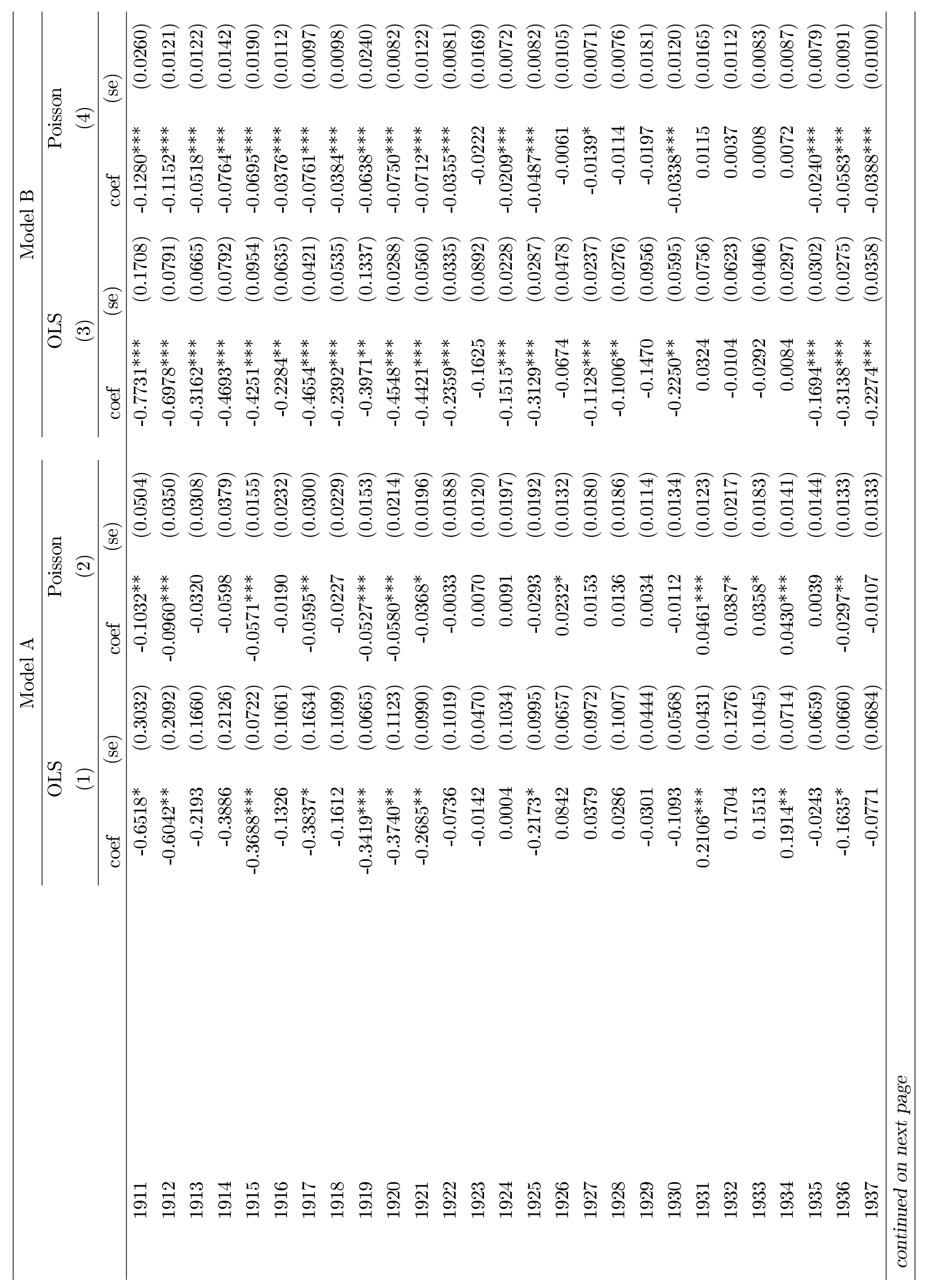




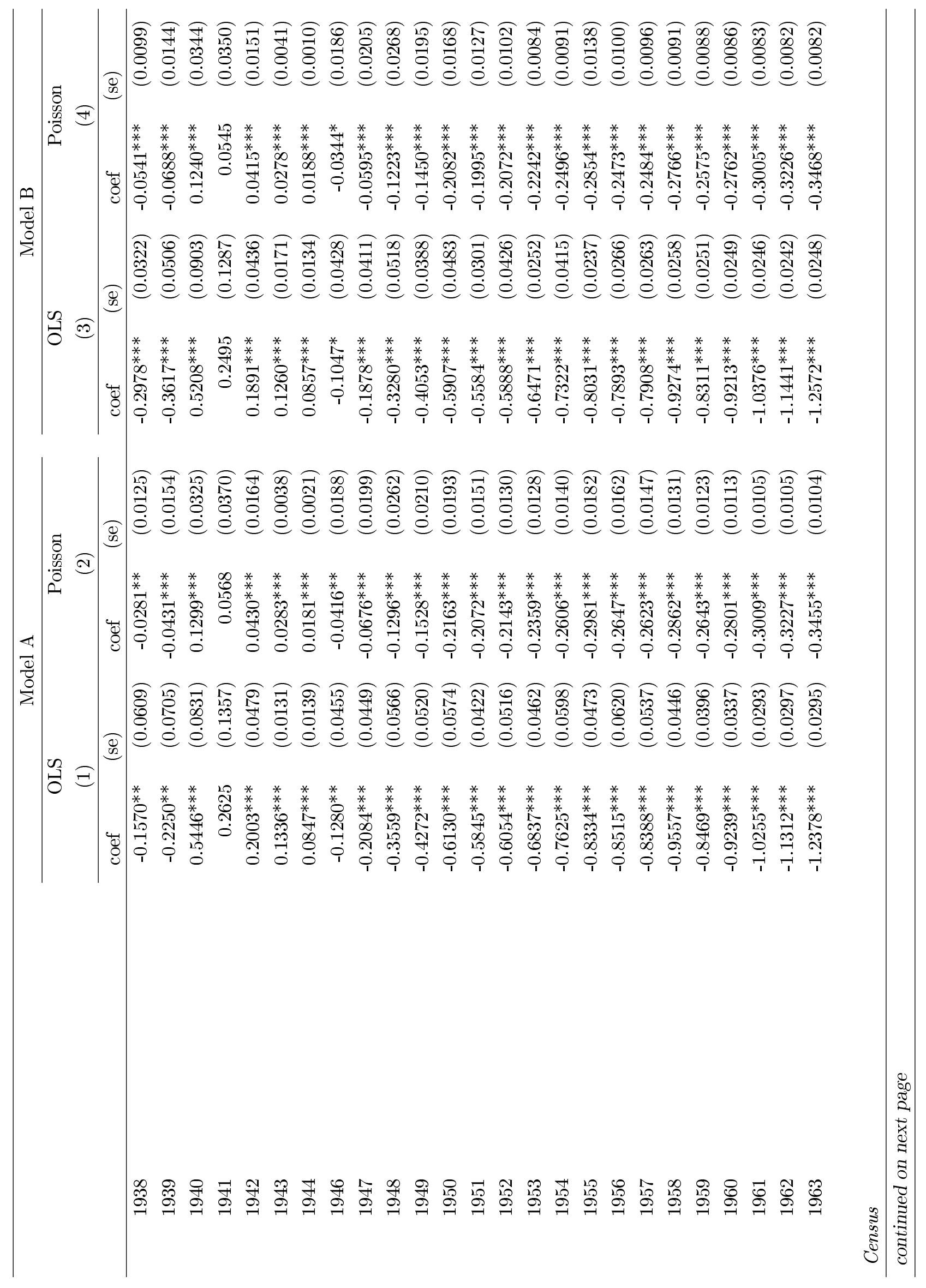




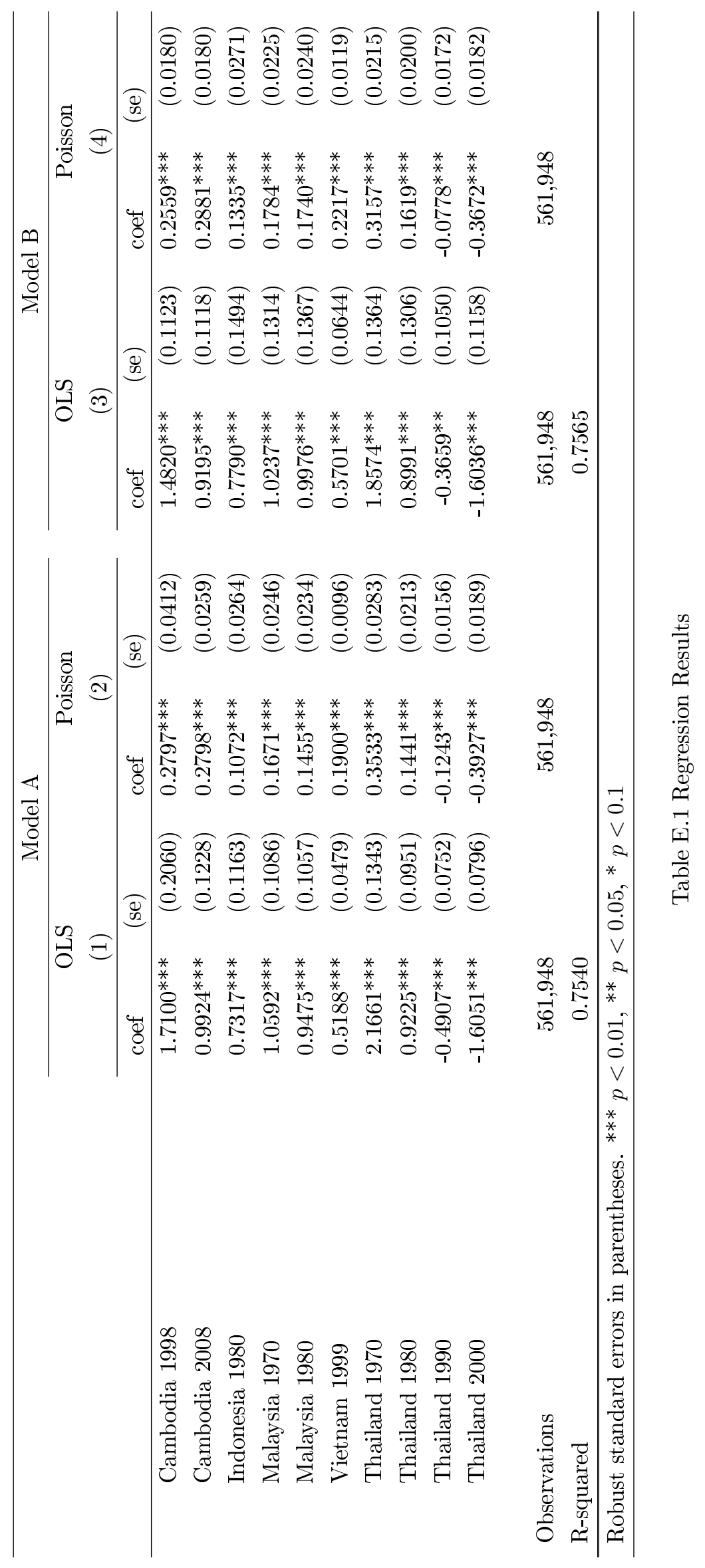




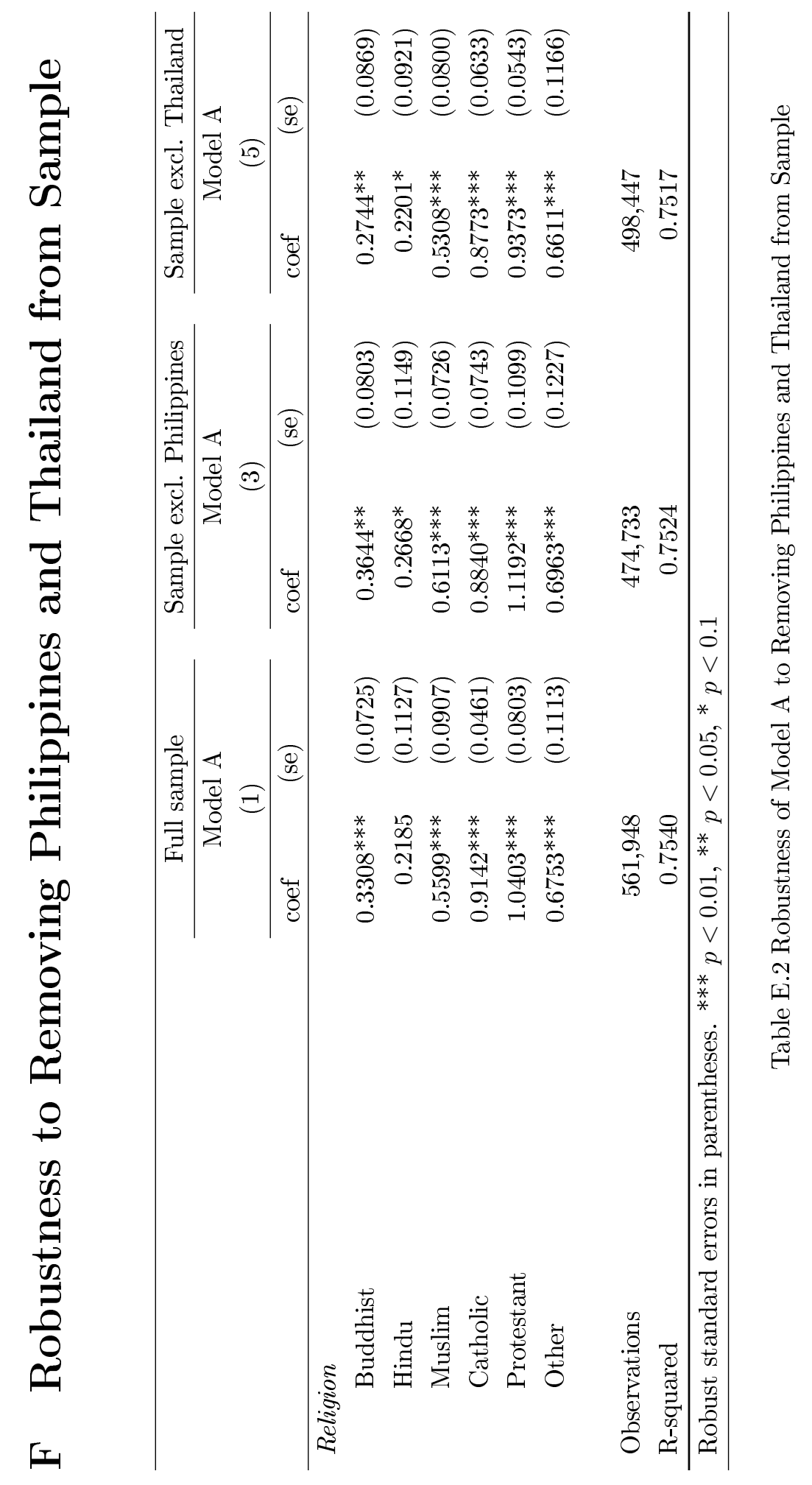




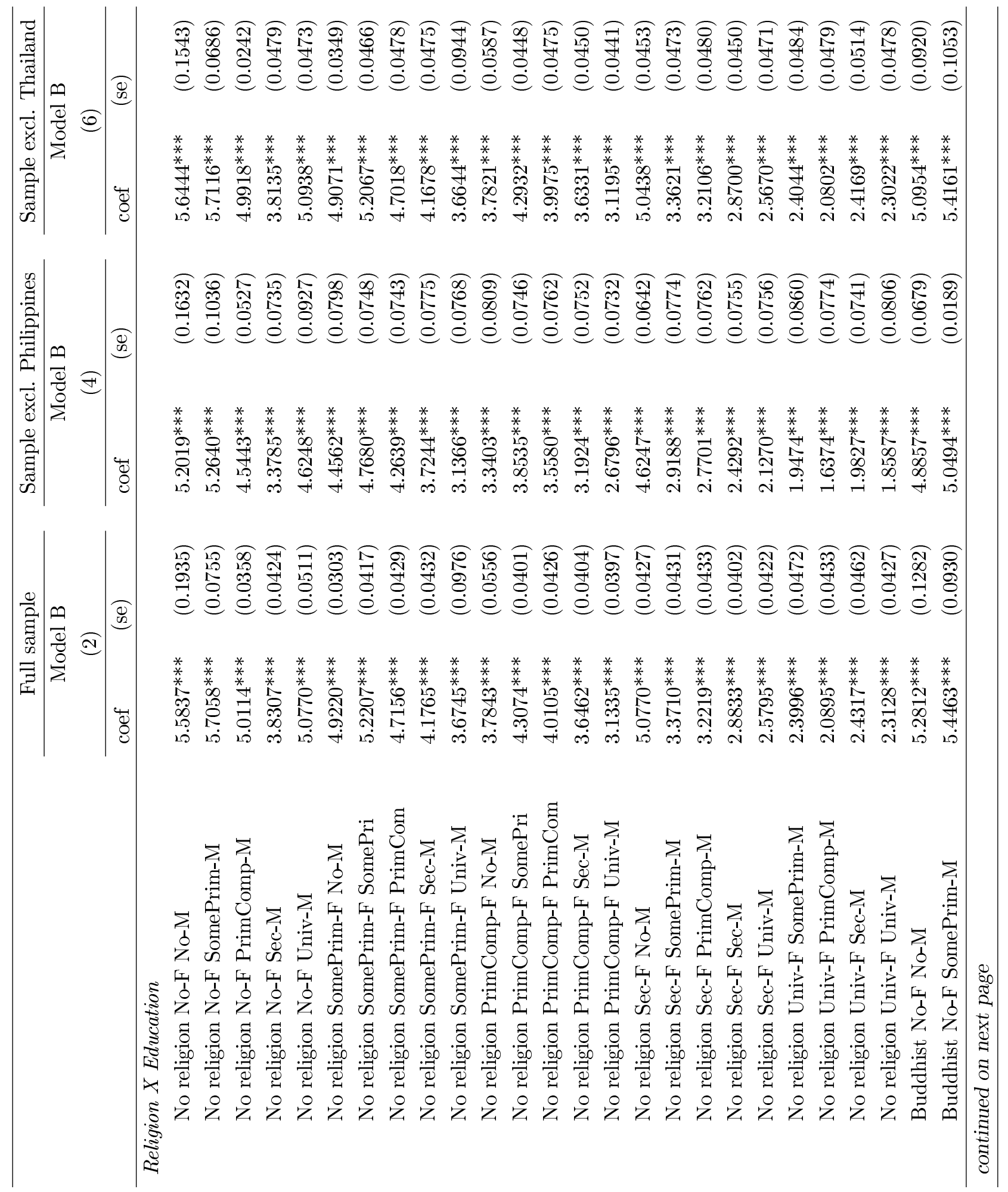




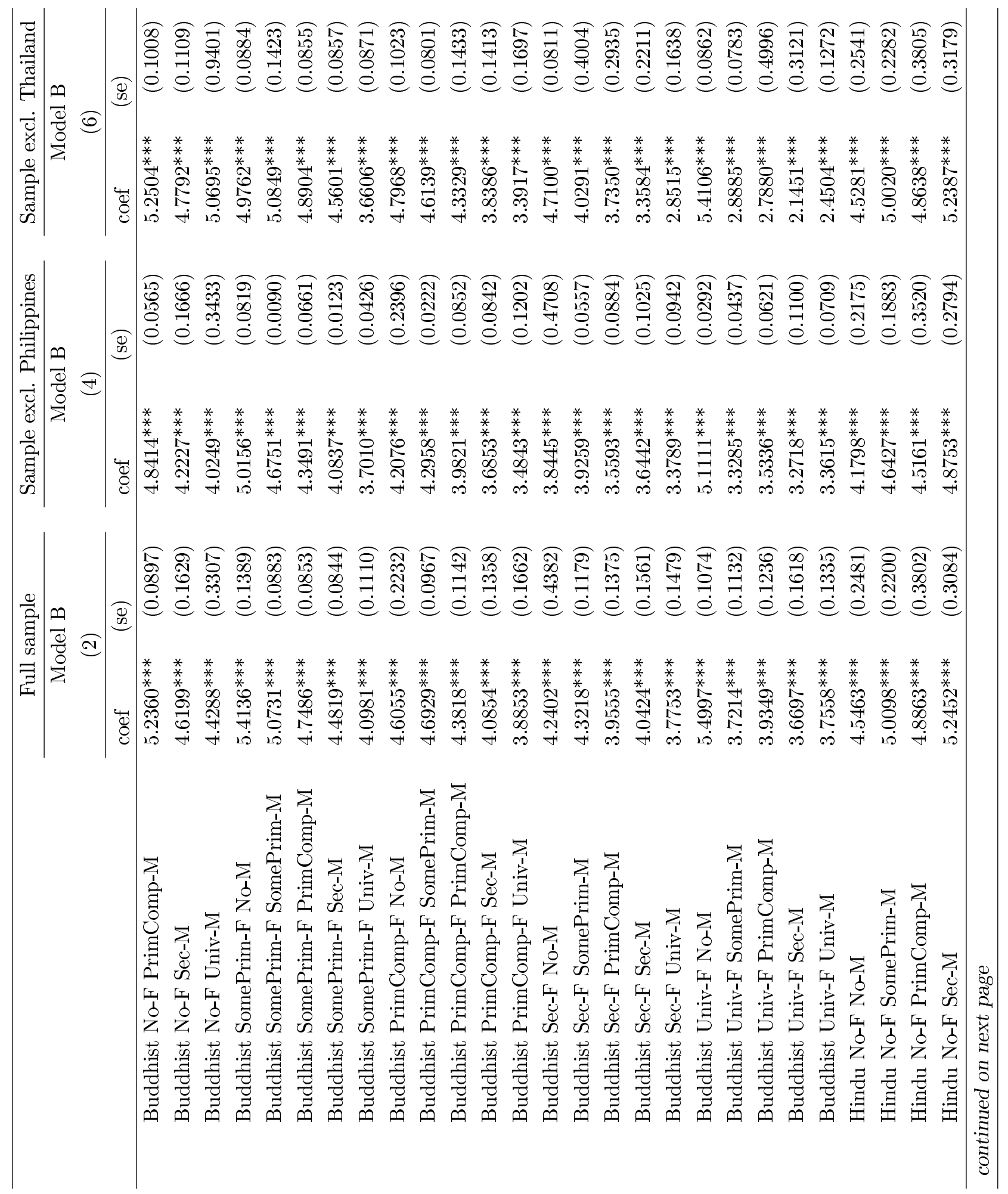




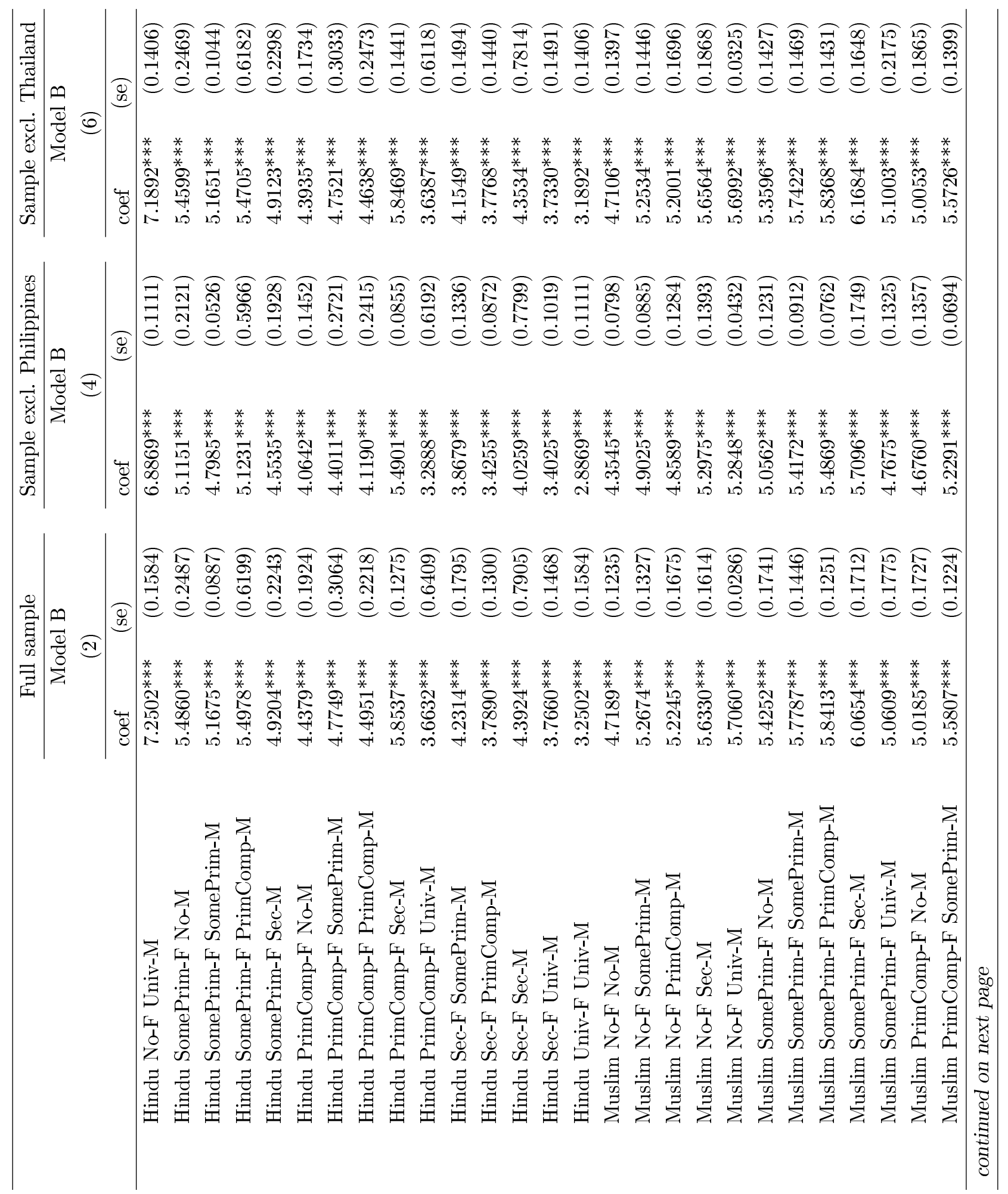




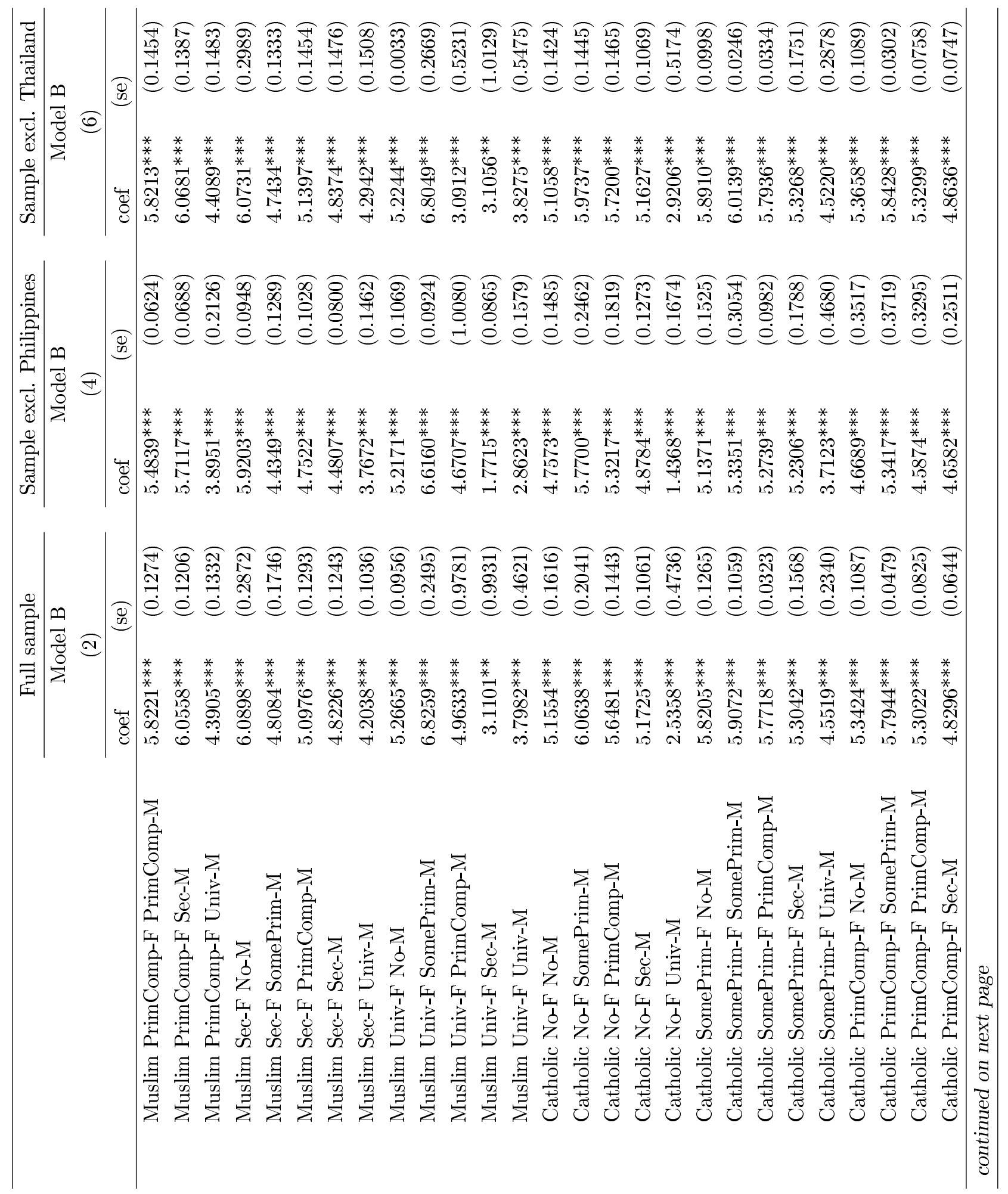




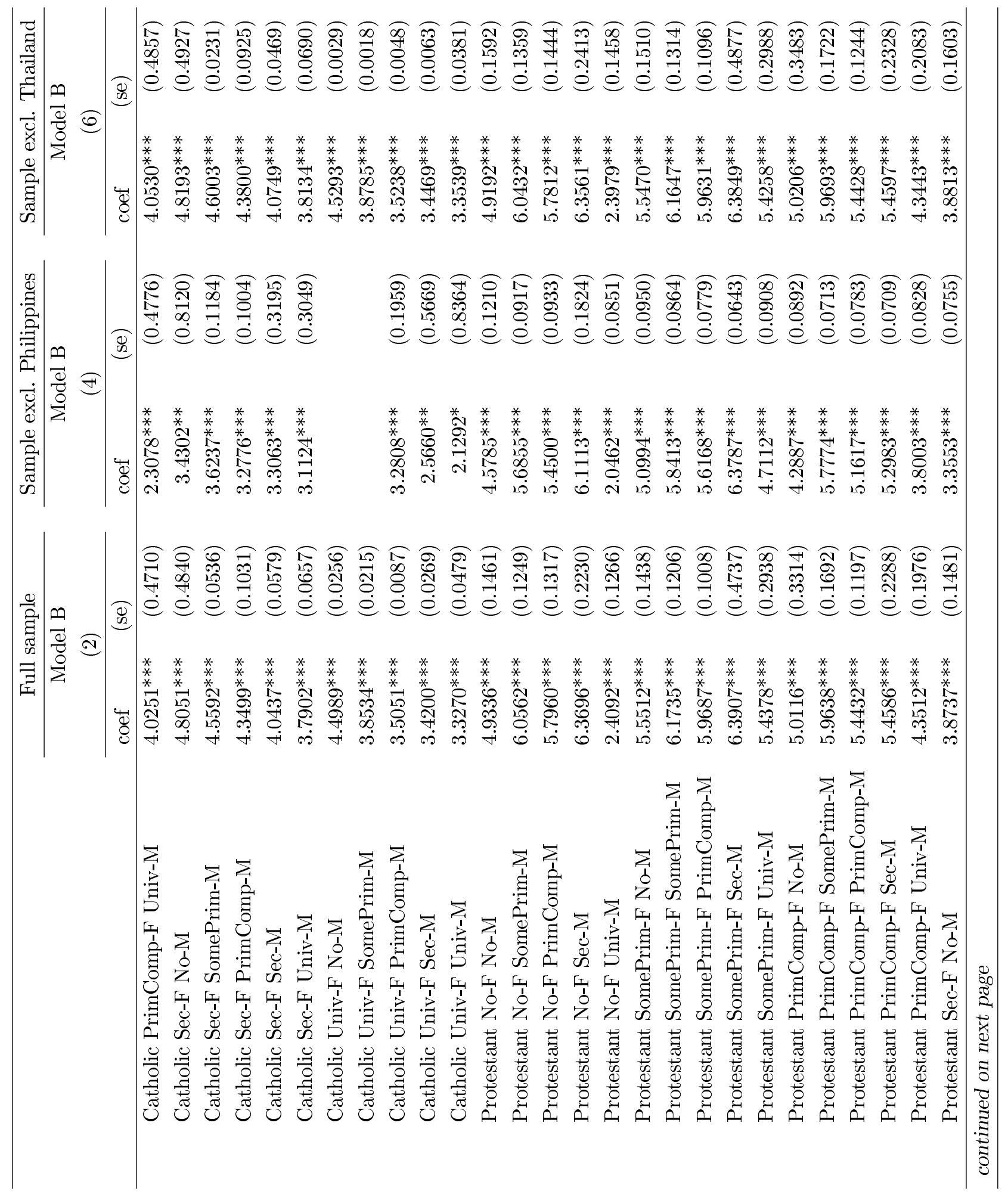




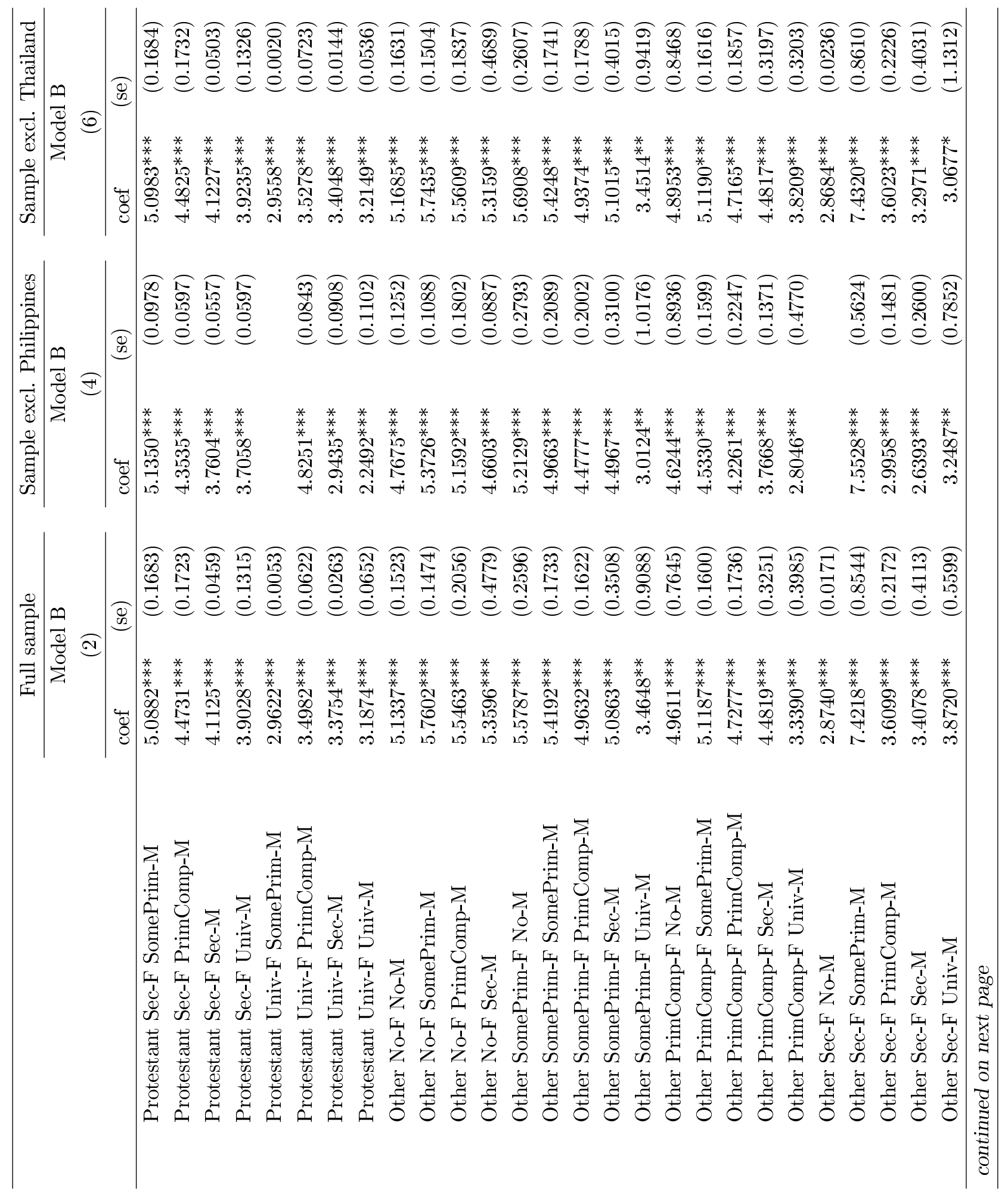




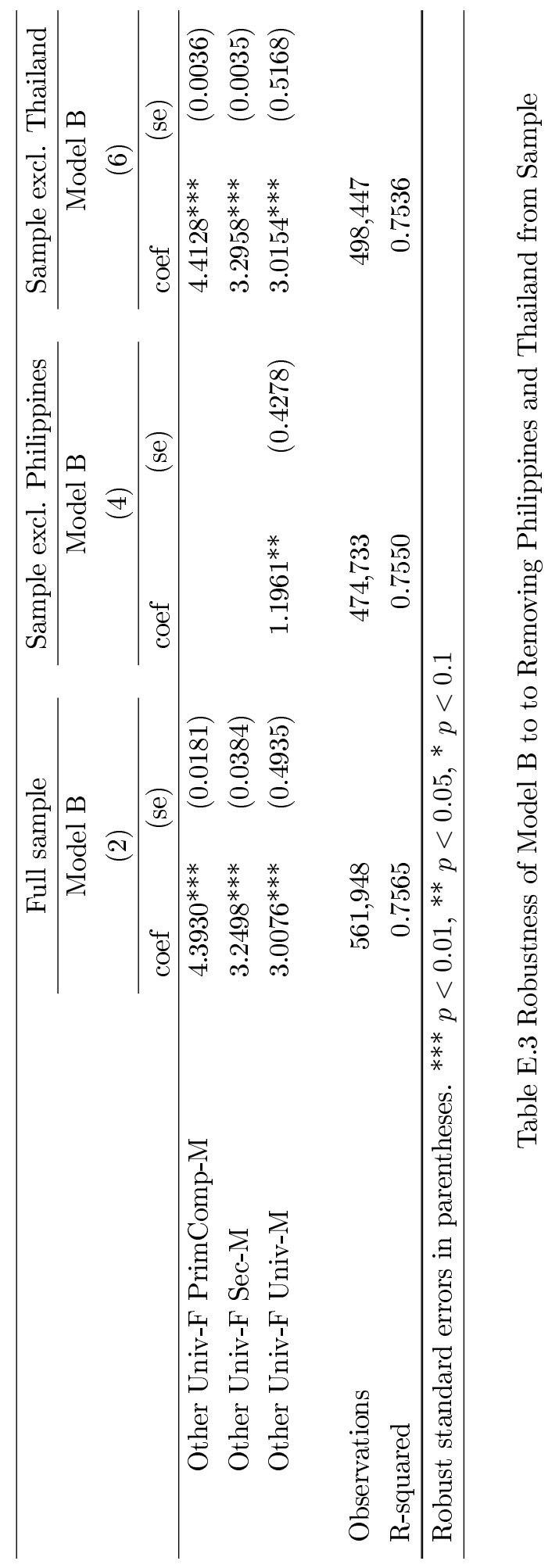




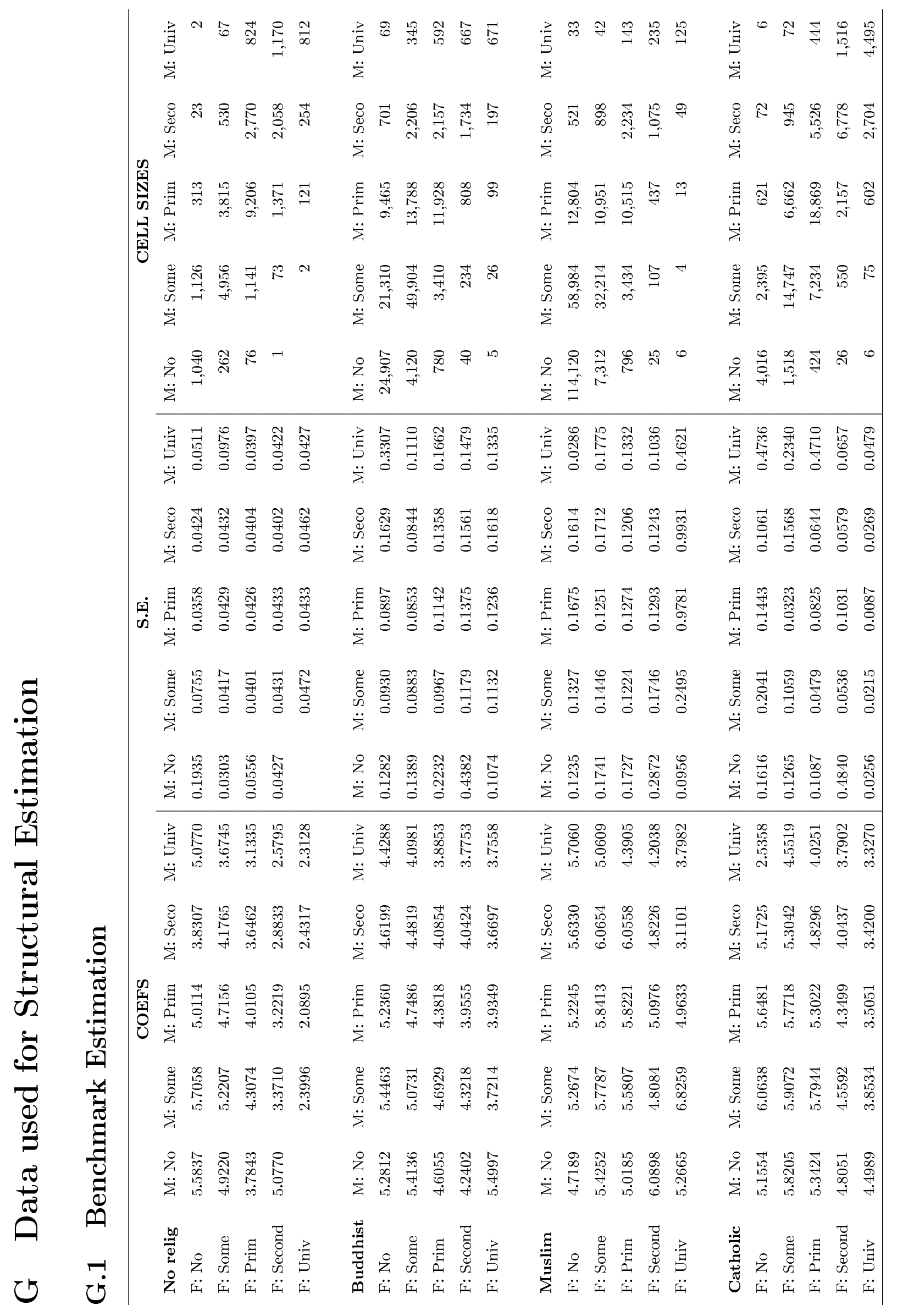




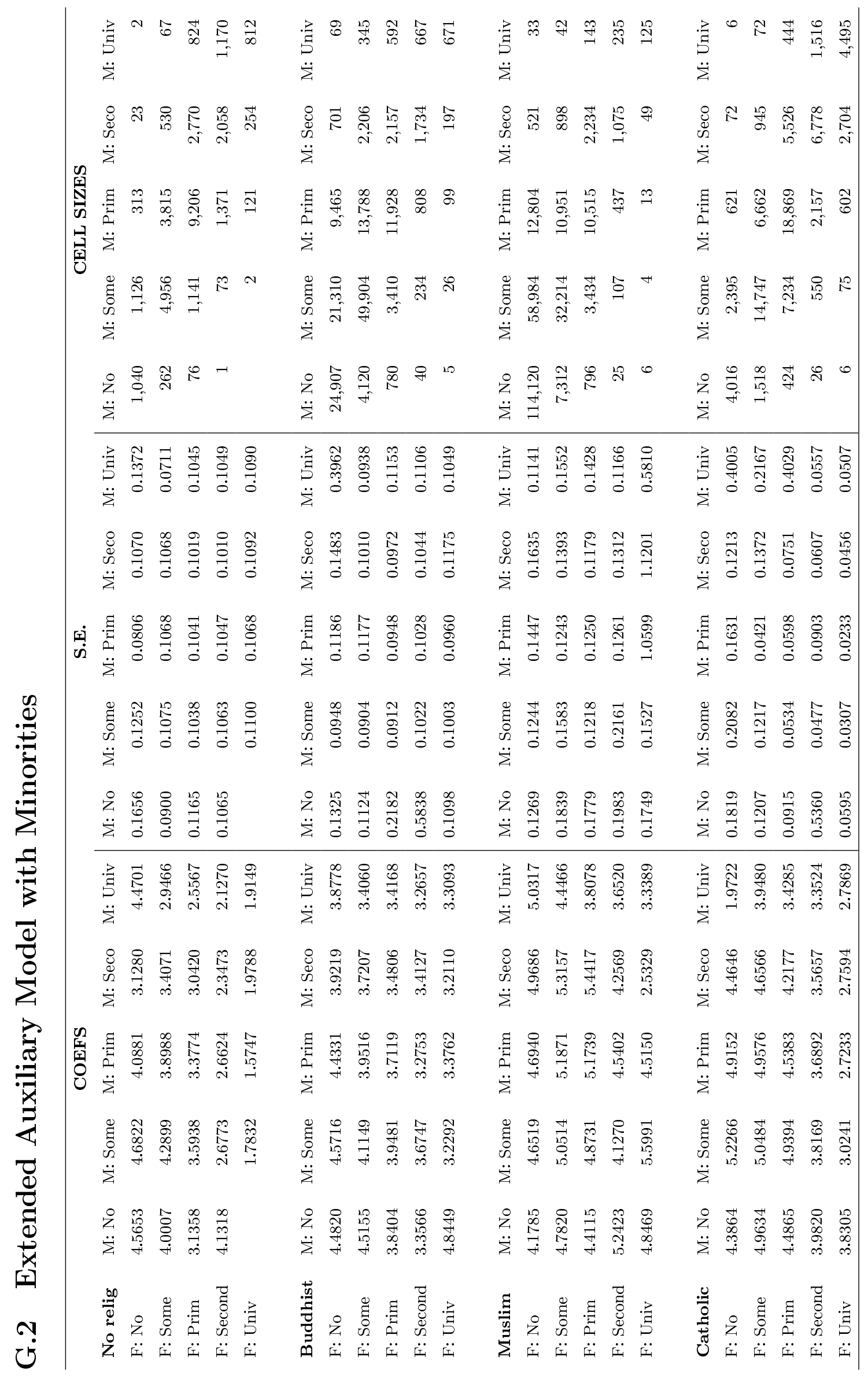




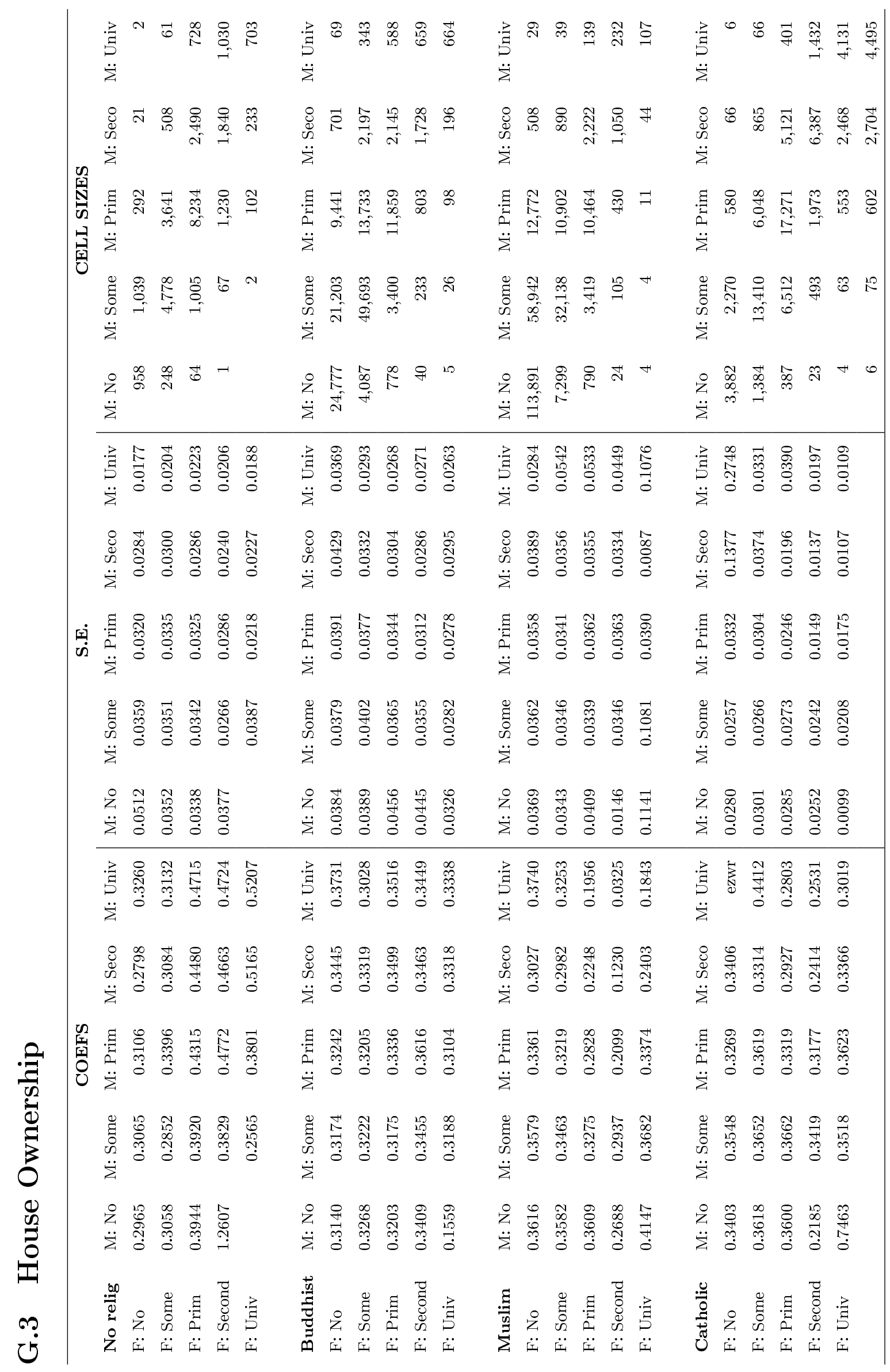

